UNIVERSIDADE DE SÃO PAULO

FACULDADE DE MEDICINA DE RIBEIRÃO PRETO

\title{
AVALIAÇÃO DO DESFECHO EM LONGO PRAZO NA CIRURGIA DE EPILEPSIA DO LOBO TEMPORAL
}

Marina Teixeira Ramalho Pereira Dalio

Orientador: Prof. Dr. Américo Ceiki Sakamoto

Ribeirão Preto 


\section{AVALIAÇÃO DO DESFECHO EM LONGO PRAZO NA CIRURGIA DE EPILEPSIA DO LOBO TEMPORAL}

Marina Teixeira Ramalho Pereira Dalio

Dissertação de mestrado apresentada ao Departamento Neurociências e Ciências do Comportamento do Programa de Pós-Graduação em Neurologia e Neurociências da Universidade de São Paulo, para concorrer ao título de Mestre em Neurologia.

Área de concentração: Neurologia

Orientador: Prof. Dr. Américo Ceiki Sakamoto

\section{Ribeirão Preto}


AUTORIZO A REPRODUÇÃO E DIVULGAÇÃO TOTAL E PARCIAL DESTE TRABALHO, POR QUALQUER MEIO CONVENCIONAL OU ELETRÔNICO, PARA FINS DE ESTUDO E PESQUISA, DESDE QUE CITADA A FONTE.

Versão corrigida. A versão original encontra-se disponível tanto na Biblioteca da Unidade que aloja o Programa, quanto na Biblioteca Digital de Teses e Dissertações da USP (BDTD).

\section{Pereira-Dalio, Marina Teixeira Ramalho}

Avaliação do desfecho em longo prazo na cirurgia de epilepsia do lobo temporal / Marina Teixeira Ramalho Pereira Dalio - Ribeirão Preto, São Paulo, 2018.

$$
123 \text { p.: il.; } 30 \mathrm{~cm}
$$

Mestrado - Dissertação de mestrado apresentada ao Departamento Neurociências e Ciências do Comportamento do Programa de Pós-Graduação em Neurologia e Neurociências da Universidade de São Paulo.

Área de concentração: Neurologia

1.Epilepsia do lobo temporal. 2. Epilepsia mesial temporal. 3. Esclerose hipocampal. 4. Epilepsia refratária. 5 Cirurgia de epilepsia. 6. Lobectomia temporal. 7. Prognóstico cirúrgico. 8. Fatores preditores de prognóstico. 
FOLHA DE AVALIAÇÃO / APROVAÇÃO

Pós-graduanda: Marina Teixeira Ramalho Pereira Dalio

Trabalho: Avaliação do desfecho em longo prazo na cirurgia de epilepsia do lobo temporal

Dissertação de mestrado apresentada ao Departamento Neurociências e Ciências do Comportamento do Programa de Pós-Graduação em Neurologia e Neurociências da Universidade de São Paulo, para concorrer ao título de Mestre em Neurologia.

Área de concentração: Neurologia

Orientador: Prof. Dr. Américo Ceiki Sakamoto

Aprovado em: 01/03/2019

\section{BANCA EXAMINADORA}

Prof. Dr. Fernando Cendes

Instituição: UNICAMP

Prof. Dr. Carlos Gilberto Carlotti Junior

Instituição: HCFMRP-USP

Prof. Dr. Antonio Carlos dos Santos

Instituição: HCFMRP-USP

Prof. Dr.

Instituição:

Prof. Dr.

Instituição: 


\section{DEDICATÓRIA}

Ao meu marido Renato, amor da minha vida, que acompanha este sonho desde o início, sempre me apoiando com muita paciência e compreensão nos momentos difíceis. Ele que está ao meu lado em todos os momentos, que é pai do maior fruto do nosso amor. Muito obrigada por fazer parte da minha vida e da nossa família.

Aos meus pais que dedicaram suas vidas à vida dos seus filhos, que me educaram na fé, no amor, na responsabilidade e dedicação. Sou hoje essa pessoa e cheguei até aqui, graças ao esforço, educação e apoio de vocês. Serei eternamente grata por esse amor. 


\section{AGRADECIMENTOS}

Ao Prof. Dr. Américo Ceiki Sakamoto, pela oportunidade, por confiar no meu trabalho, pelo acolhimento e pelos ensinamentos enriquecedores.

Ao Prof. Dr. Tonicarlo Velasco, por todo apoio, pelas reflexões críticas, discussões, ensinamentos, conselhos e pela paciência comigo.

Ao Prof. Dr. João Alberto Assirati Jr, pela disponibilidade com a ajuda da descrição das técnicas cirúrgicas, pelo carinho e amor dedicado aos pacientes ao longo de todos esses anos.

Aos colegas do CIREP, Frederico Nakano, Veriano Alexandre Jr., Úrsula Thomé e Larissa, pela convivência amigável, pelo acolhimento quando cheguei no serviço e também pelos ensinamentos.

À Izabela D. F. Feitosa, pela colaboração com a coleta dos dados e pela amizade, tornando o trabalho mais leve.

À equipe do CIREP, enfermeiros, técnicos de enfermagem, técnicos de VEEG, pela assistência e cuidado com os pacientes e pelo convívio amigável.

À equipe de neuropsicologia, psiquiatria e assistentes sociais, pelas avaliações pré-cirúrgicas e pelo acolhimento ao paciente, fundamentais em todo o processo.

Às secretárias Adriana e Elidia, pelo convívio alegre, sempre disponíveis a nos ajudar com amor, tornando o ambiente de trabalho mais agradável.

Ao Prof. Dr. Antonio Carlos dos Santos e equipe de neurorradiologia, pela análise das imagens de ressonância magnética e pelas discussões enriquecedoras.

À equipe da patologia, pelos laudos anatomopatológicos.

Ao Prof. Dr. João Pereira Leite, pelo convívio no AEPA.

À Prof. Dr. Regina Maria F. Fernandes, à equipe de neurofisiologia clínica e sono pelos ensinamentos neurofisiológicos durante a residência e por terem aberto às portas para mim desde o início.

Ao Professor Geraldo Cassio pelas orientações da análise estatística. 


\section{RESUMO}

Pereira-Dalio, M. T. R. Avaliação do desfecho em longo prazo na cirurgia de epilepsia do lobo temporal. 2019.123 f. Dissertação de Mestrado - Faculdade de Medicina de Ribeirão Preto, Universidade de São Paulo, Ribeirão Preto, 2019.

A epilepsia do lobo temporal (ELT), além de ser o tipo de epilepsia focal mais comum, também é a que tem maior refratariedade à farmacoterapia, correspondendo à $30 \%$ dos casos. Se não tratada pode levar à piora da qualidade de vida, déficits cognitivos e risco de morte (ENGEL, 1998). O tratamento padrão para ELT farmacorresistente é a remoção cirúrgica das estruturas envolvidas (ENGEL, 1996), com taxas de cura que podem chegar a 80\% (ENGEL, 2001a). Os benefícios da cirurgia são: diminuição da frequência e severidade das crises, diminuição da mortalidade, melhores índices de qualidade de vida. Recomenda-se que pacientes com ELT farmacorresistentes sejam referenciados a um centro de cirurgia de epilepsia para avaliar a possibilidade de intervenção cirúrgica (ENGEL et al., 2003). Em nosso estudo, avaliamos 621 pacientes com epilepsia mesial do lobo temporal, com confirmação histopatológica de esclerose hipocampal, que realizaram ressecção do lobo temporal no Centro de Cirurgia de Epilepsia de Ribeirão Preto (CIREP) entre os anos de 1994 até 2011. Avaliamos os principais fatores preditores que influenciam no sucesso cirúrgico relacionados ao controle das crises epilépticas, através de um estudo longitudinal e retrospectivo. Realizamos o acompanhamento clínico desses pacientes por até 23 anos, com média de 11,6 anos $( \pm 5,3)$ e encontramos que $73,6 \%$ dos pacientes ficaram livres de crises com alteração da consciência (Engel I) e $\mathbf{8 4 , 7 \%}$ tiveram um bom prognóstico cirúrgico (Engel I + II). Esse prognóstico foi relativamente mantido ao longo do tempo em $65 \%$ dos pacientes, após 20 a 23 anos da cirurgia. Encontramos que a história de crise febril foi um fator de bom prognóstico, enquanto que a aura dismnésica e olfatória foram fatores de mau prognóstico. Em relação ao tipo de técnica cirúrgica, a lobectomia temporal anteromesial (com ressecção do polo temporal), obteve significativo melhor prognóstico (78,6\% Engel I) em relação à cirurgia que poupa o polo temporal $\left(67,2 \%\right.$ Engel I), $p=0,002^{*}$, sugerindo que as conexões neurais envolvidas na zona epileptogênica podem estar além das estruturas mesiais. Concluímos que a cirurgia para epilepsia é um procedimento seguro, com baixos índices de complicações pós-operatórias e bons resultados em longo prazo. Palavras-chave: Epilepsia do lobo temporal. Esclerose hipocampal. Cirurgia de epilepsia. Prognóstico cirúrgico. 


\section{ABSTRACT}

Pereira-Dalio, M.T.R. Long term outcome of epilepsy surgery in 621 patients with mesial temporal lobe epilepsy due to hippocampal sclerosis. 2019. 123f. Dissertação de Mestrado - Faculdade de Medicina de Ribeirão Preto, Universidade de São Paulo, Ribeirão Preto, 2018.

Temporal lobe epilepsy (TLE) is the most common type of focal epilepsy and the one that has greater refractoriness to pharmacotherapy, corresponding to $30 \%$ of the cases. If untreated, it can lead to worsening of quality of life, cognitive deficits and risk of death (ENGEL, 1998). The standard treatment for medically refractory TLE is the surgical removal of the structures involved (ENGEL, 1996), with good outcomes rates that can reach to $80 \%$ (ENGEL, 2001a). The benefits of the surgery are: decrease in frequency and severity of seizures, decrease in mortality, better indexes of quality of life and higher rates of return to school and work. It is recommended that medically refractory TLE patients should be referred to an epilepsy surgery center to evaluate the possibility of surgical intervention (ENGEL et al., 2003). In our study, we evaluated 621 patients with mesial temporal lobe epilepsy secondary to hippocampal sclerosis (MTLE-HS), who underwent a temporal lobectomy at our epilepsy surgery center (CIREP) between the years 1994 to 2011. We evaluated the main predictive factors that influence the surgical outcome, through a longitudinal and retrospective study. We performed the clinical follow-up for up to 23 years and the mean follow-up was 11,6 years $( \pm 5,3)$. We found that $73,6 \%$ of the patients were free of disabling seizures and $84,7 \%$ had a good surgical outcome (Engel I + II). This prognosis was relatively maintained over the time in $65 \%$ of patients after 20 to 23 years of surgery. We found that history of febrile seizure was a good prognostic factor, whereas the dysmnesic and olfactory aura were factors of poor outcome. Regarding the type of surgical technique, the anteromesial temporal lobe resection obtained significant better outcomes $(78,6 \%$ Engel I) in relation to the surgery who preserve the temporal pole $\left(67,2 \%\right.$ Engel I), p value $=0,002^{*}$, suggesting that the neuronal networks involved in the epileptogenic zone may be beyond mesial structures. We conclude that epilepsy surgery is a safe procedure, with low rates of postoperative complications and good long-term results.

Keywords: Temporal lobe epilepsy. Hippocampal sclerosis. Epilepsy surgery. Surgical outcome. 
ILAE International League Against Epilepsy

EEG Eletroencefalograma

VEEG Vídeo eletroencegalograma

SEEG Stereo eletroencefalograma - avaliação com eletrodos profundos

ELT Epilepsia do lobo temporal

EMT Esclerose mesial temporal

EMLT Epilepsia mesial do lobo temporal

EH Esclerose hipocampal

EMLT-EH Epilepsia mesial do lobo temporal associada à esclerose hipocampal

IPI Injúria precipitante inicial

CA Corno de Ammon

RNM Ressonância nuclear magnética

AVC Acidente vascular encefálico

NCC Neurocisticercose

ZII Zona de início ictal

PET Positron emission tomography

SPECT Single photon emission computed tomography

WADA Intra-carotid amobarbital procedure

LTA Lobectomia temporal anterior

LTAM Lobectomia temporal anteromesial

AHS Amígdalo-hipocampectomia seletiva

CIREP Centro de Cirurgia de Epilepsia de Ribeirão Preto

HCFMRP-USP Hospital das Clínicas da Faculdade de Medicina de Ribeirão Preto

Universidade de São Paulo

FAE Fármacos anti-epilépticos

CNF Crise prolongada não febril

CF Crise Febril

CFF Crise febril na família

SE Status epilepticus

TCE Traumatismo Crânio Encefálico

CO Complicações obstétricas

DNPM Desenvolvimento neuropsicomotor 


$\begin{array}{ll}\text { DNF } & \text { Déficit neurológico focal } \\ \text { QIG } & \text { Quociente intelectual geral } \\ \text { CTCG } & \text { Crise tônico-clônico generalizada } \\ \text { Slict } & \text { Sinais de lateralização ictal } \\ \text { FR } & \text { Farmacorresistência } \\ \text { AB } & \text { Atividade de base } \\ \text { SPK } & \text { "Spikes” termo em inglês - descargas epilépticas } \\ \text { TC } & \text { Tomografia de crânio } \\ \text { POi } & \text { Complicação no pós-operatório imediato } \\ \text { POt } & \text { Complicações no pós-operatório tardio } \\ \text { TVP } & \text { Trombose venosa profunda } \\ \text { HIP } & \text { Hemorragia intra-parenquimatosa } \\ \text { HSD } & \text { Hemorragia subdural } \\ \text { HED } & \text { Hemorragia extradural } \\ \text { IC } & \text { Intervalo de confiança } \\ \text { ATM } & \text { Articulação têmporo-mandibular } \\ \text { AVE } & \text { Acidente Vascular Encefálico } \\ \text { ELA } & \text { Esclerose Lateral Amiotrófica } \\ \text { IAM } & \text { Infarto agudo do miocárdio } \\ \text { ICR } & \text { Insuficiência renal crônica }\end{array}$




\section{SUMÁRIO}

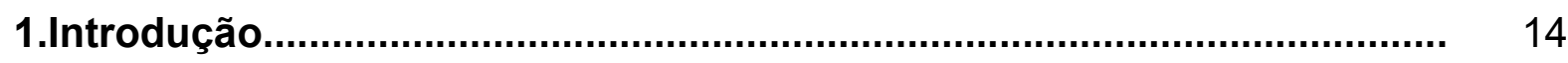

1.1 Incidência, prevalência e impacto da epilepsia......................................... 14

1.2 Definição de Epilepsia e Síndrome Epiléptica......................................... 14

1.3 Classificação das Epilepsias................................................................ 15

1.4 Epilepsia do Lobo Temporal........................................................... 17

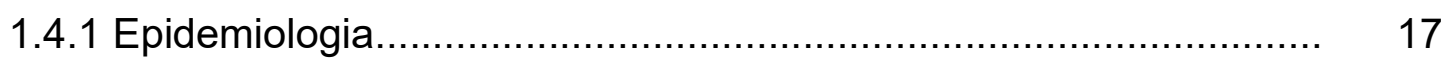

1.4.2 Definição e Subtipos............................................................... 18

1.5 Epilepsia mesial do lobo temporal associada à esclerose hipocampal (EMLT-EH)

1.5.1 História natural, injúria precipitante inicial, etiologias e fatores de risco

1.5.2 Esclerose Hipocampal........................................................ 21

1.5.3 Síndrome Eletroclínica............................................................... 23

1.5.4 Características Clínicas........................................................ 24

1.5.5 Características Neurofisiológicas.............................................. 26

1.5.6 Características Radiológicas................................................... 28

1.5.7 Alterações extra-hipocampais na EMLT..................................... 30

1.5.8 Tratamento Clínico............................................................... 30

1.6 Definição de Epilepsia Refratária....................................................... 31

1.7 Cirurgia de Epilepsia ...................................................................... 31

1.7.1 História da Cirurgia de Epilepsia................................................ 31

1.7.2 Fundamentos........................................................................ 33

1.7.3 Avaliação pré-cirúrgica........................................................... 34

1.7.4 Técnicas Cirúrgicas............................................................. 35

1.8 Classificação prognóstica (Engel).................................................. 42

1.9 Fatores Prognósticos.......................................................................... 43

1.10 Lacunas do conhecimento............................................................... 43

2. Pergunta do trabalho atual.................................................................

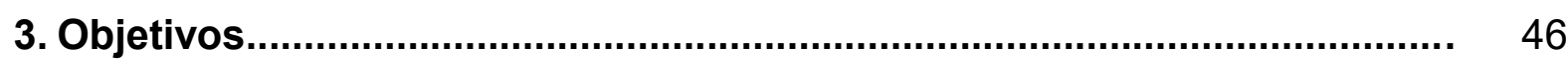

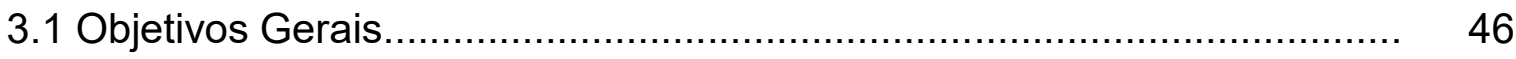

3.2 Objetivos Específicos.................................................................... 46 
4. Pacientes e métodos................................................................................ 47

4.1 Desenho do Estudo................................................................ 47

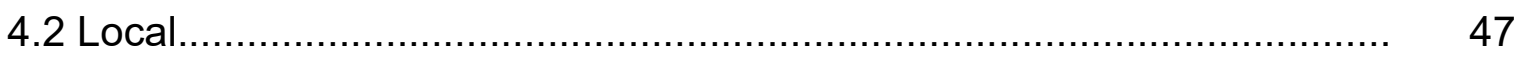

4.3 Seleção dos Pacientes......................................................................... 47

4.4 Critérios de Inclusão........................................................................ 4

4.5 Critérios de Exclusão...................................................................... 48

4.6 Coleta de dados................................................................... 48

4.7 Descrição da avaliação pré-cirúrgica.................................................... 49

4.7.1 Avaliação ambulatorial.......................................................... 49

4.7.2 Neuroimagem estrutural - Ressonância Magnética....................... $\quad 49$

4.7.3 Vídeo-Eletroencefalograma (VEEG)........................................ 50

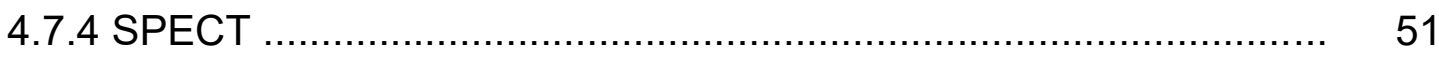

4.7.5 Avaliação Neuropsicológica.................................................... 52

4.7.6 Avaliação Psiquiátrica............................................................. 54

4.7.7 Avaliação Social................................................................... 54

4.7.8 Determinação da Zona Epileptogênica - Reunião Multidisciplinar... 55

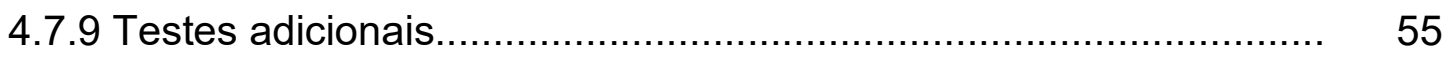

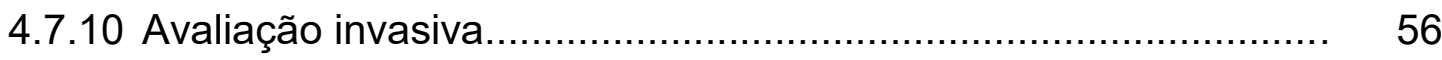

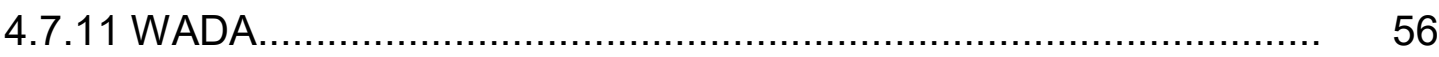

4.8 Descrição das técnicas cirúrgicas..................................................... 57

4.8.1 Cirurgia 1: Lobectomia temporal anteromesial com amígdalohipocampectomia e ressecção do polo temporal (LTAM) ..................... $\quad 57$

4.8.2 Cirurgia 2: Amígdalo-hipocampectomia com preservação do polo e parte do neocórtex temporal ........................................................ 59

4.9 Acompanhamento clínico pós-operatório............................................... 61

4.10 Análise clínica: desfechos em relação à frequência de crises............... 62

4.11 Aprovação pelo comitê de ética...................................................... 62

4.12 Declaração de conflito de interesses..................................................... 62

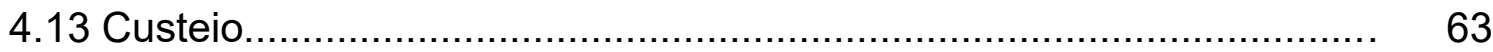

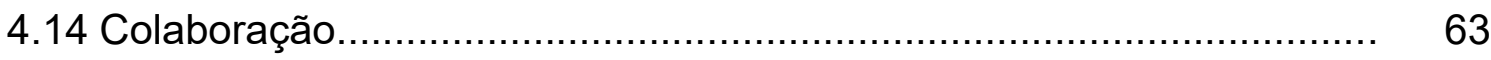

4.15 Análise Estatística........................................................................... 63

4.15.1 Tamanho da amostra............................................................ 63

4.15.2 Variáveis a serem estudadas............................................... 63 


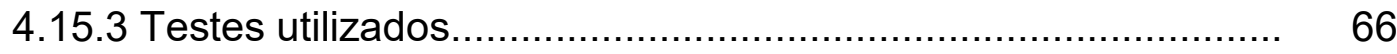

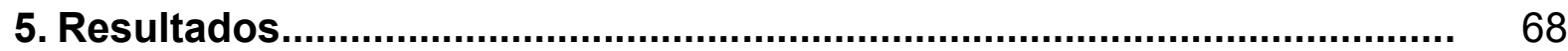

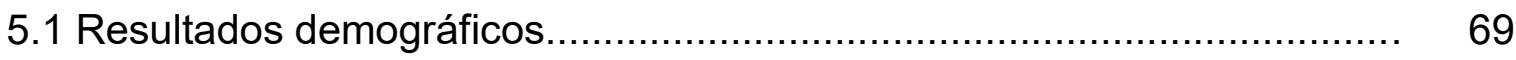

5.2 Resultados prognósticos significativos................................................. 78

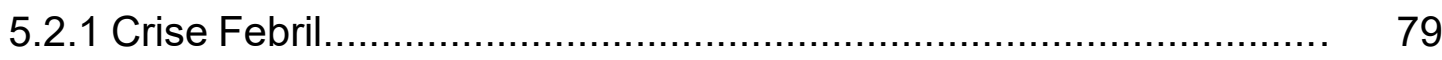

5.2.2 Aura Dismnésica..................................................................... 79

5.2.3 Aura Olfatória................................................................... 80

5.2.4 Tipo de técnica cirúrgica......................................................... 80

5.2 .5 Idade de início da epilepsia.................................................... 81

5.2.6 Número de FAEs antes da cirurgia............................................ 81

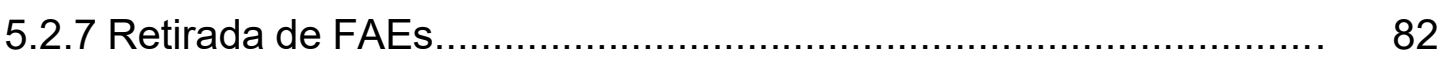

5.2.8 Experiência do serviço............................................................... 83

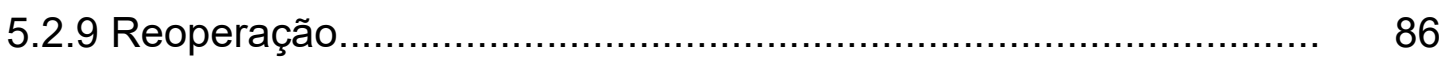

5.3 Resultados não significativos....................................................... 86

5.4 Regressão logística binária......................................................... 89

5.5 Curva de prognóstico relacionada ao tempo......................................... 91

6. Discussão....................................................................................... 95

6.1 Homogeneidade do grupo................................................................. 95

6.2 Prognóstico cirúrgico......................................................................... 95

6.3 Fatores Preditores do Prognóstico Cirúrgico......................................... 96

6.3.1 Prognóstico Cirúrgico X Tipo de Técnica Cirúrgica.......................... 96

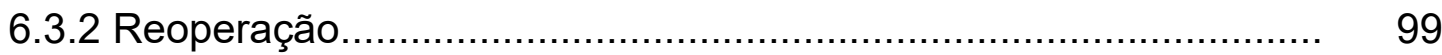

6.3.3 Esclerose Mesial Temporal Unilateral versus Bilateral................... 100

6.3.4 Experiência do Grupo X Prognóstico........................................ 101

6.3.5 Fatores Preditores do Prognóstico Cirúrgico................................. 102

6.3.5.1 Crise Febril.............................................................. 102

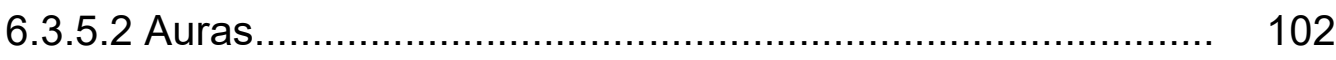

6.3.5.2.1 Aura Olfatória....................................................... 104

6.3.5.2.2 Aura Dismnésica................................................. 106

6.3.5.3 Fatores que classicamente influenciam no prognóstico

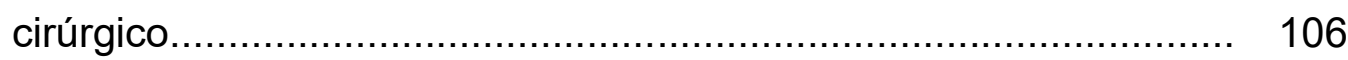

6.4 Retirada de Fármacos anti-epilépticos (FAEs) ................................. 108

6.5 Regressão Logística Binária - aplicação prática e relevância clínica...... 109 
6.6 Considerações Finais............................................................... 111

7. Conclusões............................................................................................. 112

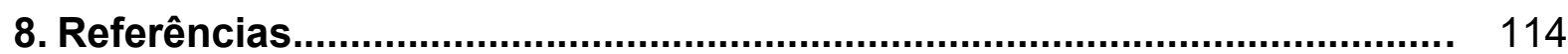

9. Apêndice .................................................................................... 124 


\section{INTRODUÇÃO}

\subsection{Incidência, prevalência e impacto da epilepsia}

Epilepsia é uma doença neurológica crônica que afeta $1 \%$ da população mundial (WA HAUSER, 1990). No mundo todo, existe uma estimativa de pelo menos 65 milhões de pessoas vivendo com epilepsia (NGUGI et al., 2010). A ocorrência de epilepsia varia substancialmente com a população estudada. Em países desenvolvidos, a incidência anual de epilepsia é de 50 por 100.000 habitantes e a prevalência de 700 por 100.000 (HIRTZ et al., 2007). Nos países em desenvolvimento, essas estimativas tendem a ser maiores (NGUGl et al., 2010). No Brasil, a prevalência estimada é de $1,89 \%$ na população urbana (BORGES et al., 2004). Marino e colaboradores em 1986 e Fernandes e colaboradores em 1992, encontraram prevalências de 11,9:1.000 na Grande São Paulo e de 16,5:1.000 para epilepsia ativa em Porto Alegre (FERNANDES JG, SCHMIDT MI, MONTE TL, TOZZI S, 1992; MARINO JÚNIOR; CUKIERT; PINHO, 1986). Borges mostrou que a prevalência de epilepsia em São José do Rio Preto, cidade no interior do Estado de São Paulo, é de 18,6 por 1.000 habitantes (BORGES et al., 2004).

Em todo o mundo, portanto, a epilepsia é considerado um problema de saúde pública, responsável por cerca de $0,5 \%$ dos gastos com doenças incapacitantes no mundo (USTUN, 2002).

\subsection{Definição de Epilepsia e Síndrome Epiléptica}

Crise epiléptica é definida como a ocorrência transitória de sinais e/ou sintomas decorrentes de atividade neuronal síncrona ou excessiva no cérebro, que podem se manifestar por fenômenos anormais súbitos e transitórios, como alteração da consciência, eventos motores, sensitivos/sensoriais, autonômicos e psíquicos, involuntários, que são percebidos pelo próprio paciente ou por um observador (THURMAN et al., 2011).

Uma definição conceitual de epilepsia foi proposta pela International League Against Epilepsy (ILAE) em 2005, a qual é a predisposição persistente do cérebro de gerar crises epilépticas recorrentes e pelas consequências neurobiológicas, cognitivas, psicossociais e sociais dessa condição. Segundo essa proposição, a 
definição de epilepsia requer a ocorrência de pelo menos uma crise epiléptica, desde que seja demonstrada uma condição que predisponha o cérebro a gerar crises, como uma lesão estrutural ou alteração eletroencefalográfica (FISHER et al., 2005).

Em 2014, a ILAE propôs uma definição operacional (prática) de epilepsia como doença do cérebro, por ser uma condição em que há uma desestruturação duradoura da função cerebral normal e não apenas um distúrbio funcional cerebral, como era tradicionalmente referida. Essa definição operacional é caracterizada por uma das seguintes condições:

a) pelo menos duas crises não provocadas (ou duas crises reflexas) ocorrendo em um intervalo superior a 24 horas;

b) uma crise não provocada (ou uma crise reflexa) com chance de recorrência estimada em $60 \%$;

c) diagnóstico de uma síndrome epiléptica (FISHER et al., 2014).

Síndrome epiléptica é definida como um distúrbio epiléptico caracterizado por um conjunto de sinais e sintomas que habitualmente ocorrem juntos, como por exemplo: história, tipos de crises, modo de ocorrência das crises, achados neurológicos e psicológicos, ou alterações detectadas por exames complementares como eletroencefalograma (EEG), tomografia computadorizada de crânio (TC) e ressonância nuclear magnética (RNM) de encéfalo (EPILEPSY, 1989).

\subsection{Classificação das Epilepsias}

A classificação das epilepsias é a principal ferramenta clínica para a avaliação de um indivíduo que se apresenta com crises epilépticas, com impacto em seu manejo e tratamento. A classificação serve para muitos propósitos: fornece estrutura para compreensão dos tipos de crises, dos potenciais gatilhos para ocorrência de crises, prognóstico e possíveis tratamentos. Além disso, pode nos informar sobre as possíveis comorbidades, tais como psiquiátricas, déficits cognitivos, desordens do spectrum autista e risco de mortalidade.

A primeira classificação das "Epilepsias e Síndromes Epilépticas" foi proposta em 1981, e depois revisada pela ILAE em 1989, a qual teve um grande impacto no cuidado da epilepsia e em pesquisas clínicas. Em 2017 a ILAE propôs uma nova 
classificação para as crises epilépticas e epilepsias. Nela, sugere-se, em um primeiro nível, a classificação do tipo de crise, se de início focal, generalizado ou desconhecido.

As crises focais são as que se originam em redes neurais limitadas a um hemisfério cerebral. As crises generalizadas são as que se originam em algum ponto e rapidamente envolvem redes neurais distribuídas em ambos os hemisférios bilateralmente. Após a caracterização do tipo de crise, podem ser propostos, em um segundo nível, a definição do tipo de epilepsia. E em um terceiro nível, a definição da síndrome epiléptica e sua provável etiologia, através de dados da história clínica, exame neurológico, exames complementares, como eletroencefalograma (EEG) e neuroimagem (FISHER et al., 2017a, 2017b).

Figura 1. Classificação dos tipos de crises epilépticas - ILAE 2017

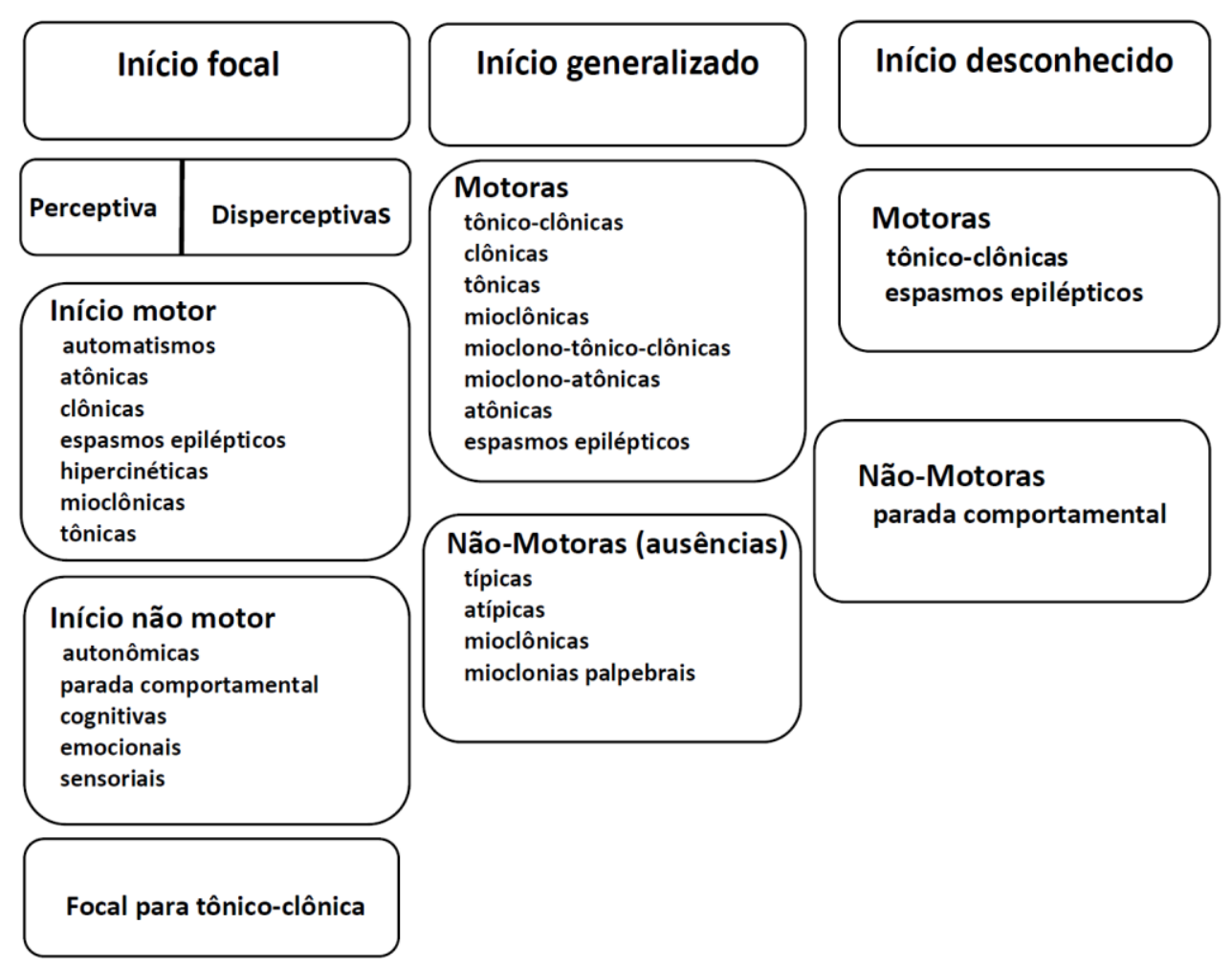

Fonte: (FISHER et al., 2017a), traduzido para o português. 
Figura 2. Estrutura da classificação das epilepsias

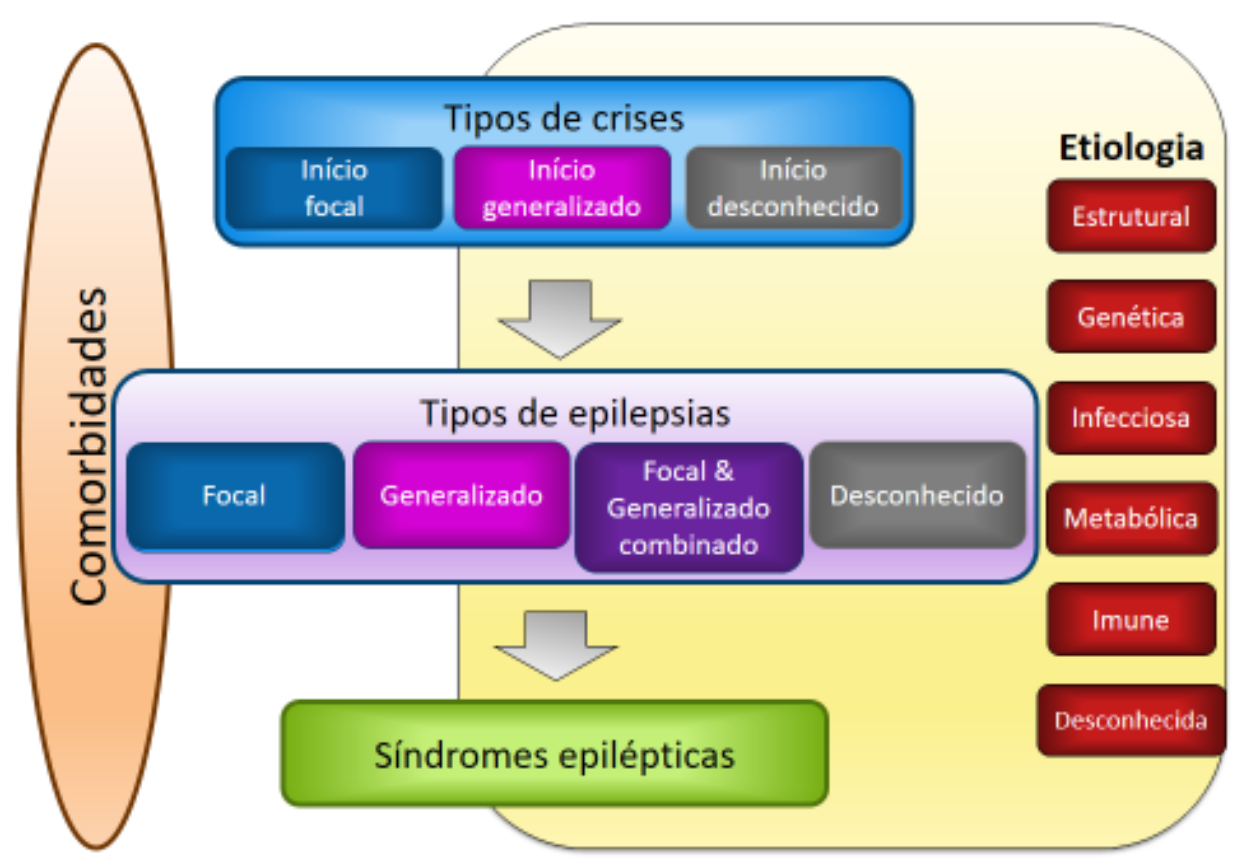

Fonte: (SCHEFFER et al., 2017), traduzido para o português.

\subsection{Epilepsia do Lobo Temporal}

\subsubsection{Epidemiologia}

Epilepsia do lobo temporal (ELT) é o tipo mais comum de epilepsia focal em adultos, constitui $30-35 \%$ de todas as epilepsias (HAUSER; ANNEGERS; ROCCA, 1996). Epilepsia mesial do lobo temporal associada à esclerose hipocampal (EMLT$\mathrm{EH}$ ) é a síndrome epiléptica mais comum, corresponde a $20 \%$ de todos os pacientes com epilepsias e $65 \%$ dos pacientes com epilepsia do lobo temporal. A esclerose hipocampal $(E H)$ é o substrato patológico mais comum das ELT refratárias (BABB T, 1993; BLÜMCKE et al., 2012; FALCONER, 1971; WIESER, 2004). A incidência de EH na população geral não é conhecida, pois a maioria dos estudos são realizados a partir de séries cirúrgicas (CENDES et al., 2014). Estudos de neuropatologia sugerem que a EH representa 44-65\% das EMLT (BABB T, 1993). Outro estudo mostrou que a EH está presente em 60-70 \% dos pacientes submetidos a tratamento cirúrgico para epilepsia refratária ao tratamento medicamentoso (BLÜMCKE et al., 2013). 


\subsubsection{Definição e subtipos da Epilepsia do Lobo Temporal}

Epilepsia do Lobo Temporal é um tipo de epilepsia focal na qual as crises se iniciam nas estruturas do lobo temporal. Pode ocorrer por diversas etiologias, idades de início, prognósticos e respostas ao tratamento.

ILAE classificou a ELT de acordo com a seguinte subdivisão anatômica:

a) ELT límbica:

- Epilepsia mesial do lobo temporal associada à esclerose hipocampal (EMLT-EH);

- EMLT por outras etiologias específicas.

b) neocortical:

- ELT lateral.

As ELT límbicas compreendem a 2/3 de todas as ELT (ENGEL, 2001b).

Muitos especialistas usam uma outra classificação baseada em conceitos anatômicos, clínicos e de neuroimagem (VELASCO; MATHERN, 2011):

a) epilepsia mesial do lobo temporal associada à esclerose hipocampal (EMLT$\mathrm{EH}$ ), bilateral ou unilateral (assimétrica);

b) ELT associada a outras lesões histopatológicas (tumores, displasias corticais, lesões vasculares, além de sequelas de trauma ou infecção do sistema nervoso central). De acordo com a localização das lesões, os pacientes podem ter EMLT ou epilepsia neocortical lateral;

c) ELT sem identificação de lesão epileptogênica (não lesionais ou antigamente chamada de criptogênica);

d) dupla patologia, que consiste na presença de esclerose hipocampal e outra lesão extra-hipocampal. 


\subsection{Epilepsia mesial do lobo temporal associada à esclerose hipocampal (EMLT-EH)}

\subsubsection{História natural, injúria precipitante inicial, etiologias e fatores de risco}

A história natural da EMLT é classicamente descrita como um período latente entre um "insulto precipitante inicial" (que pode ser uma crise febril ou outro insulto neurológico nos primeiros anos de vida) e o início das crises no final da infância ou adolescência (CENDES et al., 2014).

A injúria precipitante inicial (IPI) é qualquer insulto cerebral, que pode ocorrer intra-útero, peri-parto, no período neonatal, nos primeiros anos de vida (usualmente antes dos 4 anos de idade) ou até mais tardiamente. Exemplos dos principais IPIs:
a) crises febris prolongadas;
b) complicações obstétricas;
c) anóxia neonatal;
d) hipoglicemia severa;
e) traumatismo crânio-encefálico;
f) infecção do sistema nervoso central (meningites ou encefalites);
g) status epilepticus;
h) acidente vascular encefálico (isquêmico ou hemorrágico) (CENDES, 2005).

Acredita-se que esse insulto precipitante inicial seja o "gatilho" fisiopatológico para o desenvolvimento de hiperexcitabilidade neuronal (epileptogênese) e dano ao hipocampo, levando à morte neuronal e esclerose hipocampal (LEITE; GARCIACAIRASCO; CAVALHEIRO, 2002).

Muitos estudos retrospectivos têm mostrado a significativa relação entre a história de crises febris na infância e o desenvolvimento de EMLT-EH (CENDES; ANDERMANN, 2002).

Pacientes com história de crise febril prolongada antes dos 5 anos de idade, têm maior probabilidade de ter $\mathrm{EH}$ unilateral e um bom prognóstico cirúrgico (MATHERN et al., 1995).

Existe uma discussão em aberto: se o dano causado pela crise febril levou à $\mathrm{EH}$ ou se o paciente teve uma crise febril, porque o hipocampo já era previamente 
alterado por algum outro insulto precipitante inicial ou predisposição genética, ou seja, se a EH é causa ou consequência das crises (KOBAYASHI et al., 2001).

A predisposição genética parece ser um importante fator causal em pacientes com esclerose mesial temporal (EMT) com antecedente de crise febril prolongada. Alguns autores defendem a ideia de que a relação entre crise febril e 0 desenvolvimento da epilepsia é frequentemente genética (BAULAC et al., 2004).

Os casos de familiares de EMLT-EH geralmente têm um curso benigno, com bom controle de crises. O padrão de herança é autossômico dominante, com penetrância incompleta. A presença de $\mathrm{EH}$ nos pacientes afetados e nos assintomáticos, sugere que as anormalidades do hipocampo por si só são herdadas, mas não necessariamente o indivíduo desenvolverá epilepsia. Isso reforça a hipótese de que os fatores ambientais são importantes para desenvolvimento do fenótipo (KOBAYASHI et al., 2001).

A Etiologia e fisiopatologia da EH são multifatoriais, englobando fatores moleculares, genéticos, epigenéticos, ambientais e evolução ao longo da vida, como frequência e severidade das crises (CENDES et al., 2014).

Qualquer alteração estrutural é considerada um fator de risco para epilepsia. A dupla patologia é comum na EMLT-EH como por exemplo: malformações do desenvolvimento cortical (displasia cortical focal, microdisgenesias), malformações vasculares, tumores, heterotopias nodulares focais, calcificações, etc. (KUZNIECKY et al., 1999).

Outro fator de risco muito importante em nosso país e na América Latina é a neurocisticercose (NCC). Velasco em 2006 e Bianchin em 2015, relataram a associação entre EMT e NCC, sugerindo que a NCC é um fator de risco para EH. A infecção aguda pela NCC pode causar uma meningoencefalite e a reação inflamatória gerada pela presença do parasita, pode levar ao dano hipocampal. Nesses casos a NCC é considerada como um IPI em que provoca perda neuronal hipocampal na fase aguda (BIANCHIN et al., 2006, 2015; RANGEL et al., 1987).

Alguns autores defendem que indivíduos que vivem em algumas regiões de países em desenvolvimento com condições socioeconômicas prejudicadas, podem ter maior exposição a fatores de risco ambientais, como infecções parasitárias, meningite, crise febril, traumas, má assistência à saúde e perinatal. Observou-se uma maior incidência e prevalência de epilepsia em regiões desfavorecidas, sugerindo uma 
correlação com o status socioeconômico (BIANCHIN et al., 2006; BORGES et al., 2004).

\subsubsection{Esclerose Hipocampal}

O termo "hipocampo" vem do grego "cavalo marinho", descrito pela primeira vez em 1957 por Julius Caesar Arantius. O termo "Corno de Ammon" foi descrito por Garengoet em 1742 referindo-se ao Deus Egípcio Amun Kneph (WALTHER, 2002). Os termos "Esclerose do Corno de Ammon", "esclerose hipocampal" ou "esclerose mesial temporal (EMT)" podem ser usados como sinônimos. O termo "esclerose" é originalmente a descrição macroscópica que indica atrofia e "endurecimento" de uma estrutura. Histologicamente, implica em uma perda ou destruição neuronal seletiva, especialmente em relação as células piramidais, com proliferação astroglial secundária, que afeta vários setores do hipocampo em diferentes graus. As regiões mais vulneráveis ao dano são: o endofolium (setor CA4), depois CA3 e CA1; com preservação das células granulares do giro denteado, CA2 e subiculum (BABB T, 1993). Se essa perda celular for suficientemente pronunciada, pode ser vista na ressonância nuclear magnética de encéfalo (RNM) como atrofia e aumento de sinal nas sequências T2 (GLOOR, 1991).

Em 2013 a "Task Force for Neuropathology of the International League Against Epilepsy (ILAE) Commission", revisou a publicação de Blumcke e colaboradores em 2012, e propôs uma nova classificação histológica para EH em três subtipos:

a) EH ILAE tipo I: clássica ou de padrão completo. É perda neuronal severa ou total em CA1, CA4, CA3, CA2, giro denteado, com preservação do subiculum. Esse é o tipo mais comum, corresponde a aproximadamente $80 \%$ dos casos ELT cirúrgicos;

b) EH ILAE tipo II: perda neuronal predominante em CA1, afeta $80 \%$ das células piramidais. É um subtipo incomum, corresponde à $5-10 \%$ de todos os casos de ELT cirúrgicos;

c) EH ILAE tipo III: perda neuronal predominante em CA4. Corresponde a $4-7.4 \%$ dos casos de ELT cirúrgicos;

d) ausência de esclerose hipocampal, com apenas gliose (BLÜMCKE et al., 2013). 
Figura 3. Anatomia microscópica do hipocampo normal

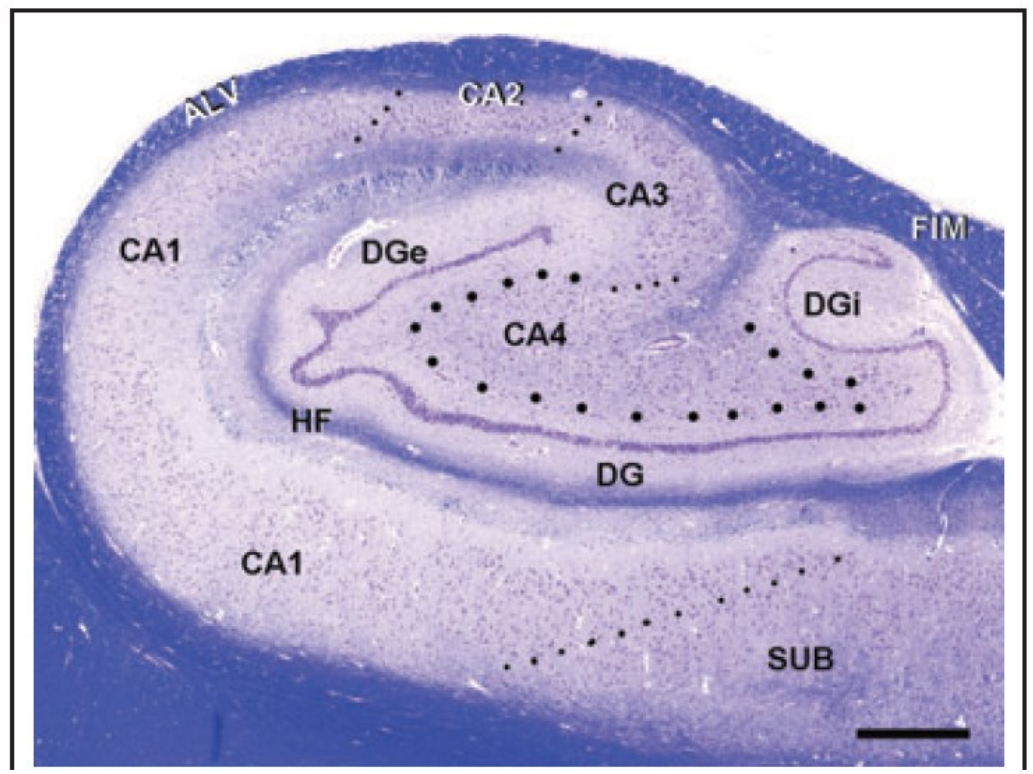

SUB: subiculum; CA1-CA4: setores do Cornu de ammonis; DG: giro denteado; DGe: giro denteado externo; DGi: giro denteado interno; HF: fissura hipocampal; ALV: alveus; FIM: fimbria.

Fonte: (BLÜMCKE et al., 2013).

Figura 4. Subtipos histológicos da EH - Classificação ILAE

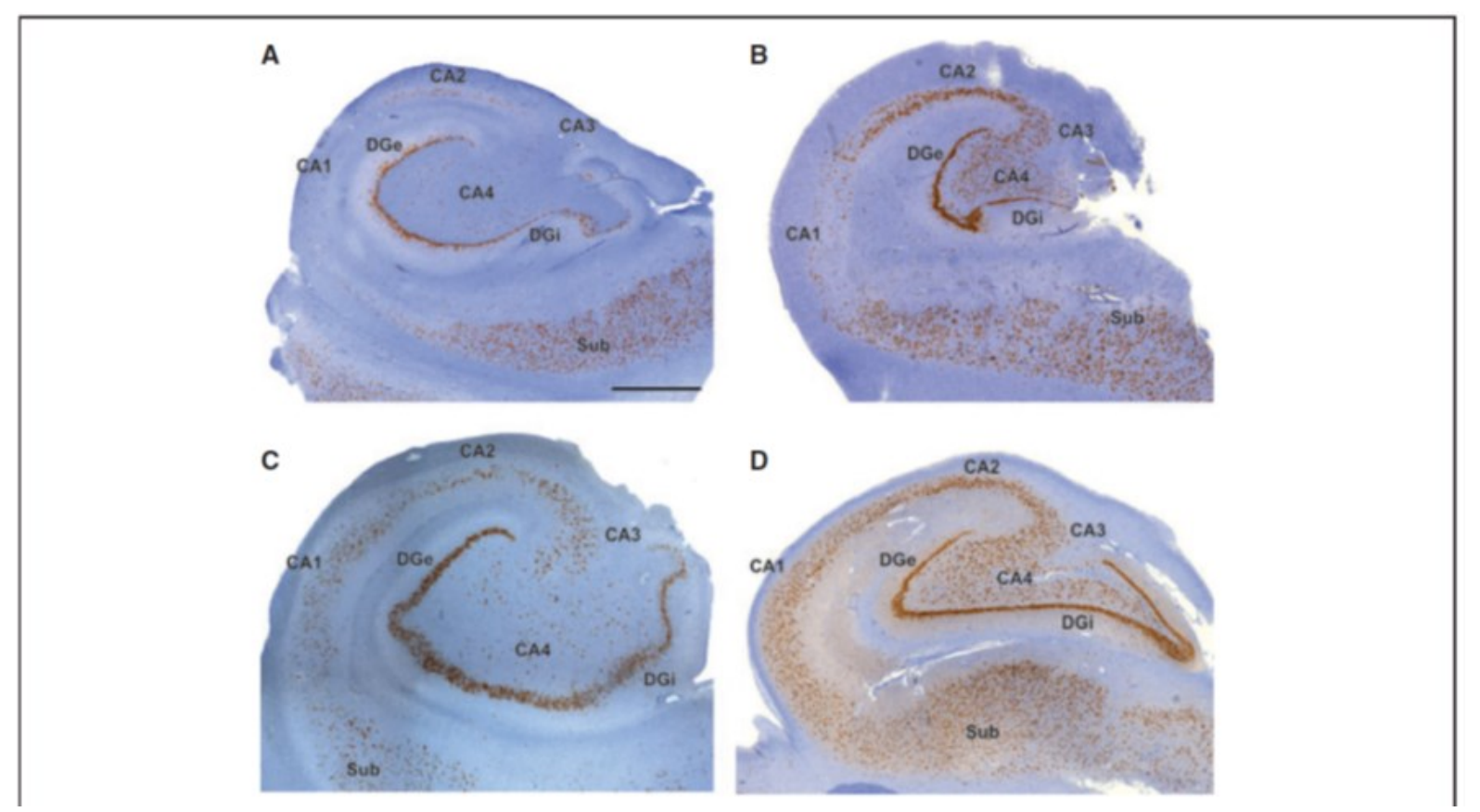

(A) ILAE tipo I; (B) ILAE tipo 2; (C) ILAE tipo 3; (D) apenas gliose, sem EH. Fonte: (BLÜMCKE et al., 2013). 
A EH ILAE tipo 1 é a mais frequentemente associada à história de injúria precipitante inicial antes dos 5 anos de idade, com início de crises precocemente e prognóstico pós-cirúrgico favorável. Já a EH ILAE dos tipos 2 e 3 têm sido menos estudadas, mas alguns estudos mostraram prognósticos menos favoráveis. O tipo 3 pode ter aparência normal na RNM e está associado com a menor duração da epilepsia, quando comparado aos tipos 1 e 2 (BLÜMCKE et al., 2007).

A esclerose hipocampal pode ocorrer de forma isolada ou em associação com outras lesões epileptogênicas (dupla patologia) como principais exemplos: tumores, malformações do desenvolvimento cortical, malformações vasculares, sequelas de encefalite, sequelas de acidente vascular encefálico (AVC), sequelas de traumatismo crânio-encefálico (TCE), gliose e neurocisticercose (NCC) (BLÜMCKE et al., 2013).

Segundo alguns autores, a EH é uma condição frequentemente bilateral, com alguns graus de assimetria. Esse conceito tem sido corroborado através de estudos de neuroimagem e autopsia em pacientes com EMLT-EH, que evidenciaram frequentes danos hipocampais de forma bilateral e assimétrica (GLOOR, 1991; MCINTOSH et al., 2004).

A fisiopatologia da epileptogênese está relacionada ao remodelamento sináptico e reorganização das células hipocampais após determinado dano. Essas mudanças aumentam a excitabilidade e predispõem à hipersincronização dos neurônios sobreviventes, que se propagam para outras estruturas límbicas e extrahipocampais, produzindo a manifestação clínica das crises epilépticas (ENGEL; WILSON; BRAGIN, 2003).

\subsubsection{Síndrome Eletroclínica}

A síndrome eletroclínica é caracterizada por crises focais com alteração da consciência, denominadas como disperceptivas de acordo com a nova classificação da ILAE 2017 e previamente descritas como crises parciais complexas (ILAE 1989). A síndrome também é caracterizada por paroxismos epileptiformes em regiões temporal anterior e média no eletroencefalograma, atrofia hipocampal com alteração de sinal na ressonância nuclear magnética (RNM) de encéfalo, além de distúrbios de memória em testes neuropsicológicos e problemas psiquiátricos (CENDES $F$, KAHANE P, BRODIE MJ, 2012; DUCHOWNY M.S, 1997). 
Características que podem colocar o diagnóstico da síndrome EMLT em dúvida:

a. história de traumatismo crânio-encefálico severo, encefalite ou eventos causais específicos;

b. déficit neurológico focal ou sintomas sensoriais específicos no início ou no final da crise;

c. déficits neurológicos focais no interictal;

d. déficit cognitivo acentuado no exame neuropsicológico;

e. descargas epilépticas bilaterais síncronas, generalizadas ou extratemporais;

f. alentecimento difuso ou extratemporal ao EEG interictal;

g. outra lesão cerebral que não esclerose hipocampal na RNM encéfalo. (JEROME ENGEL JR., GREGORY D. CASSINO, 1997).

\subsubsection{Características Clínicas}

Classicamente o evento inicial é uma crise tônico-clônica bilateral (generalizada) ou uma crise focal disperceptiva, geralmente febril, nos primeiros anos de vida, seguido por um intervalo silencioso (período latente de crises bem controladas) com doses baixas de fármacos anti-epilépticos (FAEs). Habitualmente as crises recorrem na infância tardia ou adolescência, a partir daí, relativamente estereotipadas com maior frequência, causando impacto psicossocial (CENDES et al., 1993).

A EMLT apresenta essencialmente 3 tipos semiológicos de crises:

a) Crise focal com preservação da consciência (antigamente chamada de crise parcial simples) ou aura: é definida como uma sensação subjetiva experienciada pelo paciente. É o primeiro sintoma ictal e geralmente evoluiu com alteração da consciência. As auras nos trazem informações sobre a extensão da zona sintomatogênica, com valor localizatório e lateralizatório na determinação da zona epileptogênica (FOLDVARY-SCHAEFER; UNNWONGSE, 2011). Na EMLT, as auras são tipicamente caracterizadas por uma sensação epigástrica ascendente (em mais de $80 \%$ dos casos EMLT), podendo estar associadas com outros tipos de auras como afetiva (medo), psíquica ou dismnésica (déjà-vu), autonômica (calor, rubor, 
taquicardia, midríase, etc.), olfatória, gustatória, urgência urinária (PANAYIOTOPOULOS, 2010). As auras podem ser classificadas em quatro grupos de acordo com sua localização (PENRY, 1981):

- temporal mesial: afetiva, dismnésica, autonômica, epigástrica, olfatória e gustatória;

- temporal lateral: aura vertiginosa e auditiva;

- extratemporal: sômato-sensitiva, visual e disfásicas;

- inespecíficas: sensações vagas e cefálicas.

b) Crise focal com alteração da consciência ou crise disperceptiva (antigamente conhecida como crise parcial complexa), caracterizada por: alteração da consciência, parada comportamental, desvio cefálico (não forçado), olhar fixo, automatismos oroalimentares, automatismo manual ipsilateral à zona de início ictal (ZII), postura distônica no membro superior contralateral à ZII. Pode evoluir ou não para crise tônico-clônica bilateral, com duração de 1 a 2 minutos. O período pós-ictal é caracterizado por confusão mental, sonolência, podendo ocorrer fala desconexa (hemisfério não dominante) ou algum grau de afasia (hemisfério dominante), além de comportamento de "coçar o nariz" tipicamente com a mão ipsilateral à ZII. Frequentemente os pacientes apresentam amnésia do evento, mas são capazes de se lembrar da aura (CENDES F, KAHANE P, BRODIE MJ, 2012; PANAYIOTOPOULOS, 2010);

c) Crise tônico-clônica bilateral (ou generalizada): ocorre como uma evolução da crise de início focal. Geralmente inicia-se com versão ocular e cefálica contralateral à ZII, podendo evoluir com extensão do membro contralateral e flexão do membro ipsilateral (sinal do "quatro"), seguido por abalos motores tônico-clônico bilaterais, liberação esfincteriana e sialorreia (PANAYIOTOPOULOS, 2010).

As crises geralmente ocorrem com frequência mensal a semanal e podem ocorrer durante o sono. Os principais fatores precipitantes incluem: estresse, privação de sono e alterações hormonais relacionadas ao ciclo menstrual. As crises generalizadas ou status epilepticus são infrequentes (CENDES F, KAHANE P, BRODIE MJ, 2012). 
No período interictal os pacientes podem apresentar déficits de memória, alterações comportamentais e distúrbios psiquiátricos, especialmente transtorno depressivo. O exame neurológico é tipicamente normal, exceto por uma discreta assimetria facial contralateral à zona epileptogênica (WIESER, 2004).

Déficits neurológicos focais ou rebaixamento cognitivo muito acentuado são raros e colocam o diagnóstico da síndrome em dúvida. O exame neuropsicológico pode evidenciar déficit de memória verbal em pacientes com EMT de hemisfério dominante e de memória não verbal para aqueles com EMT de hemisfério não dominante (WILLIAMSON et al., 1993).

\subsubsection{Características Neurofisiológicas}

O eletroencefalograma (EEG) interictal é caracterizado classicamente por pontas ou ondas agudas seguidas por onda lenta na região anterior e mesial do lobo temporal unilateral, que são melhores visualizados com eletrodos esfenoidais. Em até $50 \%$ dos pacientes, pode ser registrada atividade lenta teta ou delta rítmica intermitente ipsilateral, com valor localizatório para a zona epileptogênica. Em 2/3 dos pacientes as descargas ocorrem de forma unilateral, mas podem ser observadas de forma bilateral e independente (GAMBARDELLA et al., 1995).

As alterações epileptiformes podem ser encontradas em aproximadamente 1/3 dos pacientes em um único EEG de rotina. Em aproximadamente $2 / 3$ dos pacientes, um único EEG de rotina pode ser normal ou apresentar apenas alterações leves e não específicas. A monitorização prolongada, com traçado de sono, aumenta a sensibilidade para o registro das alterações epileptiformes interictais (WILLIAMSON et al., 1993).

O EEG ictal tem início a partir de estruturas mesiais do lobo temporal (amígdala, hipocampo e giro parahipocampal) em mais de $90 \%$ dos pacientes com ELT (SPENCER et al., 1992). O padrão típico do EEG ictal de superfície consiste em uma atividade teta rítmica "em crescendo" com aumento da amplitude e diminuição da frequência (5 a $8 \mathrm{~Hz}$ ) na região anterior e mesial do lobo temporal afetado. Essa atividade pode ser propagada para áreas adjacentes ou mesmo para área homóloga contralateral, mais tardiamente (EBERSOLE; PACIA, 1996). Usualmente o EEG inicia 
30 segundos antes do início clínico, mas quando a clínica ictal é observada antes das alterações no EEG, sugere-se que a atividade ictal iniciou na região mesial e ficou confinada por alguns instantes, sem evidências de alterações nos eletrodos de superfície. Nesses casos, o EEG de superfície pode ter pouco valor localizatório (MINTZER et al., 2004). Quando o início ictal não é claro, pode ter ocorrido em estruturas mais profundas ou mesmo extra temporais que se propagaram para a região temporal, assim, está indicada avaliação com eletrodos semi-invasivos (eletrodos de forame oval) ou invasivos (eletrodos profundos ou subdurais). Estes podem ser adicionados para melhorar a sensibilidade da determinação da zona de início ictal (HAMER HM, 2001).

Figura 5. EEG interictal de paciente com EMLT esquerda, evidenciando atividade interictal composta por ponta em eletrodos temporais mesiais e anteriores.

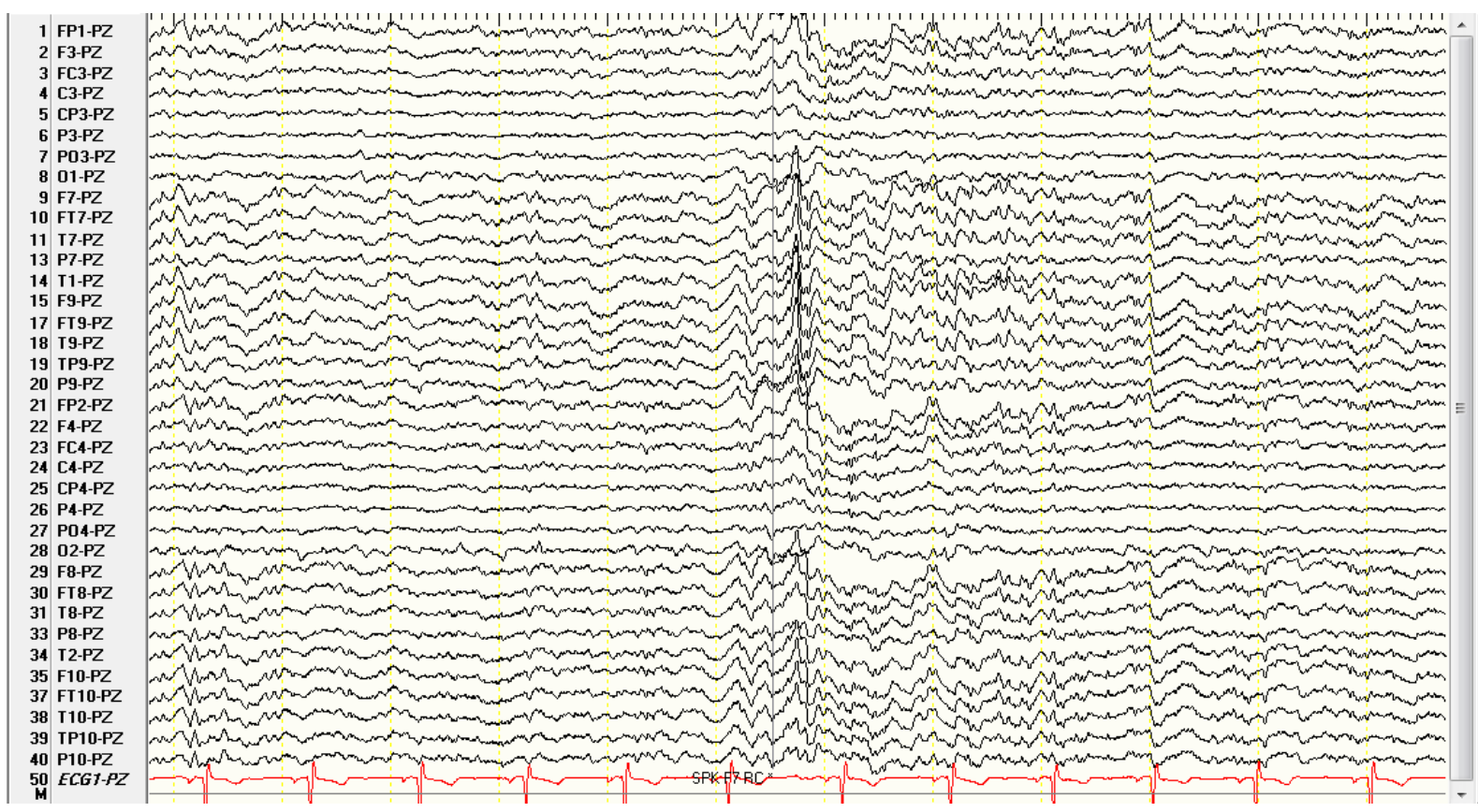

Fonte: Centro de cirurgia de epilepsia de Ribeirão Preto - CIREP 2017. 
Figura 6. EEG ictal de paciente com EMLT esquerda, evidenciando atividade teta rítmica e regular em região temporal esquerda.

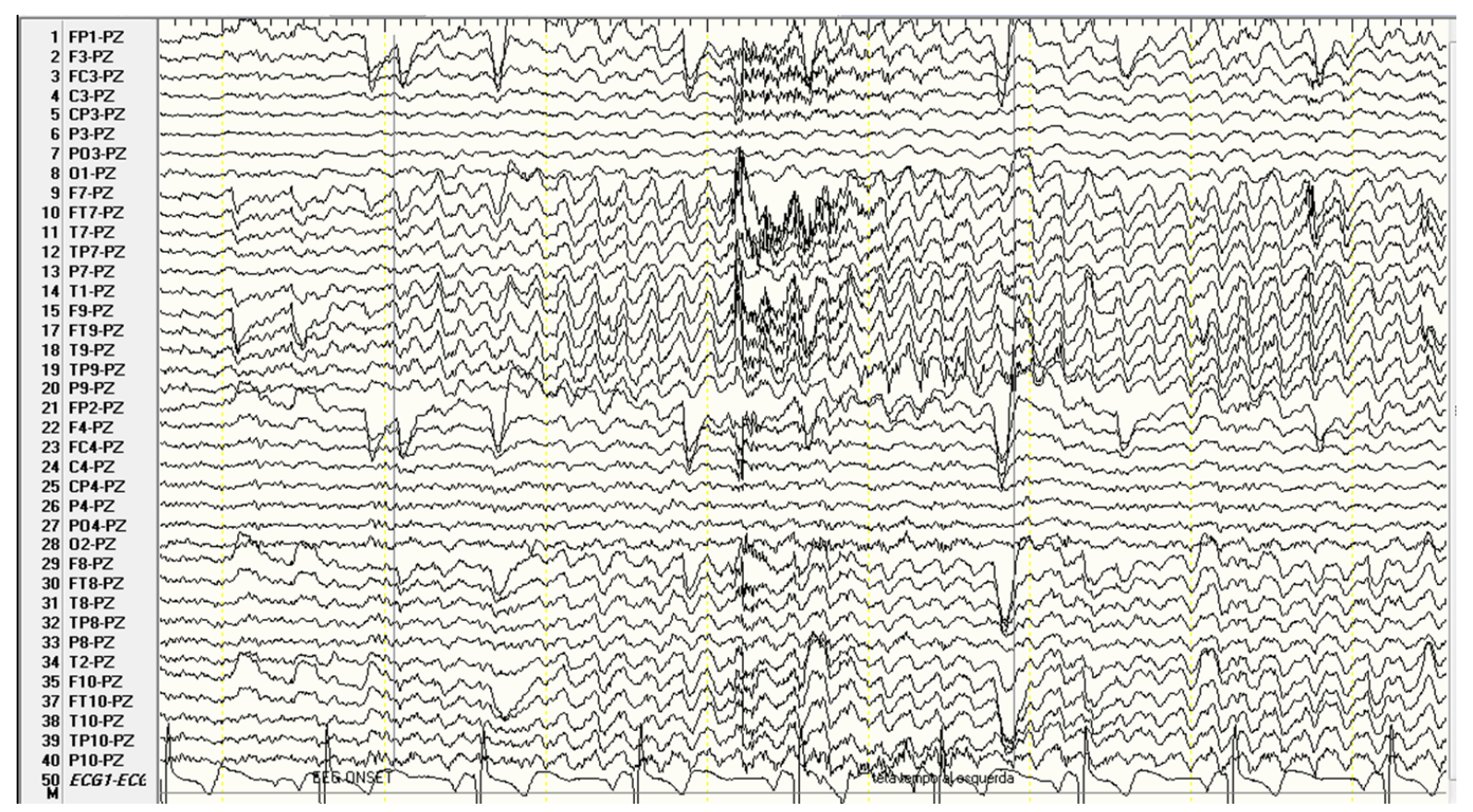

Fonte: Centro de cirurgia de epilepsia de Ribeirão Preto - CIREP 2017.

\subsubsection{Características Radiológicas}

O desenvolvimento da neuroimagem teve um impacto positivo, significativo na avaliação pré-cirúrgica da epilepsia. A Ressonância Nuclear Magnética (RNM) de alta resolução, é um método não invasivo, com alta sensibilidade e especificidade para o diagnóstico de $\mathrm{EH}$ in vivo. A maioria dos pacientes com $\mathrm{EH}$ que são submetidos à avaliação pré-cirúrgica, têm claramente os sinais clássicos da EMLT-EH, são eles:

a) redução de volume (atrofia) hipocampal unilateral;

b) aumento de sinal nas sequências ponderadas em T2 e FLAIR (fluid attenuated inversion recovery);

c) hipocampo contralateral aparentemente normal (CENDES, 2013).

Outras alterações extra-hipocampais encontradas na RNM de pacientes com EMLT são: atrofia da substância branca envolvendo não só as estruturas mesiais, mas também outras estruturas interconectadas com o sistema límbico, incluindo amigdala, córtex entorrinal, tálamo e fórnix (COAN; CENDES, 2013). Além disso, estudos com RNM quantitativa demonstraram que em pacientes farmacorresistentes, o polo 
temporal pode estar frequentemente alterado, com atrofia e alteração de sinal da substância branca em T2 (BONILHA et al., 2003).

Outros exames complementares para auxiliar na localização da zona epileptogênica:

a) PET (positron emission tomography): observa-se hipometabolismo no lobo temporal afetado, por diminuição do metabolismo da glicose que envolve as estruturas mesiais, o polo temporal e parte do córtex lateral. Este achado está relacionado com prognóstico cirúrgico favorável (DUPONT et al., 2000);

b) SPECT (single photon emission computed tomography) interictal: hipoperfusão no temporal afetado; SPECT ictal: hiperperfusão na área correspondente à zona epileptogênica (CENDES, 2005);

c) WADA (intra-carotid amobarbital procedure): consiste em anestesiar um hemisfério para simular os efeitos da cirurgia, com o objetivo de lateralização da linguagem e avaliação da memória. É o exame padrão ouro para avaliação de linguagem e memória (BAXENDALE, 2009).

Figura 7. Imagem por RNM [FLAIR à esquerda e Inversion recovery (IR) à direita], evidenciando aumento de sinal (FLAIR), redução de volume e hipossinal no IR, em hipocampo esquerdo.
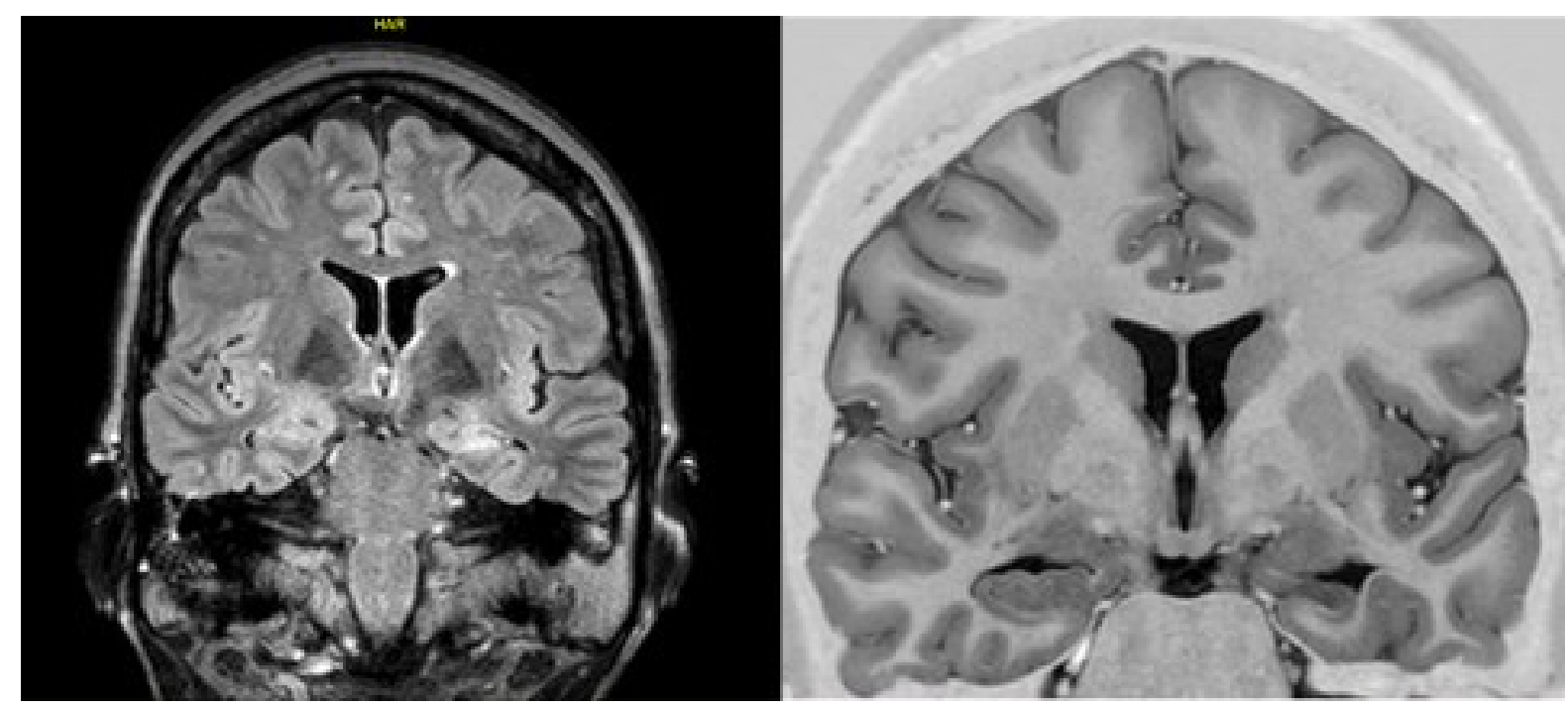

Fonte: Centro de cirurgia de epilepsia de Ribeirão Preto - CIREP 2017. 


\subsubsection{Alterações extra-hipocampais da ELT}

O espectro eletro-clínico-patológico da EMLT-EH indica que as alterações estruturais e funcionais são usualmente mais extensas do que restritas apenas ao hipocampo (BONILHA et al., 2012). Podem ser clinicamente definidas em subgrupos que variam de focal mesial até mais extensas "temporal plus", envolvendo áreas adjacentes à região temporal mesial. As alterações extra-hipocampais podem envolver as estruturas límbicas (amígdala, fórnix, corpos mamilares, trato mamilotalâmico), assim como áreas paralímbicas (córtex entorrinal, região têmporo-polar) e o neocórtex temporal. Quando a região epileptogênica envolve áreas mais extensas do que a mesial temporal, pode-se explicar a falha das ressecções seletivas, assim como a persistência de auras ou crises após a lobectomia temporal (BARBA et al., 2016; KAHANE; BARTOLOMEI, 2010)

\subsubsection{Tratamento Clínico}

O tratamento clínico de escolha para epilepsia focal são os fármacos bloqueadores dos canais de sódio ( $\mathrm{Na}+$ voltagem dependentes), tais como: carbamazepina, oxcarbazepina, fenitoína, lamotrigina, valproato de sódio e topiramato. A escolha será influenciada pela idade, sexo, comorbidades, bem como o uso de outros fármacos utilizados pelo paciente. (BRODIE; DICHTER, 1996).

Em 2006 a ILAE publicou uma revisão sobre a eficácia do tratamento inicial em monoterapia em pacientes com diagnóstico recente de epilepsia não tratada, que depois foi atualizada em 2013. Concluiu-se que Levetiracetam, Zonisamida, Carbamazepina e Fenitoína têm nível de evidência IA em eficácia e efetividade como monoterapia inicial em pacientes adultos com epilepsia focal (GLAUSER et al., 2013).

Dos pacientes com epilepsia do lobo temporal, aproximadamente $70 \%$ conseguem bom controle medicamentoso (ENGEL, 1998). 
1.6 Definição de Epilepsia Refratária (de difícil controle) ou Farmacorresistente

A epilepsia do lobo temporal, além de ser o tipo de epilepsia mais comum, também é a que possui maior refratariedade à farmacoterapia, correspondendo à $30 \%$ dos casos. Esta condição está associada à piora da qualidade de vida, déficits cognitivos e risco de morte (ENGEL, 1998).

O conceito de epilepsia intratável, de acordo com "The International League Against Epilepsy (ILAE)", é definido como: epilepsia na qual as crises persistem apesar da terapia otimizada, com duas ou mais medicações antiepilépticas apropriadamente indicadas, com doses adequadas, boa tolerabilidade e uso de forma regular (KWAN et al., 2010).

Depois de um segundo fármaco antiepiléptico (FAE), a chance do paciente ficar livre de crises com um terceiro ou quarto FAE é de aproximadamente $5 \%$ em 2 a 3 anos (WIEBE et al., 2001).

O tratamento padrão para ELT intratável é a remoção cirúrgica das estruturas envolvidas (ENGEL, 1996).

A doença é um continum, progressiva; se não tratada corretamente, pode ter prejuízos cognitivos, psicológicos, sociais e laborais, além de interferir substancialmente com a qualidade de vida.

\subsection{Cirurgia de Epilepsia}

\subsubsection{História da Cirurgia de Epilepsia}

Os fundamentos para o desenvolvimento da neurocirurgia para epilepsia iniciaram-se a partir de estudos realizados no século XIX:

a) em 1861 Paul Broca descobriu a localização cerebral da linguagem;

b) em 1870 Fritsh, Hitzig and Daniel Ferrier descreveram o córtex motor usando estimulação cortical;

c) em 1884 Rickman Godlee operou o primeiro tumor cerebral baseado em sua típica crise focal motora;

d) em 1886 Victor Horsley realizou a primeira cirurgia de epilepsia em um paciente de 22 anos, com crises focais motoras secundárias a um TCE; 
e) em 1886 Horsley ressecou um tumor cerebral com o córtex adjacente guiado pela análise da semiologia ictal "in order to prevent, as far as possible, the recurrence of the epilepsy" (HORSLEY, 1886);

f) Hans Berger em 1929 realizou o primeiro registro da atividade elétrica cerebral, com o objetivo de estudar a natureza da alteração comportamental (BERGER, 1929);

g) na década de 1940 o aprimoramento do EEG permitiu a melhor caracterização das crises "psicomotoras" (GIBBS; GIBBS; FUSTER, 1948);

h) em 1950 foi realizada primeira lobectomia temporal (PENFIELD; FLANIGIN, 1950). As primeiras ressecções não incluíam o hipocampo, pois acreditavam que a esclerose era consequência das crises (BRATZ, 1899; GOWERS, 1901);

i) entre 1950-1960 esse ponto de vista mudou a partir de alguns estudos clínicos apontando a região mesial e temporal inferior como importantes áreas que reproduziam os fenômenos ictais;

j) na mesma década de 1950 Penfield descreveu o sucesso do controle de crises quando aumentou a ressecção, incluindo uncus e hipocampo, em pacientes os quais a resseção anterior e lateral não eliminou as crises (KAADA, 1951; PENFIELD, 1950);

k) em 1957 Paulo Niemeyer descreveu a técnica cirúrgica cuja a remoção da amígdala e hipocampo se dá através de uma abordagem transventricular, sem ressecar o córtex adjacente e demonstrou que vários pacientes ficaram livres de crises (NIEMEYER, 1958);

I) finalmente em estudos com eletrodos profundos, observou-se que o EEG ictal iniciava-se nas estruturas mesiais do lobo temporal (CRANDALL; WALTER; RAND, 1963).

A partir de 1970, vários avanços no tratamento de pacientes com epilepsia do lobo temporal foram alcançados, através da melhoria das técnicas de neuroimagem, neurofisiologia e cirúrgicas. 


\subsubsection{Fundamentos da cirurgia de epilepsia}

EMLT é considerada uma "síndrome cirurgicamente remediável". A intervenção cirúrgica precoce, após a confirmação de farmacorresistência, proporciona melhores prognósticos psicossociais durante a adolescência e a fase adulta. Se as crises persistirem, consequências psicossociais podem surgir. Se a cirurgia for realizada na fase adulta mais tardia, a reabilitação completa pode não ser atingida (ENGEL, 1996).

O primeiro estudo controlado e randomizado para cirurgia do lobo temporal foi realizado por Wiebe e colaboradores em 2001 e revelou que após 1 ano de acompanhamento clínico, a proporção acumulada dos pacientes com EMLT que ficaram livres de crises com alteração da consciência foi de $58 \%$ no grupo dos pacientes submetidos à lobectomia temporal, contra $8 \%$ do grupo submetido apenas ao tratamento farmacológico. A proporção dos pacientes que ficaram livres de todos os tipos de crise (Engel IA) após 1 ano de segmento foi de $38 \%$ no grupo tratado cirurgicamente, contra apenas $3 \%$ no grupo medicamentoso (WIEBE et al., 2001).

Em um segundo estudo controlado e randomizado, $73 \%$ de 15 pacientes tratados cirurgicamente ficaram livres de crises por 2 anos, enquanto que nenhum dos 23 pacientes tratados farmacologicamente atingiu esse objetivo (ENGEL, 2012a). Após esses estudos citados acima, os mesmo autores concluíram que os benefícios da cirurgia são:

a) diminuição da frequência e severidade das crises;

b) diminuição da mortalidade;

c) melhores índices de qualidade de vida;

d) maiores índices de retorno ao trabalho e escola.

Recomenda-se que pacientes com EMLT farmacorresistentes sejam referenciados a um centro de cirurgia de epilepsia para avaliar a possibilidade de intervenção cirúrgica (ENGEL et al., 2003). 


\subsubsection{Avaliação pré-cirúrgica}

O objetivo da avaliação pré-cirúrgica é identificar a zona epileptogênica (área cortical capaz de gerar crises a qual sua remoção completa é necessária para que o paciente fique livre de crises epilépticas), determinar a localização de áreas eloquentes e deixar o paciente livre de crises (CARRENO M, 2008; ROSENOW; LÜDERS, 2001).

Os pacientes selecionados para cirurgia de epilepsia devem preencher os critérios da síndrome eletroclínica da EMLT, já descrita anteriormente, com correspondentes achados de imagem e refratariedade ao tratamento farmacológico. Após a localização da lesão, correlação clínico-eletrográfica através do vídeoeletroencefalograma (VEEG), o suporte de outros métodos diagnósticos (RNM, PET, SPECT e WADA), além das avaliações neuropsicológicas, psiquiátrica e social, a cirurgia pode ser indicada.

O início ictal registrado a partir de eletrodos de escalpe, pode ser suficiente para assumir a localização da zona epileptogênica, quando associada com achados concordantes de neuroimagem, semiologia das crises e exame neuropsicológico. Em algumas situações em que não é possível determinar o início ictal, eletrodos invasivos podem ser úteis (VIVES, 2008).

Em resumo, a avalição de fase I obrigatória para todos os pacientes candidatos à cirurgia inclui:

a) RNM encéfalo de alta resolução com protocolo dedicado para epilepsia;

b) vídeo-EEG de escalpe prolongado para registrar anormalidades interictais e crises epilépticas;

c) avaliação neuropsicológica;

d) outras avaliações complementares podem ser realizadas nessa fase, de acordo com cada caso, para melhor localização da zona epileptogênica e estimar os riscos de déficits neurológicos focais e cognitivos, que incluem:

- RNM com análise morfométrica e volumétrica;

- RNM funcional

- magneto-eletroencefalografia;

- EEG de alta resolução;

- PET; 
- SPECT;

- teste de WADA;

- tractografia.

Se a localização da zona epileptogênica não for conclusiva nas avaliações de fase I, recomenda-se passar para a avaliação de fase II, que consiste no registro intracraniano com eletrodos semi-invasivos (eletrodos de forame oval), invasivos por estéreo EEG (SEEG - eletrodos profundos) ou subdurais (RYVLIN; CROSS; RHEIMS, 2014).

\subsubsection{Técnicas cirúrgicas utilizadas para o tratamento de epilepsia} do lobo temporal farmacorresistente

O objetivo da cirurgia de epilepsia é deixar o paciente livre de crises epilépticas, sem produzir danos neurológicos ou déficits cognitivos.

As técnicas cirúrgicas utilizadas para o tratamento de epilepsia do lobo temporal farmacorresistente podem ser tanto as técnicas anatômicas "padrão" ou as chamadas "tailored ressections", do termo em inglês que são técnicas específicas para cada caso, ou seja, que mudam de acordo com o contexto clínico e etiológico do paciente. Nas "tailored ressections", os dados clínicos, de neuroimagem, neuropsicológicos, neurofisiológicos e eletrocorticografia são utilizados para guiar a abordagem e o local específico a ser ressecado. Este tipo de abordagem, geralmente é indicado para casos com RNM normal, lesões neocorticais como tumores ou displasia cortical.

As técnicas anatômicas "padrão" mais conhecidas na literatura são:

a) Lobectomia temporal anterior (LTA) clássica dois terços "en bloc", na qual as estruturas neocorticais e mesiais são removidas em conjunto (amígdala, hipocampo e giro parahipocampal). A ressecção vai do polo temporal até aproximadamente $4,5 \mathrm{~cm}$ do lobo temporal no hemisfério dominante e até $5,5 \mathrm{~cm}$ no hemisfério não dominante, descrita por Falconer e colaboradores em 1953 (HILL et al., 1953). 
Figura 8: Estágio inicial LTA: linha de incisão em relação aos vasos silvianos e veia de Labbé

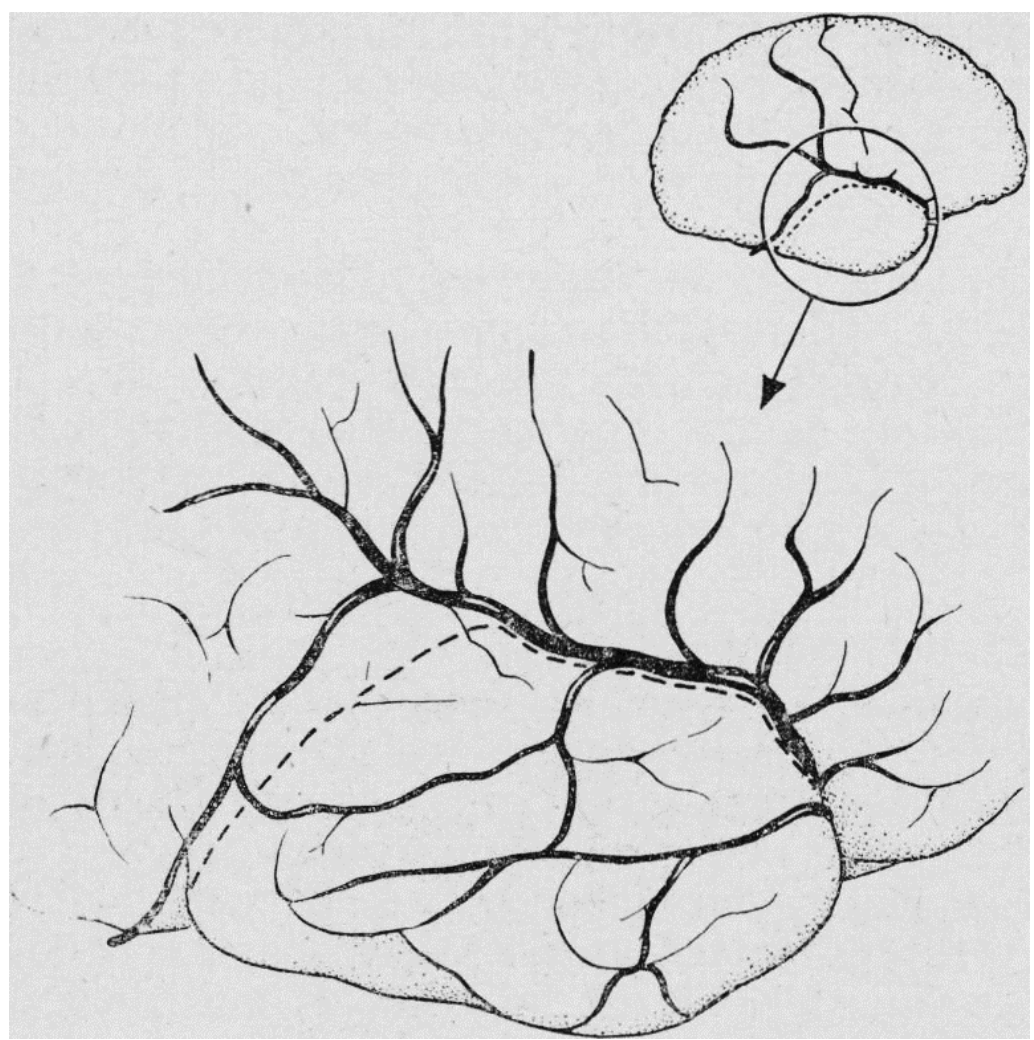

Fonte: (HILL et al., 1953)

Figura 9: Segundo estágio LTA: exposição da ínsula e abertura do corno temporal

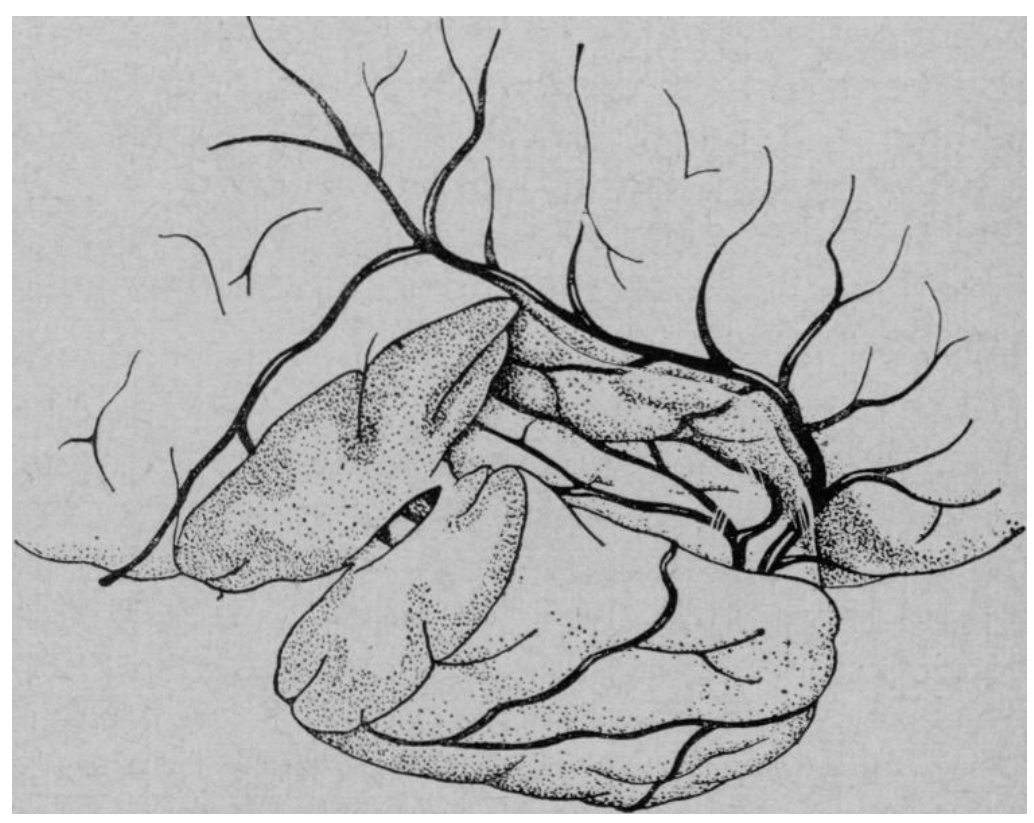

Fonte: (HILL et al., 1953) 
Figura 10. Terceiro estágio LTA: abertura do corno temporal, com exposição do hipocampo e o plexo coroide.

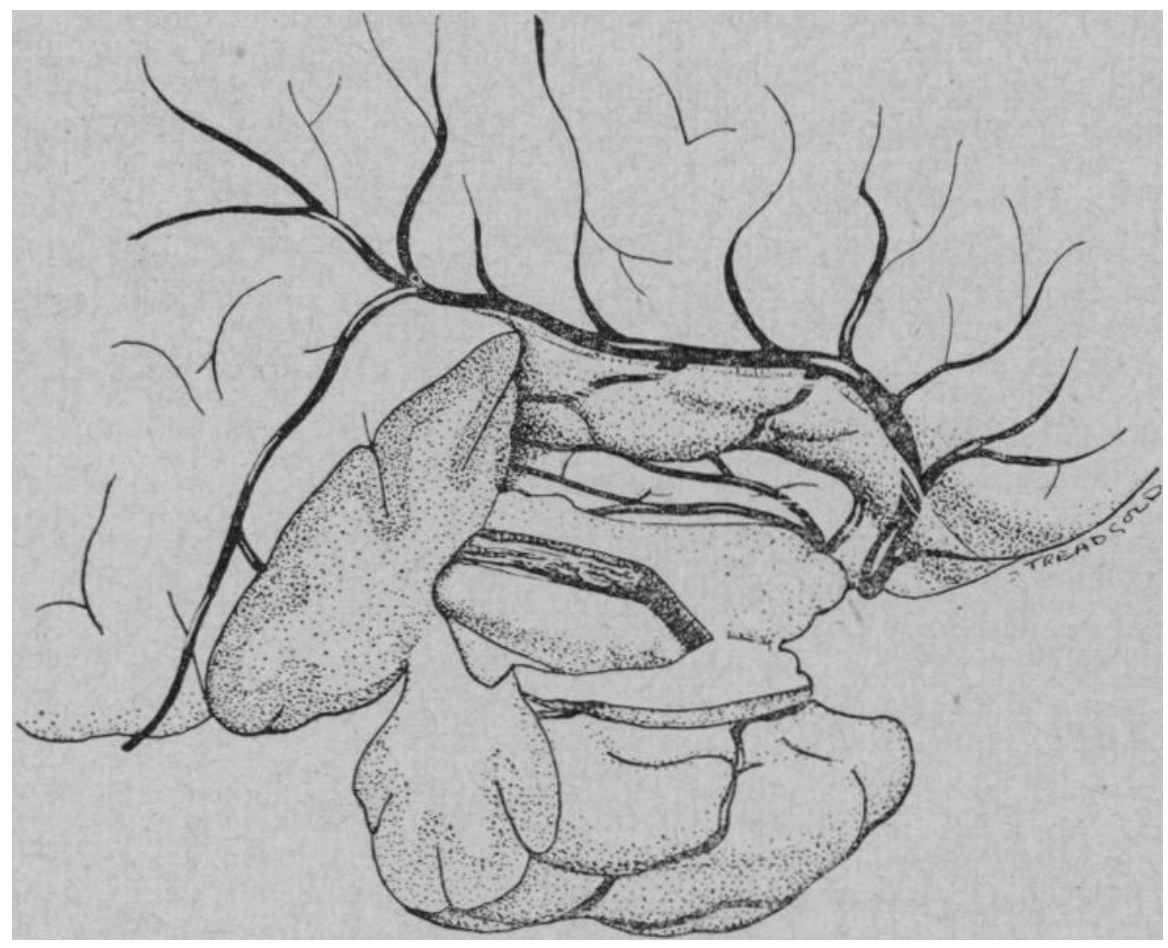

Fonte: (HILL et al., 1953)

Figura 11. Representação da extensão da LTA completa

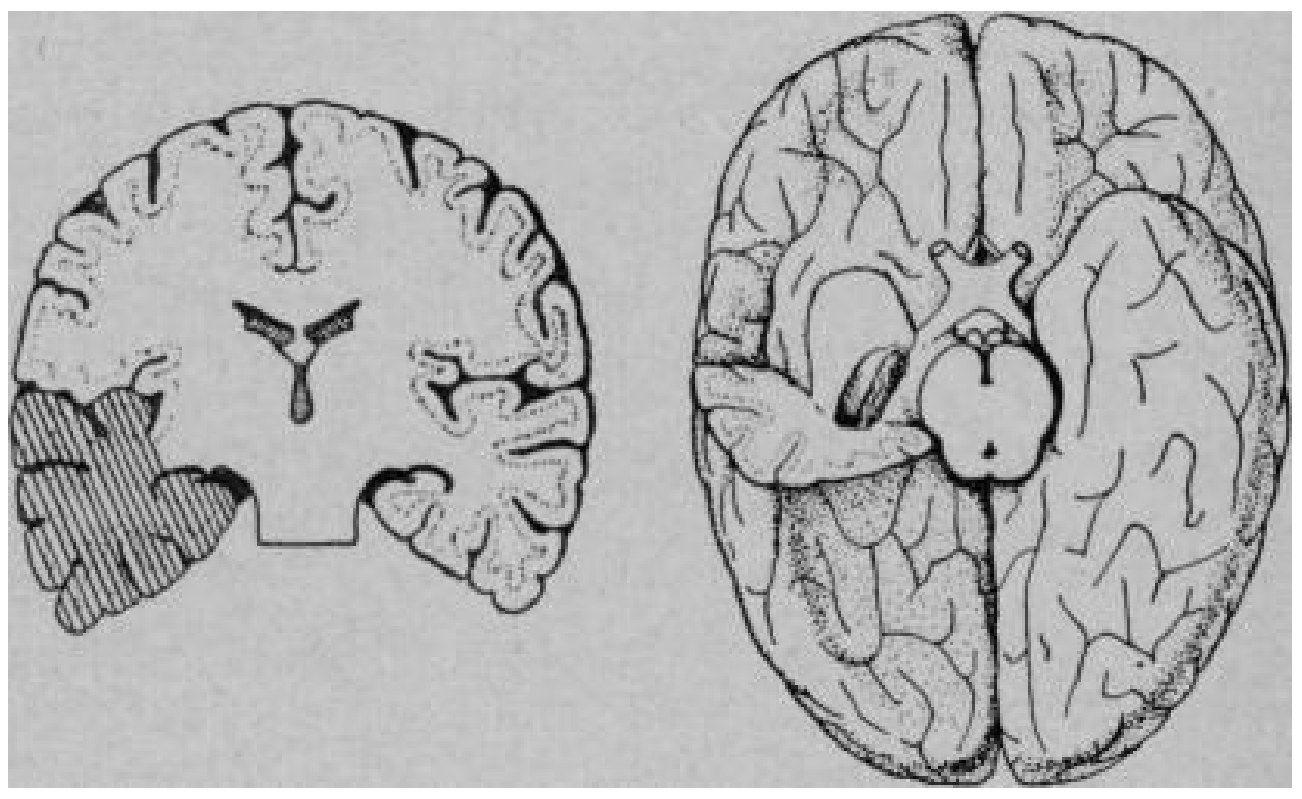

Fonte: (HILL et al., 1953) 
b) Lobectomia anterior "um-terço" com amigdalo-hipocampectomia ou lobectomia temporal anteromedial ou hipocampectomia radical: desenvolvida por Spencer em 1984 com o objetivo de preservar as estruturas funcionais do neocórtex temporal lateral e promover acesso às estruturas mesiais mais posteriores, a qual preserva o polo temporal e o neocórtex (SPENCER et al., 1984);

c) Amígdalo-hipocampectomia seletiva transsilviana: descrita em 1982 na escola de Zurich onde o neurofisiologista Wieser e o neurocirurgião Yasargil utilizavam estéreo-eletroencefalografia, quando durante uma monitorização intra-operatória, observaram que as crises iniciavam-se exclusivamente no hipocampo. A técnica consiste na ressecção das estruturas mesiais com preservação do neocórtex. É indicada para os pacientes com clara evidência de foco epileptogênico nas estruturas mesiais do lobo temporal (casos típicos de EMT). Com o passar do tempo essa técnica apresentou modificações, considerando a maestria do autor, devido às dificuldades de outros cirurgiões e complicações encontradas (WIESER; YAŞARGIL, 1982);

Figura 12. Acesso cirúrgico da AHS transsilviana

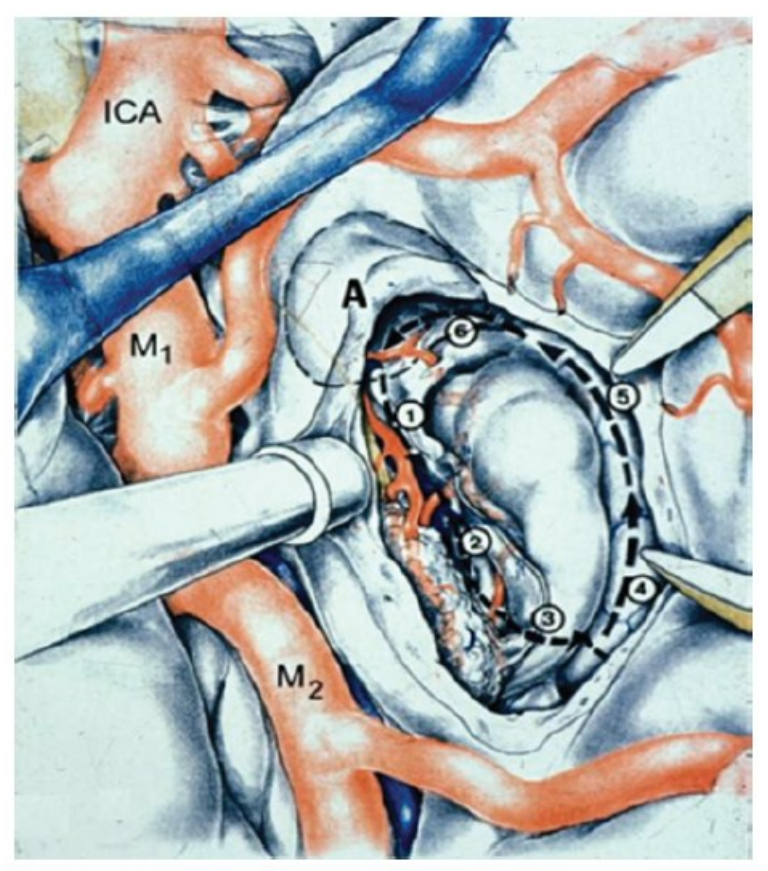

Incisão através do córtex piriforme, sobre a amígdala, entre as artérias temporal e polar. Fonte: (YAŞARGIL et al., 2010). 
Figura 13. Ilustração dos dois-terços anteriores do hipocampo e parahipocampo, na AHS transsilviana.

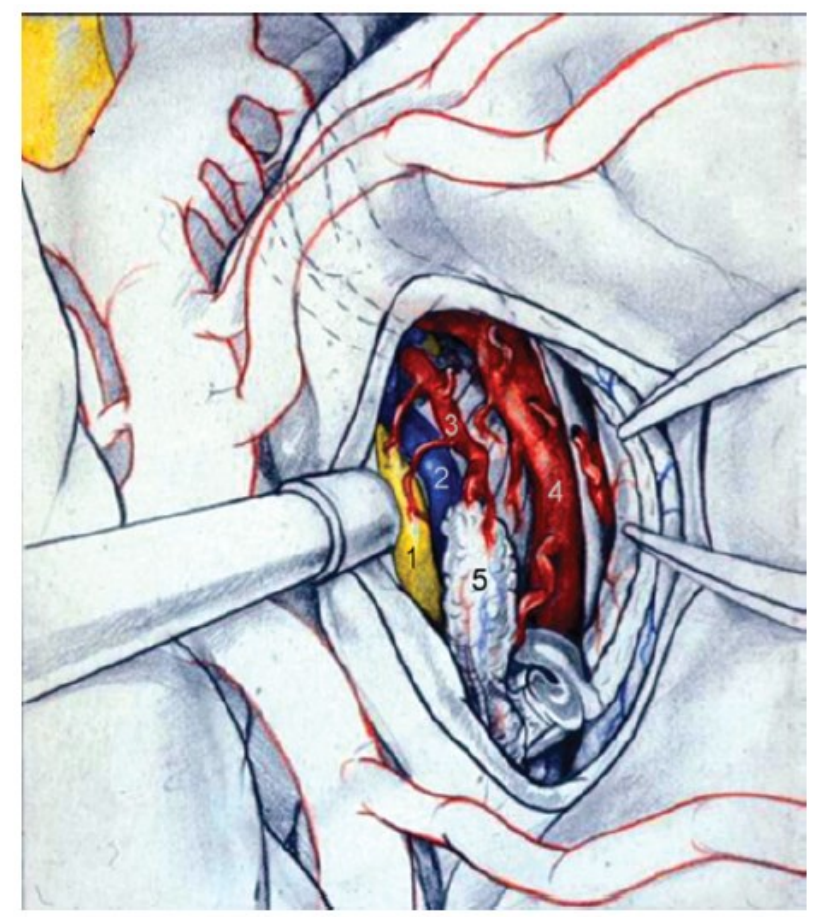

1. Tracto óptico; 2. Veia basilar; 3. Artéria coroideia anterior; 4. Segmento P2 da artéria cerebral posterior; 5. Plexo coroide.

Fonte: (YAŞARGIL et al., 2010).

d) Amígdalo-hipocampectomia seletiva transcortical: descrita por Niemeyer em 1958, consiste na incisão do giro temporal médio, que promove acesso ao corno temporal do ventrículo lateral, com subsequente ressecção de aproximadamente $3 \mathrm{~cm}$ do hipocampo, amígdala e giro parahipocampal. Indicada para pacientes com patologia mesial e neocórtex lateral temporal normal (NIEMEYER, 1958); 
Figura 14. Amígdalo-hipocampectomia seletiva transcortical: posição da craniotomia, incisão cortical e trajeto cirúrgico.

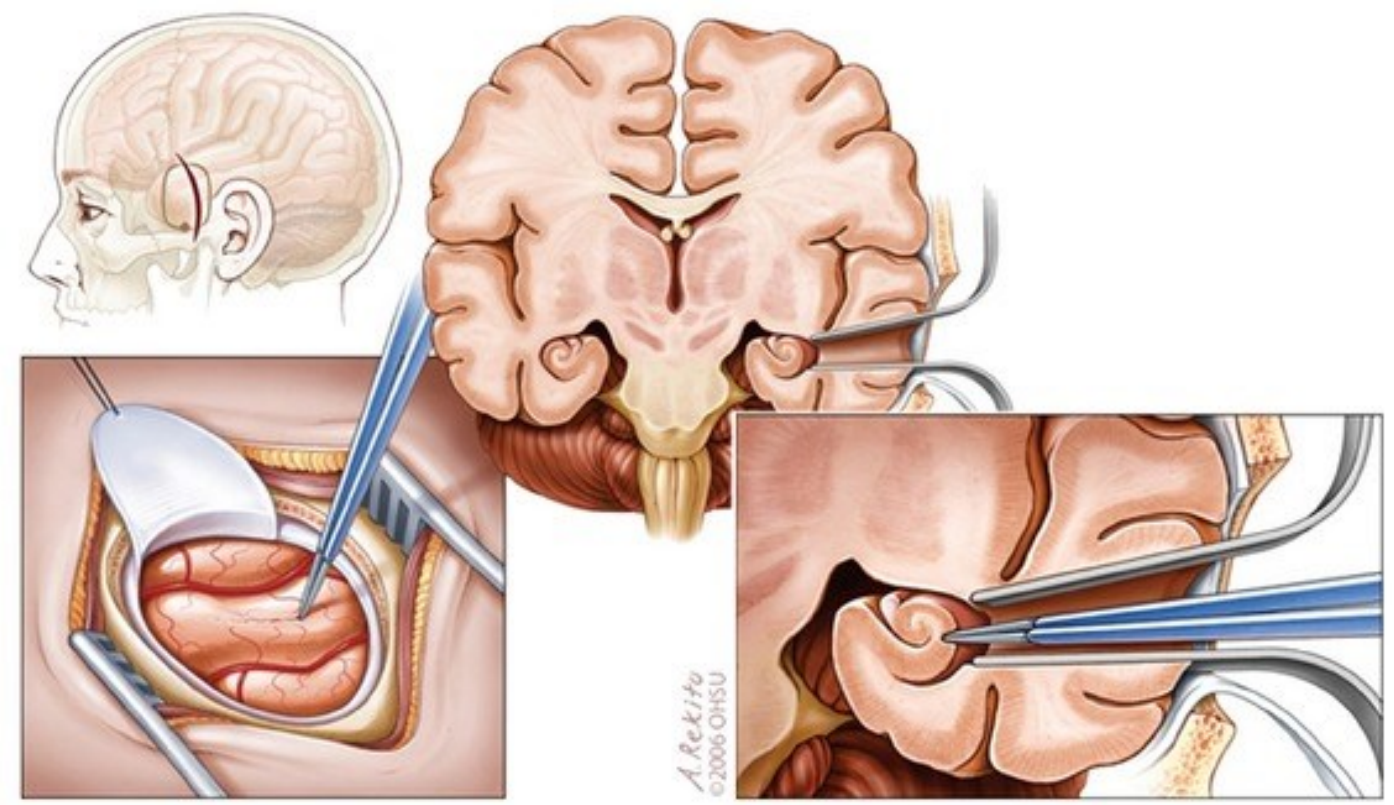

Fonte: (SPENCER; BURCHIEL, 2012).

Figura 15. Lobectomia temporal anteromesial $\mathrm{X}$ amígdalo-hipocampectomia seletiva

Anterior temporal lobectomy
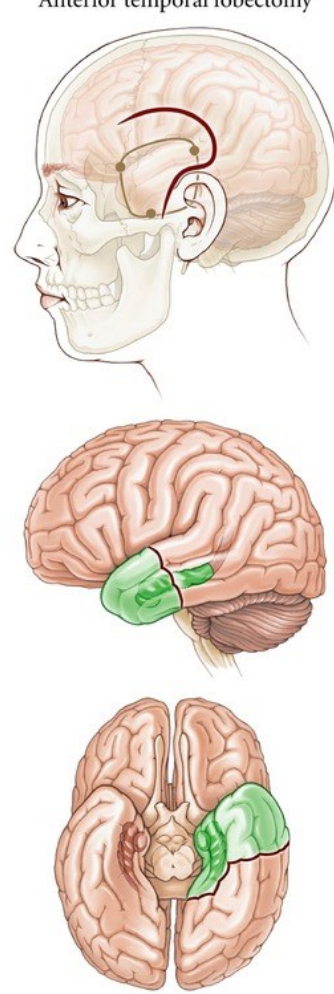

Amygdalohippocampectomy
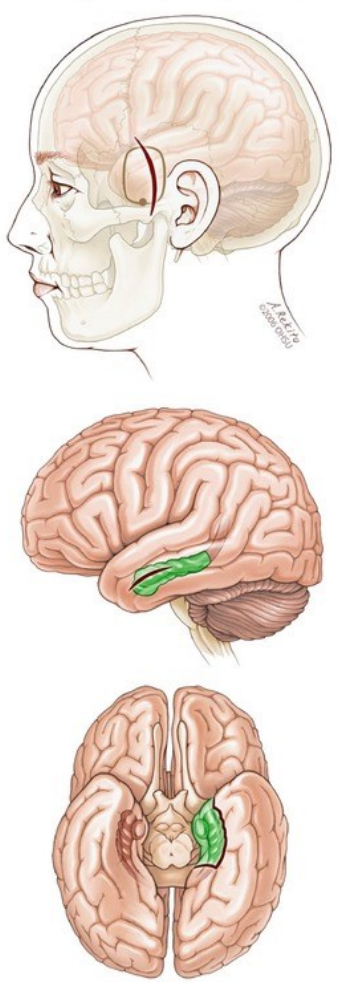

Fonte: (SPENCER; BURCHIEL, 2012) 
e) Lesionectomia associada ou não a amígdalo-hipocampectomia, indicada para pacientes com epilepsia do lobo temporal lesional (BINDER; SCHRAMM, 2008).

Figura 16. Diversos tipos de acesso às estruturas mesiais do lobo temporal.

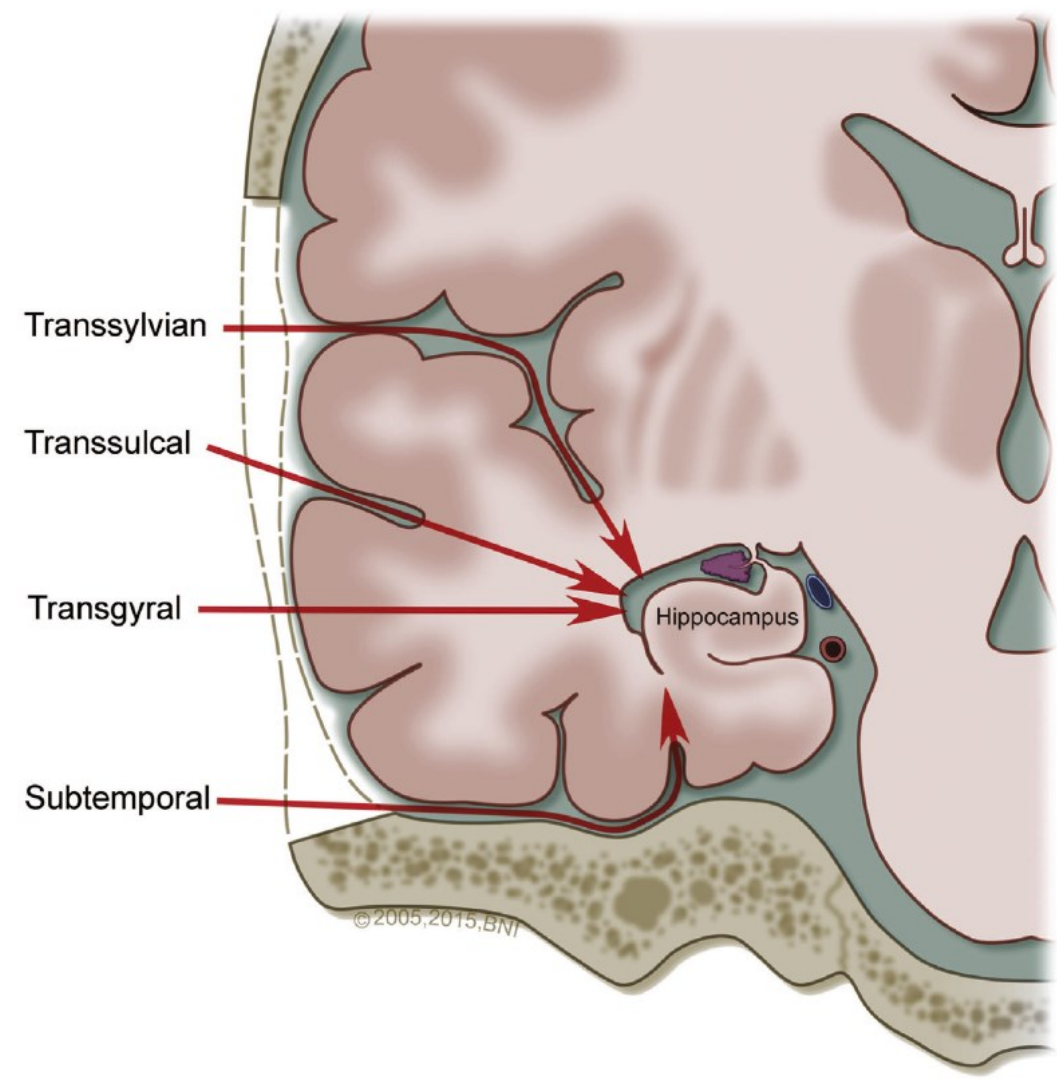

Acesso transsilviano; acesso transsulcal; acesso transgiral (transcortical); acesso subtemporal, através do sulco colateral.

Fonte: (HOYT; SMITH, 2016). 


\subsection{Classificação prognóstica (Engel)}

A classificação mais utilizada atualmente é a idealizada por Engel em 1993, a qual descreve os desfechos com relação a frequência de crises em 1 ano e à presença de crises debilitantes, consideradas quando há alteração da consciência e/ou generalização secundária. Abaixo segue o resumo da classificação traduzida para o português:

- Engel classe I: descreve desfechos favoráveis como sendo "excelentes" quando livre de crises debilitantes, mesmo na presença de auras, ou algum evento relacionado à mudança de dose da medicação;

- Engel Classe IA: pacientes que estão completamente livres de crises;

- Engel Classe IB: crises focais com preservação da consciência, apenas auras;

- Engel Classe IC: algumas crises debilitantes após a cirurgia, porém livre de crises há pelo menos 2 anos;

- Engel Classe ID: presença de crises generalizadas apenas quando ocorre descontinuação da medicação anti-epiléptica;

- Engel Classe II: raras crises debilitantes, ou crises noturnas apenas;

- Engel Classe III: melhora global subjetiva, com prognóstico menos favorável;

- Engel Classe IV: sem melhora ou mesmo piora do controle de crises (ENGEL et al., 1993).

Tabela 1. Classificação de Engel original em inglês.

Table 130.1 Engel's classification of postoperative outcome

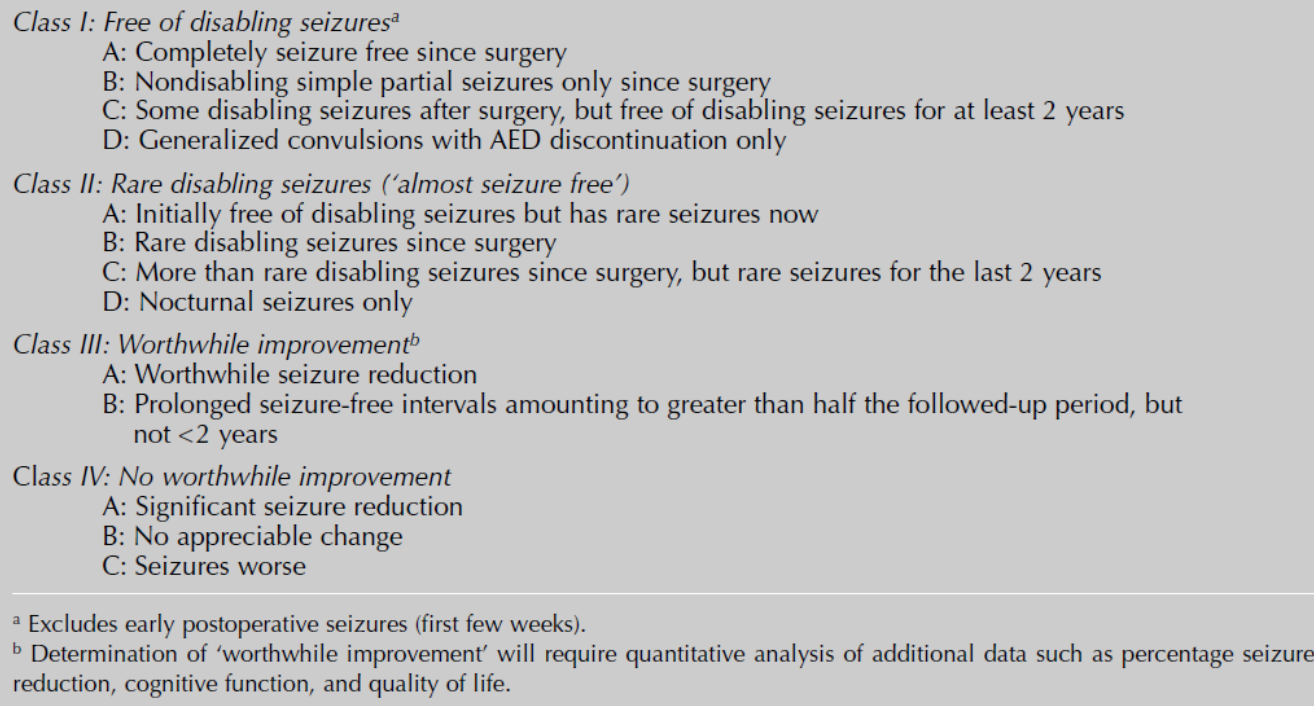

Fonte: (ENGEL et al., 1993). 
Hemb M., Palmini A. e colaboradores em 2013, realizaram um estudo longitudinal, no qual os pacientes foram acompanhados durante 18 anos após lobectomia temporal para tratamento de epilepsia mesial do lobo temporal. Neste estudo foi encontrado que $62 \%$ dos pacientes ficaram completamente livres de crises (Engel Classe IA) durante todo o estudo, enquanto que $77 \%$ mantiveram-se como Engel Classe I. Esse estudo mostrou que a cirurgia para epilepsia mesial do lobo temporal, pode promover alívio nas crises por pelo menos uma a duas décadas após a cirurgia (HEMB et al., 2013).

\subsection{Fatores prognósticos}

Estudos prévios mostraram que características clínicas como esclerose hipocampal, epilepsia mesial do lobo temporal unilateral, ausência de história de crises tônico-clônico generalizadas e ausência de características clínicas atípicas, são fatores preditores de remissão de crises no pós-operatório (MCINTOSH et al., 2004).

O candidato ideal para cirurgia de epilepsia é aquele que tem achados clínicos concordantes com o sugestivo foco epileptogênico durante a avaliação pré-cirúrgica.

A ausência de crises após cirurgia de lobo temporal, está relacionada com redução de mortalidade e melhora na qualidade de vida (LOWE et al., 2004; SALANOVA; MARKAND; WORTH, 2002; WIEBE et al., 2001).

\subsection{Lacunas do conhecimento}

Vários estudos já foram publicados em relação ao prognóstico cirúrgico de longo prazo para epilepsia do lobo temporal, mas ainda não há um consenso sobre qual é a técnica cirúrgica relacionada com melhores prognósticos. Alguns grupos defendem as técnicas mais seletivas que preservam o polo temporal e o neocórtex, com o argumento de que a zona epileptogênica encontra-se nas estruturas mesiais do lobo temporal, além de acreditarem em melhores desfechos cognitivos (SPENCER; BURCHIEL, 2012). Outros defendem técnicas cirúrgicas mais amplas, com ressecção do neocórtex e polo temporal, além das estruturas mesiais, pois acreditam que as redes neuronais envolvidas na epileptogênese são mais amplas e argumentam que os desfechos cognitivos são similares aos dos pacientes que não operaram, pois o 
lobo temporal provavelmente já era previamente alterado (CHABARDĖS et al., 2005; SAUVIGNY et al., 2016).

Será que a técnica cirúrgica, o tipo do tecido e o volume ressecado, tanto das estruturas mesiais quanto do neocórtex, influenciam no prognóstico relacionado ao controle de crises epilépticas? 


\section{Pergunta do trabalho atual}

Quais são os principais fatores preditores que influenciam no sucesso cirúrgico relacionado ao controle de crises epilépticas em pacientes com epilepsia mesial do lobo temporal secundário à esclerose hipocampal? 


\section{Objetivos}

\subsection{Objetivos Gerais}

Avaliar os fatores preditores de prognóstico cirúrgico relacionados ao controle de crises em longo prazo (23 anos), em pacientes adultos submetidos à lobectomia temporal para o tratamento de epilepsia mesial do lobo temporal secundária à esclerose hipocampal farmacorresistentes.

\subsection{Objetivos Específicos:}

a) descrever o desfecho clínico relacionado ao controle das crises epilépticas;

b) identificar fatores preditores de prognóstico, em longo prazo, no controle das crises epilépticas;

c) comparar as diferentes técnicas cirúrgicas em relação ao prognóstico;

d) descrever a relação entre o controle de crises e a quantidade de medicações antiepilépticas no pré e pós-operatório;

e) descrever a ocorrência de complicações cirúrgicas intra e pós-operatórias imediatas e em longo prazo, incluindo óbitos;

f) estabelecer uma relação entre eficácia e segurança do procedimento com o intuito de auxiliar na tomada de decisão cirúrgica com segurança. 


\section{Participantes e Métodos}

\subsection{Desenho do estudo}

Longitudinal e retrospectivo.

\subsection{Local}

Centro de Cirurgia de Epilepsia (CIREP), localizado no Hospital das Clínicas da Faculdade de Medicina de Ribeirão Preto (HCFMRP-USP).

\subsection{Seleção dos pacientes}

Foram selecionados 621 pacientes adultos (idade maior que 18 anos), de ambos os sexos, com epilepsia do mesial do lobo temporal refratária, submetidos à lobectomia temporal, no HCFMRP-USP no período de janeiro de 1994 a dezembro de 2011. Todos os pacientes faziam acompanhamento clínico no ambulatório de Epilepsia de Difícil Controle Adulto (EDC) e apresentavam diagnóstico provável de epilepsia do lobo temporal associada à esclerose hipocampal. A origem dos pacientes em sua maioria foi a região Sudeste, mas também das regiões Norte, Nordeste, Centro-oeste e Sul, compondo um grupo representativo de praticamente todas as regiões do Brasil.

\subsection{Critérios de Inclusão}

Foram incluídos pacientes que preencheram os seguintes critérios:

a) idade maior do que 18 anos à época da cirurgia;

b) diagnóstico clínico de epilepsia do lobo temporal;

c) RNM encéfalo sugestiva de esclerose hipocampal uni ou bilateral;

d) terem sido submetidos à cirurgia de lobectomia temporal;

e) diagnóstico anatomopatológico confirmado de esclerose hipocampal;

f) terem sido submetidos à avaliação pré-operatória completa e operados pela mesma equipe neurocirúrgica do centro referente; 
g) dados pessoais, da história clínica e cirúrgica completos, de forma clara, nos prontuários médicos;

h) tempo mínimo de seguimento clínico de 1 ano após a intervenção cirúrgica;

\subsection{Critérios de Exclusão}

Os critérios de exclusão foram:

a) dupla patologia, exceto neurocisticercose;

b) ter realizado ressecção extra temporal ou multilobar;

c) ressonância magnética NORMAL;

d) informações insuficientes no prontuário médico;

e) pacientes com idade menor que 18 anos e que foram operados pela equipe neurocirúrgica pediátrica;

f) pacientes com tempo de segmento menor do que 1 ano e que não foi possível contatá-los;

g) pacientes que apresentaram crises de origem não epiléptica no pós-operatório, documentadas através do VEEG;

h) pacientes sem informação do Engel no prontuário médico.

\subsection{Coleta de dados}

O presente estudo foi realizado através da revisão de prontuários físicos e eletrônicos do HCFMRP-USP. As informações obtidas foram armazenadas no banco de dados do CIREP (Access - Microsoft office 2013). Foi elaborado um formulário específico para a inserção das informações revisadas, as quais foram armazenadas e posteriormente analisadas.

As seguintes informações pré e pós-operatórias foram coletadas: dados da história clínica, avaliação pré-cirúrgica e acompanhamento clínico pós-operatório, considerando a última consulta do paciente (último registro no prontuário médico), como tempo de segmento para a análise do Engel.

Os pacientes que perderam acompanhamento clínico por mais de 2 anos no HCFMRP-USP, foram contatados via telefone, através de 3 tentativas, tanto por telefone fixo, quanto por telefone móvel, em diferentes períodos e em diferentes dias. 
A entrevista foi realizada pela própria pesquisadora, médica assistente da equipe do CIREP e por uma outra pesquisadora, médica colaboradora do projeto, capacitadas para realizar as perguntas estabelecidas através de instrumento determinado no apêndice do projeto. As ligações foram registradas em prontuário eletrônico e as informações foram armazenadas no banco de dados do CIREP, com o consentimento do paciente. Os pacientes que não puderam ser localizados, foram mantidos na pesquisa, e o Engel analisado foi o da última consulta registrada no prontuário médico.

Para os pacientes contatados via telefônica, o Engel foi analisado no momento da entrevista, não sendo possível a avaliação referente aos anos anteriores, pois a informação é subjetiva.

\subsection{Descrição da Avaliação pré-cirúrgica do CIREP}

A descrição do protocolo de avaliação pré-cirúrgica de fase I realizado no CIREP, já foi publicado na tese de doutorado e na revista Neurosurgery pelo mesmo autor (VELASCO, 2007; VELASCO et al., 2011), o qual faz parte da equipe médica do CIREP. Esse protocolo sofreu algumas alterações ao longo dos anos que serão descritas a seguir de forma adaptada:

\subsubsection{Avaliação Ambulatorial}

Todos os pacientes selecionados foram avaliados no ambulatório de Epilepsia de Difícil Controle Adulto (EDC), com anamnese completa, história clínica e exame físico detalhados. Foi realizado tratamento clínico com pelo menos um fármaco de primeira linha (carbamazepina, fenitoína ou valproato de sódio), mais frequentemente com dois ou mais fármacos anti-epilépticos (FAE). Após a configuração de farmacorresistência ou intratabilidade clínica, foi oferecido aos pacientes a possibilidade de investigação pré-cirúrgica no CIREP.

\subsubsection{Neuroimagem Estrutural - Ressonância Nuclear Magnética}

Todos os exames de RNM até 2007, foram realizados no equipamento Siemens, 1,5 Tesla. A partir de 2008 passaram a ser realizados no equipamento 
Philips Achieva Duo de 3,0 Tesla (Philips Medical Systems, Best, the Netherlands), usando uma bobina de oito canais de recepção e com disponibilidade de gradiente de campo magnético de até $80 \mathrm{mT} / \mathrm{m}$ (amplitude máxima de gradiente). As imagens foram armazenadas em formato DICOM no LAPIR do HCFMRP-USP para integrarem no banco de dados, avaliadas por neurorradiologistas experientes e discutidas em reunião clínica com toda a equipe do CIREP.

A seguir será descrito o protocolo de rotina para epilepsia mais recente e de forma resumida, publicado na tese de doutorado (ABUD, 2017).

a) SAGITAL 3D T1 Gradiente eco (MP-RAGE);

b) AXIAL T2;

c) CORONAL FLAIR;

d) AXIAL FLAIR;

e) CORONAL T2 STIR;

f) AXIAL DWI.

\subsubsection{Vídeo-Eletroencefalograma (VEEG)}

Para a realização do Vídeo-Eletroencefalograma (VEEG) pré-operatório, utilizaram-se eletrodos de escalpe com sistema internacional 10-10, com ou sem eletrodo esfenoidal, para o registro eletroencefalográfico (EEG) interictal e ictal com vídeo sincronizado.

Para a aquisição e análise do sinal de EEG, foram utilizados o sistema de VEEG digital Vangard Systems (Clevland Clinic Foundation, Clevland, Ohio, USA) até o ano de 2008 e após o segundo semestre de 2008, passou-se a utilizar o sistema NIHON KODEN. Os dados do VEEG (EEG interictal, semiologia e EEG ictal) foram analisados por neurofisiologistas experientes. Os dados foram ainda discutidos em conjunto com os supervisores da unidade de VEEG e em reunião clínica.

Quando necessário, a droga anti-epiléptica foi lentamente reduzida até que o paciente apresentasse pelo menos uma crise epiléptica, considerada habitual para o mesmo.

Em alguns casos, a critério clínico, por EEG ictal duvidoso ou não lateralizatório, foram submetidos à SPECT ictal.

Quando o EEG ictal era bilateral, difuso ou não lateralizatório, os pacientes foram submetidos à avaliação semi-invasiva com eletrodos de forame oval ou até 
avaliação invasiva com eletrodos subdurais ou profundos, de acordo com os achados neurofisiológicos de superfície.

\subsubsection{SPECT}

Alguns pacientes foram submetidos ao SPECT ictal e interictal à critério clínico e neurofisiológico. Quando o EEG ictal era duvidoso, difuso, não lateralizatório ou contralateral ao lado suspeito (através da história clínica, semiologia e RNM), foi indicada a realização do SPECT ictal durante internação para VEEG.

As rotinas para a realização do SPECT já foram previamente descritas conforme (JUNI, 1994; JUNI et al., 1998; WICHERT-ANA et al., 2001, 2004).

Foi utilizado o fármaco Etil Cisteinato Dimer (ECD), marcado com três GBq do radioisótopo ${ }^{99 m}$ Tc e injetado em dose máxima de 1.295 MBq (35 mCi), imediatamente após o início clínico ou eletrográfico da crise epiléptica. O gerador estéril do radioisótopo ${ }^{99 m}$ Tc e EDC foram fornecidos pela coordenadoria de processamento de material radioativo do Instituto de Pesquisas Energéticas - Conselho Nacional de Energia Nuclear (IPEN-CNEN/SP).

Antes da injeção o paciente era submetido a venopunção com cateteres flexíveis de médio calibre (Abocath ${ }^{\circledR}$ No. 20 ou 22), heparinizados para garantir a permeabilidade, com testagem periódica.

A dose do radiofármaco (RF) foi reajustada a cada hora, seguindo a taxa de decaimento do radioativo para o 99mTc (SEPKUTY et al., 1998). O RF esteve continuamente disponível no CIREP, substituído de 8/8 horas, acondicionado em um recipiente de chumbo. A taxa de exposição radioativa ao redor deste recipiente foi calculada e considerada segura pelo Centro de Ciências das Imagens e Física Médica (CCIFM) - HCFMRP- USP.

Os SPECTs intercríticos somente foram realizados nos pacientes que foram submetidos ao SPECT crítico, utilizando o mesmo RF utilizado nos estudos críticos, quando o paciente referia estar livre de crises nas últimas 24 horas.

Todos os exames de SPECT foram adquiridos em uma câmara de cintilação (gama-câmara) circular, de duplo detector, marca SOPHA (modelo Vision DST, SMV América, Twinsburg, Ohio), equipado com colimador de baixa energia e alta resolução (LEHR), com fotopico para ${ }^{99 m}$ Tc centrado em $140 \mathrm{keV}$ e uma janela de aceitação de $20 \%$. As imagens foram registradas, processadas e posteriormente analisadas por um 
médico nuclear experiente em SPECT cerebral. As anormalidades encontradas no SPECT crítico foram consideradas localizatórias quando as áreas de hiperperfusão ou hipoperfusão foram localizadas em um dos lobos temporais e lateralizatórias quando envolveram mais de uma região, porém claramente predominantes no hemisfério cerebral onde se localiza a suspeita da zona epileptogênica aventada pelo conjunto dos dados da avaliação pré-cirúrgica. Nos casos de hiperperfusão bitemporal, se claramente assimétrica, o lado com maior hiperperfusão foi considerado o lado de início ictal pelo SPECT.

A partir do ano de 2007, após a tese de doutorado de um dos médicos neurofisiologistas do CIREP (VELASCO, 2007), que fez um estudo randomizado sobre a utilidade clínica do SPECT ictal em pacientes com epilepsia mesial do lobo temporal refratária, concluiu que o SPECT ictal não trouxe informação adicional ao protocolo de investigação pré-cirúrgica no que se refere à acurácia do protocolo em determinar o lado de início das crises epilépticas e que o SPECT não deve ser recomendado de rotina para pacientes com EMT-EH.

\subsubsection{Avaliação Neuropsicológica}

A Avaliação neuropsicológica foi realizada em todos os pacientes do estudo. Objetivos da avaliação:

a) avaliar o estado cognitivo geral e o impacto da epilepsia ou da lesão epileptogênica em funções cognitivas específicas antes da cirurgia;

b) avaliar possibilidade de déficits cognitivos no pós-operatório;

c) servir de ferramenta controle da qualidade do prognóstico pós-operatório;

d) controle prognóstico pós-operatório referente à cognição. 
Tabela 2. Teste Neuropsicológico

\begin{tabular}{ll}
\hline TESTE NEUROPSICOLÓGICO & FUNÇÕES AVALIADAS \\
\hline $\begin{array}{l}\text { Escada de inteligência reduzida Weschler } \\
\text { para adultos }\end{array}$ & $\begin{array}{l}\text { Eficiência intelectual estimada de adultos } \\
\text { de } 16 \text { a } 79 \text { anos (subtestes: cubos e } \\
\text { vocabulário) }\end{array}$ \\
Teste de fluência verbal & $\begin{array}{l}\text { Produção de palavras sob condições } \\
\text { delimitadas }\end{array}$ \\
Teste de nomeação de Boston & Habilidade de nomeação \\
$\begin{array}{l}\text { Escala de memória de Wechsler revisada } \\
\text { (memória lógica I e II) }\end{array}$ & $\begin{array}{l}\text { Capacidade de memória imediata e tardia } \\
\text { para trecho verbal complexo }\end{array}$ \\
$\begin{array}{l}\text { Escala de memória de Wechsler revisada } \\
\text { (reprodução visual I e II) }\end{array}$ & $\begin{array}{l}\text { Capacidade de memória imediata e tardia } \\
\text { para desenhos geométricos simples }\end{array}$ \\
$\begin{array}{l}\text { Teste de aprendizagem de Rey: verbal e examinar o span de memória imediata, } \\
\text { não verbal }\end{array}$ & $\begin{array}{l}\text { Exarendizagem e memória tardia para } \\
\text { material verbal e não verbal }\end{array}$ \\
Teste da figura complexa de Rey & $\begin{array}{l}\text { Habilidade de planejamento, organização } \\
\text { vísuo-espacial, motricidade }\end{array}$ \\
$\begin{array}{l}\text { Reprodução tardia da figura complexa de habilidade de organização vísuo- } \\
\text { Rey }\end{array}$ & $\begin{array}{l}\text { A espacial e memória visual } \\
\text { Teste de Stroop }\end{array}$ \\
$\begin{array}{l}\text { Capacidade de controle inibitório } \\
\text { Veste de Trilhas } \\
\text { manutenção da atenção, flexibilidade } \\
\text { mental e função motora }\end{array}$ \\
\hline
\end{tabular}

O exame foi considerado convergente com a zona epileptogênica quando totalmente lateralizados para o mesmo lado, parcialmente convergentes quando bilaterais, mas mais intenso do lado evidenciado pelos demais exames e divergente quando bilaterais ou contralaterais ao lado da zona epileptogênica. Embora a avaliação neuropsicológica pudesse fornecer indícios de disfunção cerebral localizada, não teve função primordial na determinação do lado de início das crises, e sim em relação à expectativa de déficits adicionais no pós-operatório. 


\subsubsection{Avaliação Psiquiátrica}

Pacientes com epilepsia refratária representam um grupo de alto risco para distúrbios psiquiátricos (KANNER et al., 2012), sendo assim, todos os pacientes foram submetidos à avaliação psiquiátrica antes do procedimento cirúrgico. A avaliação constituiu-se de uma entrevista diagnóstica estruturada de acordo com as categorias diagnósticas maiores do DSM-IV ("Diagnostic and Statistical Manual of Mental Disorders IV"), inicialmente apenas com o paciente e depois com os familiares. O objetivo da avaliação foi investigar a presença atual ou pregressa de qualquer doença psiquiátrica maior, como distúrbios do humor (mania, depressão ou distimia), ansiedade, somatização (com ou sem crises psicogênicas), psicose, transtornos de personalidade, assim como dependência química ou uso de álcool e substâncias ilícitas. Os sintomas foram avaliados se estavam ou não associados temporalmente ao evento ictal ou se precipitados pelo uso de medicamentos. O resultado da avaliação foi interpretado pela equipe multidisciplinar do CIREP em reunião clínica em conjunto com os demais dados da avaliação pré-cirúrgica. A decisão sobre a realização da cirurgia foi baseada na probabilidade de cura das crises epilépticas, obtida a partir da anamnese, do Vídeo-EEG, RNM, avaliação neuropsicológica e do SPECT ictal, quando realizado. A avaliação psiquiátrica não teve função localizatória, sendo assim, a cirurgia de epilepsia somente foi contraindicada do ponto de vista psiquiátrico na presença de anormalidade maior, como psicose franca ou depressão maior ativa.

\subsubsection{Avaliação Social}

A avaliação social foi realizada por duas assistentes sociais experientes, com o objetivo de analisar os aspectos psicossociais da vida dos pacientes portadores de epilepsia. Foram investigados aspectos do relacionamento interpessoal, ajustamento vocacional, situação laboral, a dependência ou independência tanto econômica quanto de vida diária, o ajustamento pessoal em termos de autoimagem, funcionamento sexual e iniciativa pessoal. Além disso, a percepção do impacto das crises epilépticas, do tratamento com FAEs, ou dos distúrbios psiquiátricos concomitantes sobre o funcionamento global, a presença do apoio familiar ao procedimento cirúrgico e o funcionamento psicossocial geral foram analisados. 
Assim como a avaliação psiquiátrica, a avaliação social não teve nenhuma função localizatória. A decisão de contraindicar ou adiar a cirurgia ocorreu em casos de problemas que potencialmente pudessem colocar o paciente em risco no pósoperatório, como conflitos familiares, falta de apoio familiar, ou falta de aderência ao tratamento medicamentoso.

A avaliação pré-cirúrgica baseia-se em um olhar multidisciplinar, onde o paciente é considerado como um todo, neurológico, psíquico e social.

\subsubsection{Determinação da Zona Epileptogênica - Reunião Multidisciplinar}

Baseou-se na identificação de uma patologia inequívoca na região mesial temporal e que pudesse ser removida sem causar déficit neurológico ou cognitivo adicional.

Após a realização de todos os exames básicos da avaliação pré-cirúrgica de fase I (RNM, VEEG, teste neuropsicológico, avaliação neuropsiquiátrica e social), os dados foram discutidos em reunião clínica multidisciplinar que reuniu todos os membros da equipe do CIREP: epileptologistas, neurofisiologistas, neurocirurgiões, radiologistas, médicos nucleares, psiquiatras, neuropsicólogas, assistentes sociais e enfermeira clínica.

A definição da zona epileptogênica foi baseada em dados da história clínica, exame neurológico, neuroimagem (RNM), semiologia ictal, neurofisiologia durante VEEG e SPECT (quando realizado), já estabelecida na literatura (ROSENOW; LÜDERS, 2001). Nos casos em que todos os exames acima mencionados apontavam para um dos lobos temporais ou naqueles em que a maioria dos dados foi convergente

e os demais não divergentes, nenhuma avaliação adicional foi necessária, sendo oferecido ao paciente a possibilidade de realização de lobectomia temporal.

Nos casos, cujos dados da avaliação foram divergentes ou indeterminados, foi indicada a realização de testes adicionais de acordo com o consenso do grupo, discutidos individualmente.

\subsubsection{Testes adicionais}

De acordo com os dados obtidos da fase I da avaliação pré-cirúrgica, exames adicionais foram necessários para melhor definição da zona epileptogênica ou para 
definição da dominância hemisférica e da reserva de memória. Por exemplo, na presença de RNM próxima do normal, exames adicionais como volumetria hipocampal, espectroscopia por RNM ou PET scan (tomografia por emissão de pósitrons) foram realizados. Em pacientes com esclerose hipocampal bilateral ou RNM normal, foi realizado teste de WADA, devido ao risco de déficit de memória no pós-operatório. A RNM funcional foi utilizada como coadjuvante na determinação da lateralização da linguagem em pacientes canhotos ou ambidestros ao exame neuropsicológico.

\subsubsection{Avaliação Invasiva}

A indicação da avaliação invasiva ou semi-invasiva foi baseada nas observações obtidas durante a fase I.

Em pacientes cuja investigação evidenciou uma clara hipótese de que as crises se originavam na região mesial do lobo temporal, mas cujos dados falharam em demonstrar um início ictal unilateral, foram investigados com a implantação de eletrodos semi-invasivos de forâmen oval (FO). Se os eletrodos de FO também falharam em demonstrar um início ictal unilateral indubitável, os pacientes também foram submetidos à implantação de eletrodos profundos no lobo temporal. Nesses casos, a cirurgia foi indicada apenas se houvesse evidência inequívoca de que apenas um dos lobos temporais era o responsável pelo início das crises. Nos casos de crises bilaterais independentes, mesmo após a avaliação invasiva, a cirurgia foi contraindicada.

Chamamos de avaliação invasiva aquela na qual foram utilizados eletrodos subdurais, eletrodos profundos (SEEG) ou com eletrodos de forame oval (apesar de ser uma avaliação semi-invasiva).

\subsubsection{Teste de WADA}

Teste do amobarbital sódico (Teste de WADA) foi realizado em pacientes com RNM normal, em pacientes com evidência de lesão hipocampal bilateral, e em alguns casos em que a disfunção de memória no teste neuropsicológico, foi inequivocamente não dominante em pacientes destros com epilepsia do lobo temporal esquerdo. 
O exame foi realizado em sala equipada para procedimentos hemodinâmicos com equipamento radiológico digital. Inicialmente foi realizado estudo angiográfico com a cateterização da artéria femoral direita, para avaliação de presença de variações anatômicas, malformações arteriovenosas, aneurismas, estenoses ou outras anormalidades assintomáticas. Somente após, o teste de WADA foi procedido. Inicialmente, o exame era realizado com Amobarbital, depois passou-se a utilizar o Etomidato na dose de $0.3 \mathrm{mg} / \mathrm{kg}$ por 30 a 60 segundos em bolus e manutenção de 0.003- $0.004 \mathrm{mg} / \mathrm{kg} / \mathrm{minuto}$ (JONES-GOTMAN et al., 2005).

Antes da injeção do Etomidato, o paciente foi instruído à elevar suas mãos e contar até 100. O anestésico era injetado até que o paciente apresentasse hemiplegia contralateral ao lado injetado ou afasia. Quando a injeção era realizada no hemisfério dominante, o paciente deveria permanecer afásico por 2 a $3 \mathrm{mim}$. O protocolo do exame inclui: apresentação de 20 itens que consistiam de objetos, figuras abstratas, palavras escritas, quadros de objetos e palavras ou frases a serem repetidas. Após 0 término da apresentação dos itens, aguardava-se cerca de 10-15 mim após o fim da infusão anestésica, para que o paciente recuperasse toda a força contralateral e ficasse eufásico, assim iniciava-se o teste de memória dos objetos que haviam sido apresentados. A memória foi avaliada por recuperação espontânea ou por reconhecimento visual em múltipla escolha. Cerca de $30 \mathrm{mim}$ foram aguardados para a injeção do hemisfério contralateral. Durante todo o procedimento, foi registrado EEG simultaneamente para avaliar as consequências neurofisiológicas da injeção do anestésico, ou seja, alentecimento da atividade de base ipsilateral.

\subsection{Descrição das técnicas cirúrgicas realizadas em nosso serviço}

Colaboração da equipe de neurocirurgia, representada pelo Prof. Dr. João Alberto Assirati Junior.

\subsubsection{Cirurgia 1: Lobectomia temporal anteromesial com amígdalo-} hipocampectomia e ressecção do polo temporal (LTAM)

Inicialmente realiza-se uma incisão tipo "question mark" na região temporal, retira-se o giro temporal médio e inferior, com extensão de aproximadamente $4 \mathrm{~cm}$ da fossa média. Segue-se com a identificação do límem do lobo temporal, ao nível do 
sulco circular inferior da ínsula, que corresponde ao teto do corno temporal do ventrículo, permitindo a visualização do hipocampo e amígdala. Em seguida, o polo temporal é retirado juntamente com o giro fusiforme em seus limites com o parahipocampo. Os passos seguintes consistem na dissecção em bloco de 2/3 da amígdala para a identificação mais completa da fímbria, desconexão do corpo do hipocampo na extensão de aproximadamente $2,5 \mathrm{~cm}$, seguindo-se com a incisão da fímbria ao longo do hipocampo para a exposição da superfície pial do parahipocampo na fissura coroideia. Visualiza-se o plexo arterial hipocampal, permitindo a incisão subpial do parahipocampo e retirada em bloco do hipocampo.

Figura 17. Acesso para Lobectomia temporal anteromesial com amígdalohipocampectomia e ressecção do polo temporal

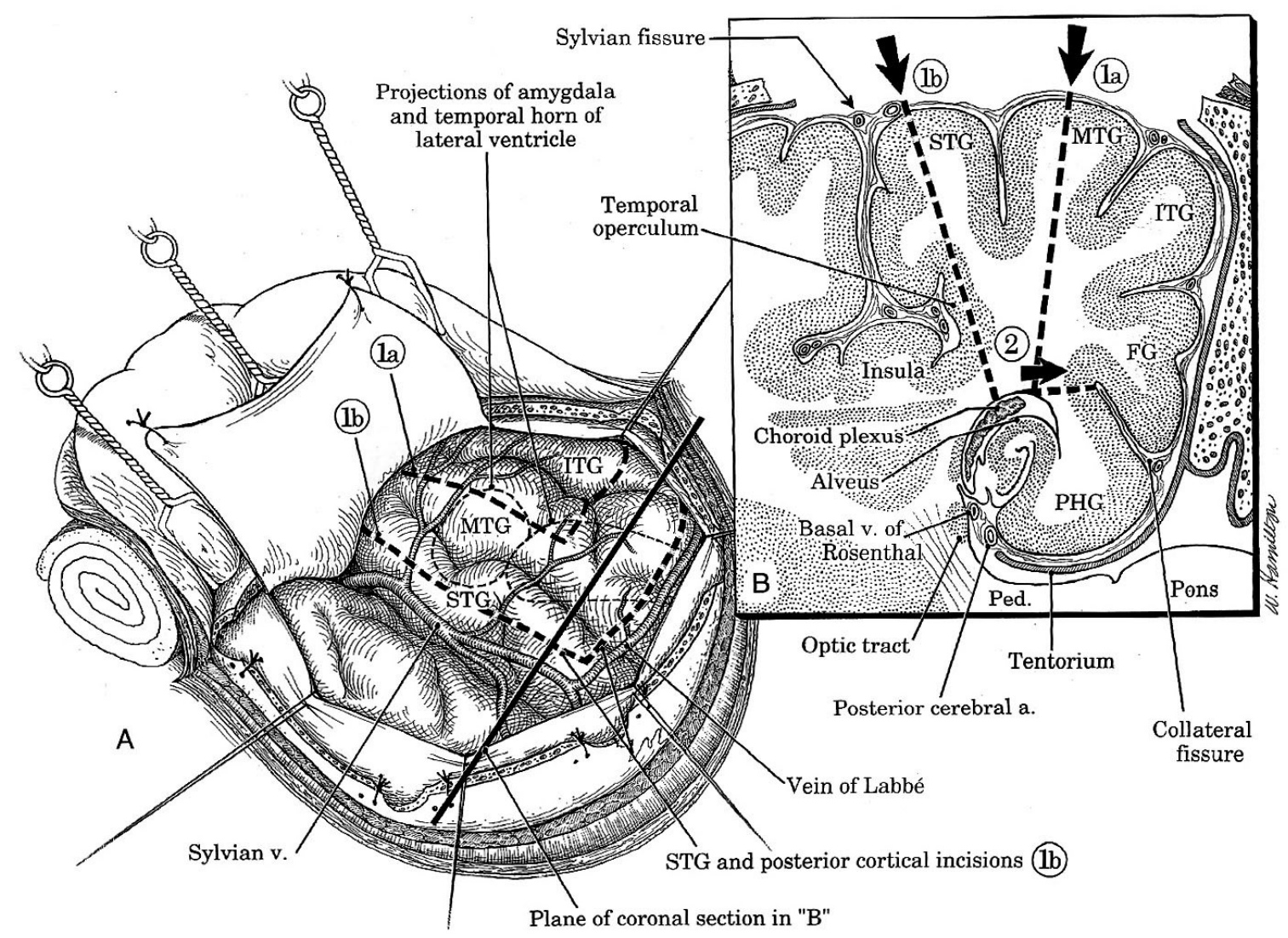

A. exposição lateral do lobo temporal. B. secção coronal através do lobo temporal direito, aproximadamente $1 \mathrm{~cm}$ do hipocampo, em uma perspectiva posterior-anterior. 1a. incisão cortical através do giro temporal médio (MTG), de forma ortogonal pela substância branca subcortical para entrar no corno temporal do ventrículo lateral. 1b. incisão pelo giro temporal superior (STG), com discreta angulação lateral através da substância branca do operculum temporal até o corno temporal do ventrículo lateral. a: artéria; FG: giro fusiforme; ITG: giro temporal inferior; Ped: pedúnculo; PHG: giro parahipocampal; v: veia.

Fonte: (YOSHOR; HAMILTON; GROSSMAN, 2006). 
Figura 18. Exemplo de lobectomia anteromesial com amígdalo-hipocampectomia e ressecção do polo temporal. Imagem de Ressonância de Encéfalo - Esquerda: Corte Axial T1; Direita: Corte Sagital T1.
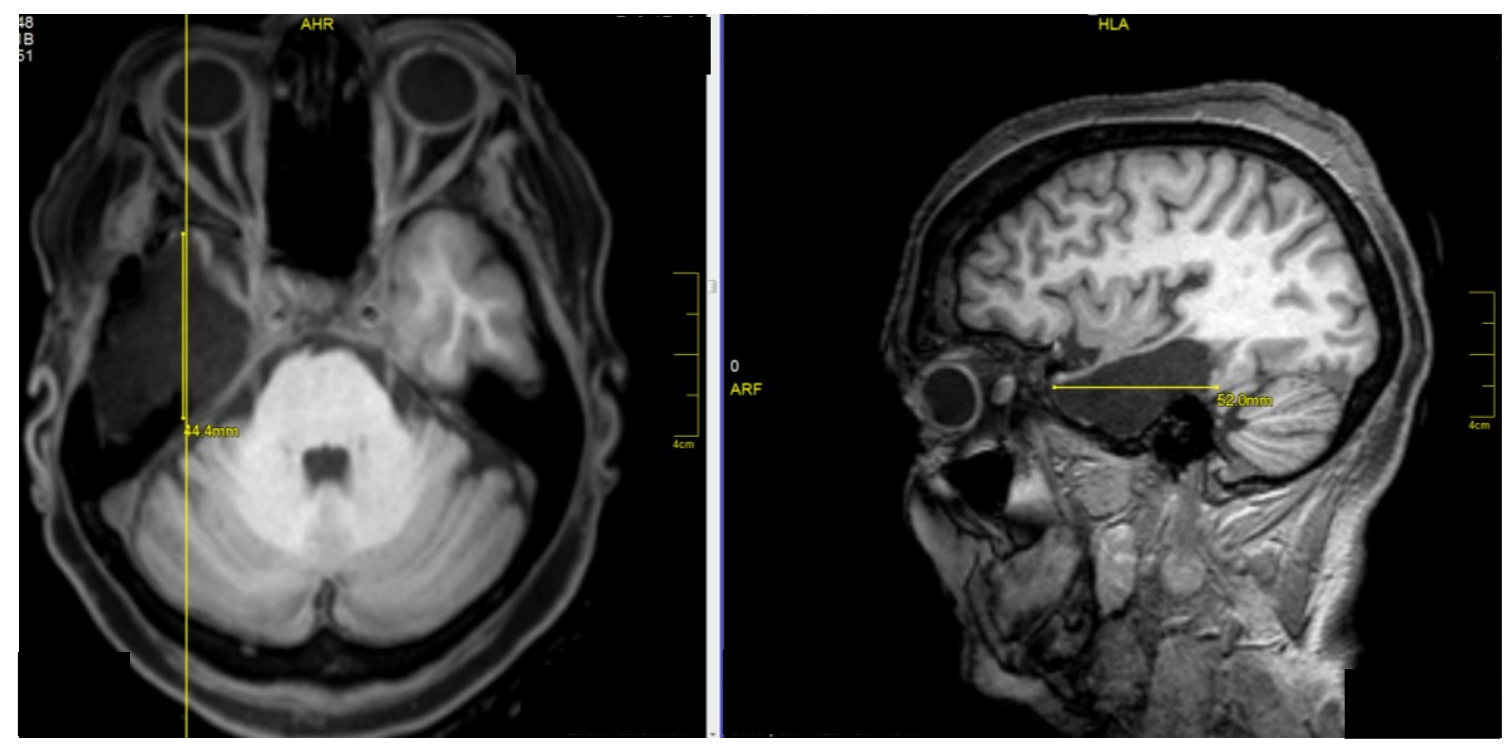

Fonte: CIREP 2011.

\subsubsection{Cirurgia 2: Amígdalo-hipocampectomia com preservação do polo e} parte do neocórtex temporal

Essa técnica é realizada através de uma craniotomia em região temporal. O acesso ao corno temporal do ventrículo pode ser feito pela retirada do giro temporal médio e inferior até o sulco colateral (referência utilizada para acesso definitivo no corno temporal). Outras opções de acesso ao ventrículo, podem ser por via transcortical, através da fissura Silviana ou pelo giro temporal médio. Com esses acessos é possível a identificação das estruturas mesiais incluindo hipocampo, amígdala e parahipocampo, para que estes sejam ressecados. Além da ressecção das estruturas mesiais, também é realizada a ressecção mais restrita da base do lobo temporal de forma variável.

Como pontos fundamentais às diversas técnicas descritas, quando comparadas com a lobectomia temporal padrão são: o acesso é mais restrito e a ressecção do neocórtex têmporo-polar e basal é menor, com preservação do polo temporal. Observação: Existem variações para essa técnica, que se diferenciam pelo tipo de incisão, pelo acesso e pela resseção do neocórtex temporal lateral e basal, que serão exemplificadas nas figuras abaixo por RNM pós-operatória dos pacientes operados no CIREP (Figuras 19). 
Figura 19a. Exemplo de amígdalo-hipocampectomia com ressecção de aproximadamente 3 cm do neocórtex temporal lateral e preservação do polo temporal. Imagem de Ressonância de Encéfalo - Esquerda: Corte Axial T1; Direita: Corte Sagital T1.
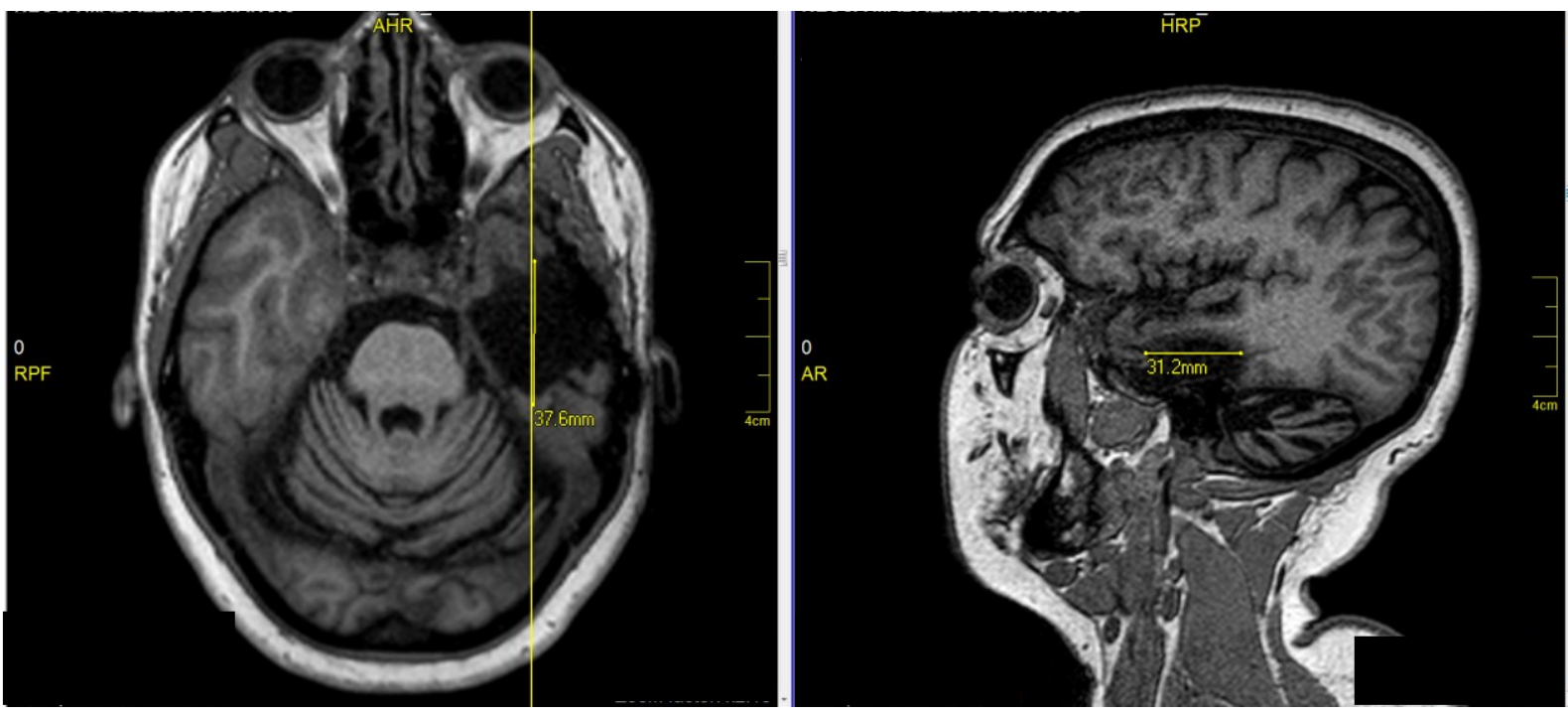

Fonte: CIREP 2011

Figura 19b. Exemplo de amígdalo-hipocampectomia com ressecção menor que $3 \mathrm{~cm}$ (aproximadamente $2 \mathrm{~cm}$ ) do neocórtex temporal lateral, com preservação do polo temporal. Imagem de Ressonância de Encéfalo - Esquerda: Corte Axial T1; Direita: Corte Sagital T1.
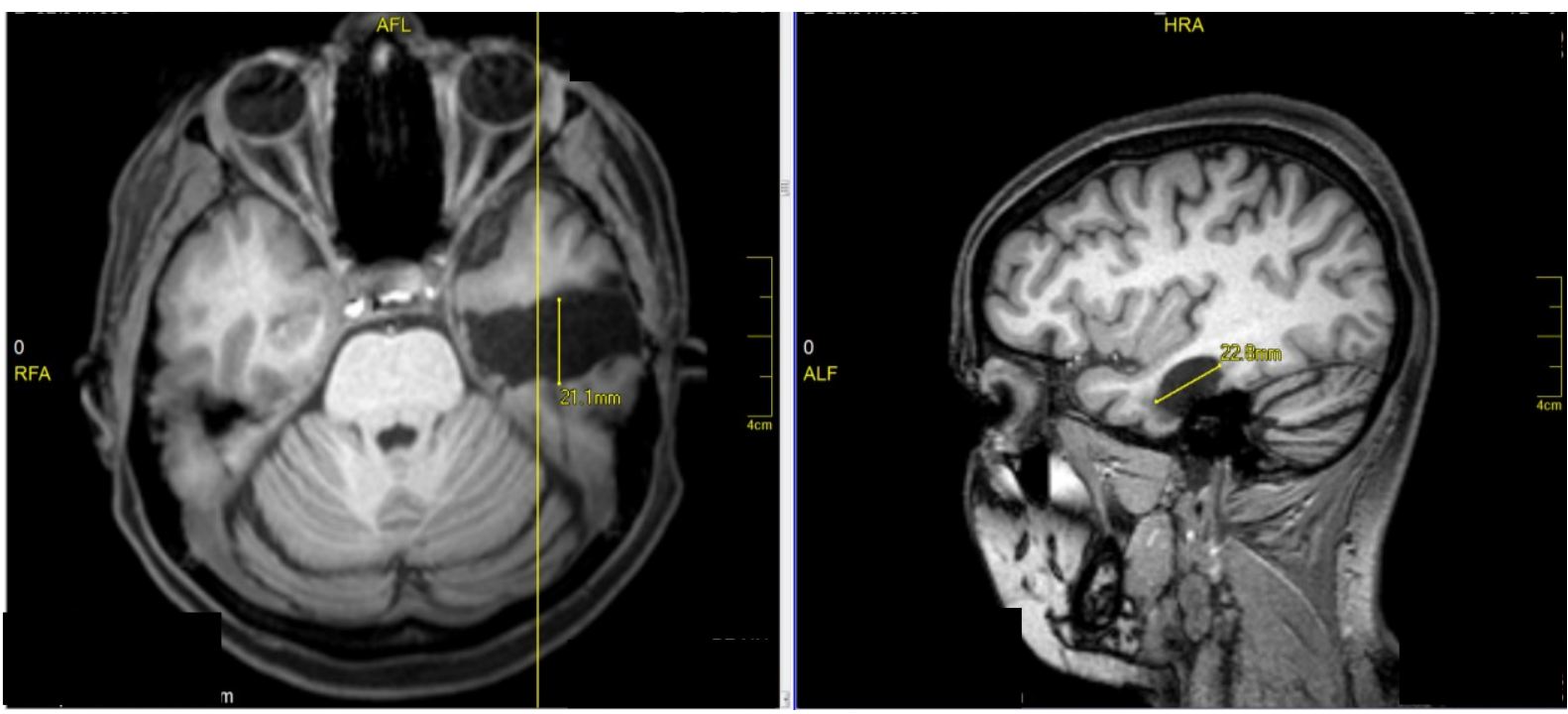

Fonte: CIREP 2010 
Figura 19c. Exemplo de amígdalo-hipocampectomia com mínima ressecção neocórtex temporal lateral, com preservação do polo temporal. Imagem de Ressonância de Encéfalo - Esquerda: Corte Axial T1; Direita: Corte Sagital T1.
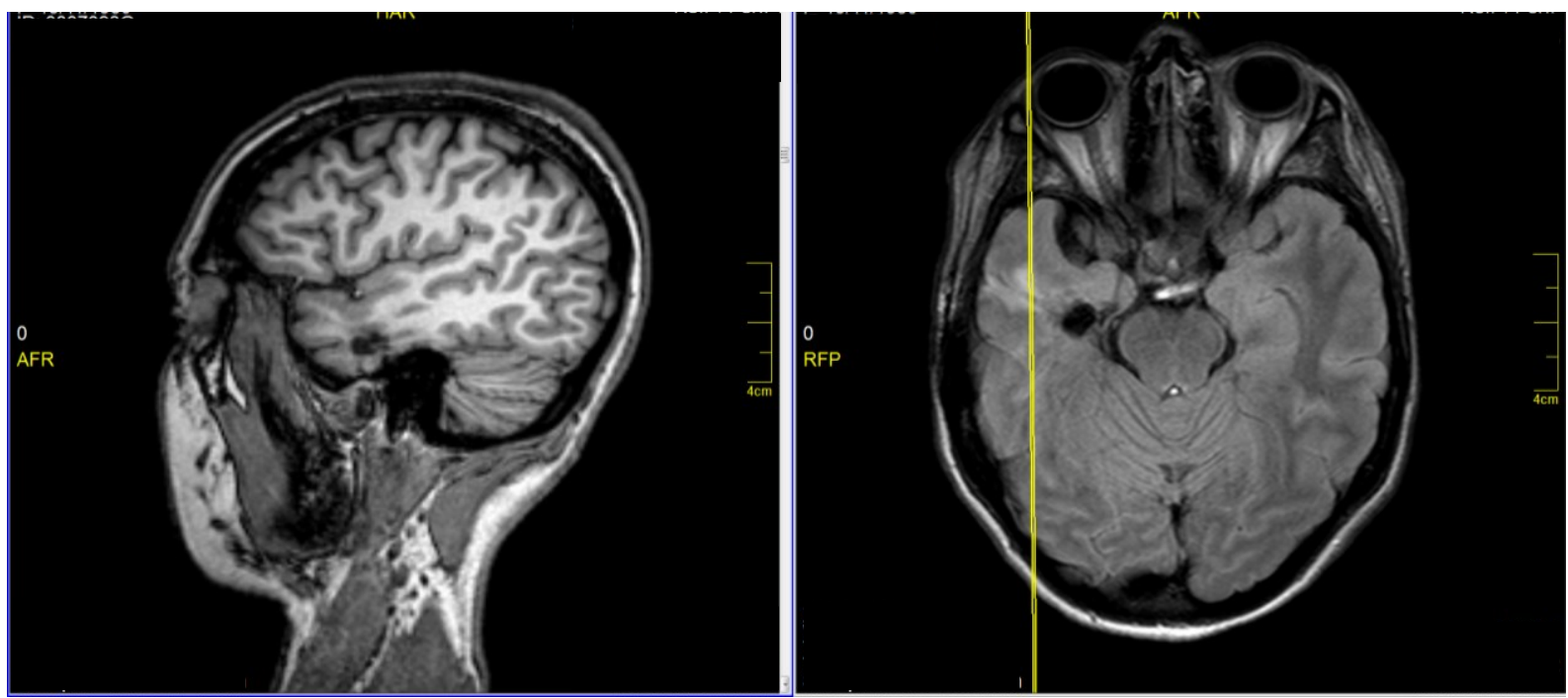

Fonte: CIREP 2011.

Para a análise dos dados, consideramos essas três variações da mesma técnica de amigdalo-hipocampectomia com preservação do polo temporal.

A seleção dos pacientes para cada tipo de procedimento foi aleatória, de acordo com a disponibilidade de data cirúrgica de cada cirurgião e fila de espera para cirurgia.

Antes do procedimento cirúrgico, os pacientes, familiares e/ou responsáveis legais foram informados quanto aos riscos e benefícios da cirurgia e um termo de consentimento informado foi assinado pelo paciente ou responsável legal.

\subsection{Acompanhamento pós-operatório}

Todos os pacientes que realizaram cirurgia de epilepsia no CIREP tiveram a oportunidade de seguir acompanhamento no Ambulatório de Epilepsia de Difícil Controle Pós-Operatório (EDCP) do HCFMRP-USP, com retorno de 1, 3 e 6 meses no primeiro ano após a cirurgia e após anual ou a critério clínico, a depender do controle de crises. Nos retornos ambulatoriais foram avaliados os desfechos pósoperatórios como a frequência de crises epilépticas (para a classificação do Engel) e as complicações pós-operatórias tardias. O manejo dos fármacos anti-epilépticos (FAE) foi realizado de acordo com a frequência de crises epilépticas e com os efeitos 
colaterais. Nos casos em que o paciente ficou livre de crises, após 3 anos de acompanhamento clínico, foi oferecido ao paciente a possibilidade de redução ou retirada total do $\mathrm{FAE}$, conduta que foi definida de acordo com o desejo do paciente.

As doses FAE foram reduzidas mais precocemente se houvesse efeitos adversos da medicação. Os pacientes que eram de outros estados e estavam livres de crises epilépticas receberam alta do nosso serviço para acompanhamento neurológico no estado de origem, devido às dificuldades logísticas e financeiras.

\subsection{Análise clínica: desfechos em relação à frequência de crises}

Para análise dos desfechos quanto à incidência de crises, foi utilizada a classificação de Engel, adaptada para o uso após o primeiro ano da cirurgia (ENGEL et al., 1993). A informação para a interpretação do Engel foi obtida através do registro em prontuário médico da última consulta / visita do paciente ou através de ligação telefônica.

Consideramos como recidiva de crises, apenas crises com alteração da consciência (crises disperceptivas) e crises tônico-clônico generalizadas. Não consideramos aura como recidiva.

\subsection{Aprovação pelo Comitê de Ética}

O presente estudo foi aprovado pelo CEP (Comitê de Ética em Pesquisa) do HCFMRP-USP, com o processo de número 2258/2017. Foi dispensada a aplicação do termo de consentimento livre e esclarecido.

\subsection{Declaração de conflito de interesses}

A autora declara ser neurologista assistente do Centro de Cirurgia de Epilepsia (CIREP) do Hospital das Clínicas de Ribeirão Preto e seu orientador é o diretor clínico do referido Centro. Ambos possuem vínculo empregatício com a instituição. 


\subsection{Custeio}

Não houve qualquer tipo de suporte financeiro específico para o desenvolvimento do trabalho.

\subsection{Colaboração}

Esse trabalho foi realizado com a colaboração da equipe médica, enfermagem, neuropsicologia do CIREP, além da equipe de neurocirurgia, neuroimagem e anatomia patológica do HCFMRP-USP.

\subsection{Análise Estatística}

Todas as análises estatísticas foram realizadas por meio do software estatístico IBM SPSS Statistics (Statistical Package for the Social Science Inc., Chicago, IL, EUA) versão 23 para Windows. Os resultados foram considerados estatisticamente significantes quando $p<0,05$.

\subsubsection{Tamanho da amostra}

O Tamanho da amostra foi de 621 pacientes.

\subsubsection{Variáveis a serem estudadas:}

a) Para cada paciente, serão analisadas as seguintes variáveis independentes:

1) sexo;

2) idade de início da observação das crises epilépticas (início epilepsia);

3) duração da epilepsia até o momento da intervenção cirúrgica (tempo de epilepsia);

4) tempo de segmento clínico (tempo de segmento);

5) idade do paciente no ato cirúrgico (idade na cirurgia);

6) crise prolongada não febril (CNF);

7) crise febril (CF);

8) história de crise febril na família (CFF); 
9) status epilepticus como evento inicial (SE);

10) status epilepticus em algum momento na evolução da história da epilepsia (SE evolução);

11) história de meningite e encefalite;

12)história de traumatismo crânio encefálico (TCE) com alteração da consciência;

13) complicações obstétricas (CO);

14) desenvolvimento neuropsicomotor (ADNPM);

15) déficit neurológico focal prévio (DNF);

16) quociente intelectual (QIG) pré-operatório:

- grupo 1: < 79 - limítrofe - extremamente baixo;

- grupo 2: 80-89 - médio inferior;

- grupo 3: 90-109 - médio;

- grupo 4: 110-119 - Médio superior;

- grupo 5: > 120 Superior e muito superior.

17) história de crises tônico-clônico-generalizadas (CTCG) frequentes = mais do que duas por ano;

18) semiologia ictal (semio ictal): crise focal com preservação da consciência ou aura, crise disperceptiva, crise focal disperceptiva com evolução para tônicoclônico bilateral, crise tônico-clônico bilateral desde o início;

19) sinais de lateralização da semiologia ictal (Slict), se concordantes, discordantes ou sem lateralização;

20) presença de aura;

21) presença de diversos tipos de aura:

- nega aura;

- inespecífica;

- epigástrica;

- afetiva (medo);

- dismnésica;

- autonômica;

- sômato-sensitiva;

- visual;

- gustativa;

- olfativa; 
- cefálica;

- vertiginosa;

- auditiva;

- afásica;

- temporal mesial (epigástrica, dismnéstica, afetiva, autonômica, olfatória, gustatória);

- temporal lateral (vertiginosa, auditiva);

- extratemporal (sensitiva, visual, afásica);

- inespecíficas (sensações inespecíficas e cefálicas).

22) frequência de crises epilépticas antes da cirurgia (frequência de crises): diária, semanal, quinzenal ou mensal;

23) número de fármacos anti-epilépticos (FAE) em utilização imediatamente antes da cirurgia: $1,2,3$ ou mais do que 4 ;

24) número de farmacorresistências (FR): 1,2,3 ou maior que 4;

25) neurofisiologia pré-operatória:

- atividade de base (AB): normal; alentecimento focal ipsilateral; alentecimento focal bilateral; alentecimento focal contralateral; alentecimento difuso;

- atividade epileptiforme interictal (EEG interictal): normal; unilateral ipsilateral (SPKs > 90\%); bilateral; unilateral contralateral; extratemporal, multifocal; generalizado;

- EEG ictal: temporal ipsilateral; temporal contralateral; temporal bilateral simétrico; temporal bilateral independente; extratemporal; difuso.

26) RNM pré-operatória:

- EMT unilateral;

- EMT bilateral.

27)TC crânio: com ou sem calcificação;

28) avaliação invasiva: se realizada ou não;

29) tipo de cirurgia: lobectomia temporal anterior padrão (com ressecção do polo temporal) ou seletiva (que preserva o polo temporal);

30) lado da lobectomia: esquerda ou direita;

31) presença ou ausência de complicações no pós-operatório imediato (POi);

32) presença ou ausência de complicações no pós-operatório tardio (POt); 
33) tempo de recidiva de crises no pós-operatório em meses;

34) Engel na última consulta: I x II, III e IV; CONE (crise de origem não epiléptica);

35) número de fármacos anti-epilépticos na última consulta: 1,2,3 ou >4;

36) se o paciente foi reoperado ou não;

37) óbitos;

b) Variáveis dependentes:

a) Engel

b) Tempo

\subsubsection{Testes Utilizados}

a) Estatística descritiva

Para as variáveis categóricas apresentamos a frequência, o percentual relativo, o percentual válido e o intervalo de confiança, para as variáveis contínuas apresentamos as médias e desvios-padrão.

b) Variável dependente "ENGEL"

Analisamos as variáveis preditoras do prognóstico pós-operatório, através da análise univariada com o teste do Qui Quadrado para as variáveis categóricas e o Teste-T para as variáveis contínuas, com a variável dependente "ENGEL". Após, realizamos uma análise multivariada, através da regressão logística binária, incluindo no modelo inicial as variáveis em que na análise univariada "p" foi menor que 0,2 e no modelo final apenas as variáveis em que o valor de $p<0,05$.

O objetivo foi avaliar quais são as variáveis que influenciam no prognóstico cirúrgico e criar um modelo em que possamos futuramente aplicar para novos casos semelhantes, podendo assim, explicar ao paciente de forma mais clara e objetiva qual será a probabilidade de ficar livre de crises após a cirurgia. 
c) Variável dependente "TEMPO"

Utilizamos a curva de Kaplan-Meier e verificamos o tempo de recidiva, ou seja, o tempo que o paciente leva para recorrer de crises no pós-operatório, ou em outras palavras, o tempo que o paciente leva para "mudar o Engel”, sair de Engel I para Engel II, III ou IV, partindo-se do pressuposto que após a cirurgia o paciente é automaticamente classificado como Engel IA, e quando tem a primeira crise muda de Engel. 


\section{Resultados}

De um total de 692 pacientes estudados com esclerose hipocampal na RNM, 621 pacientes permaneceram para a análise final, conforme o fluxograma abaixo.

Número total de Vídeo-EEGs em pacientes adultos realizados no CIREP de 1994 até junho 2018

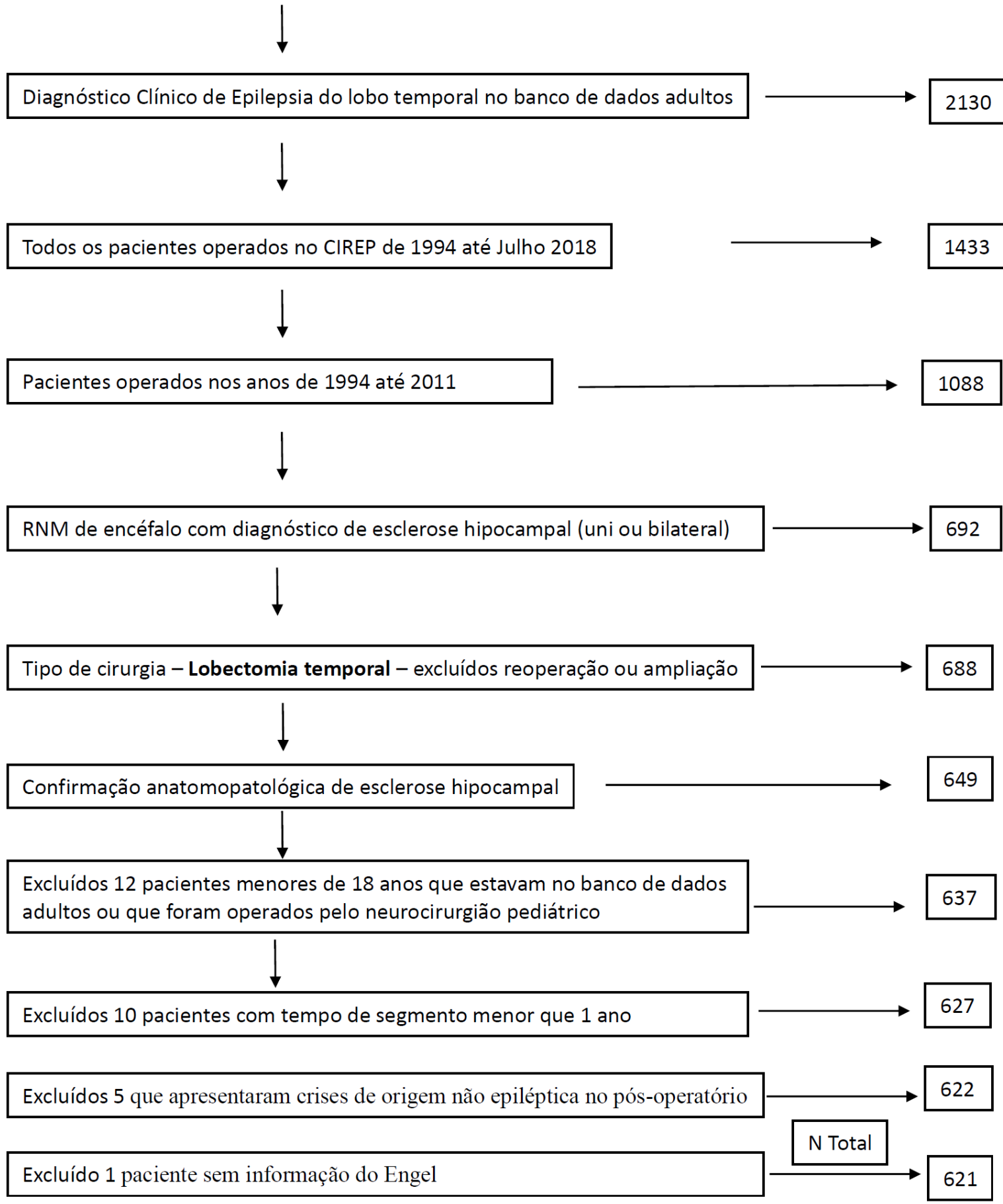


Foram excluídos pacientes com RNM normal, patologia extra-hipocampal, pacientes que realizaram outra cirurgia que não lobectomia temporal $(n=4)$, pacientes em que o anatomopatológico (AP) não era esclerose hipocampal ou os quais o AP não foi encontrado por questões técnicas $(n=39)$, pacientes menores do que 18 anos $(n=12)$, pacientes com tempo de segmento menor que 1 ano $(n=10)$, pacientes que apresentaram crise de origem não epiléptica no pós-operatório, confirmada por VEEG diagnóstico $(n=5)$, paciente sem informação do Engel $(n=1)$.

Os pacientes que foram submetidos a reoperação ou ampliação da lobectomia temporal foram incluídos apenas uma vez, na sua primeira cirurgia, para não serem duplamente analisados.

\subsection{Resultados demográficos}

De um total 621 pacientes estudados, 336 eram do sexo feminino (54,1\%; IC 95\%: 50,1-58,1\%) e 285 do sexo masculino (45,9\%; IC 95\%: 41,9-49,9\%).

A idade dos pacientes na cirurgia variou entre 18,6 a 70 anos (média $=\mathbf{3 8 , 6} \pm 9,4$ ), a idade de início da epilepsia variou de 0 a 47 anos (média de 12,0 \pm 8,5), o tempo de epilepsia (a duração da epilepsia) variou de 0,7 a 57,3 anos (média de 26,7 anos \pm 10,85).

Em relação aos antecedentes pessoais e fatores de risco para epilepsia destacam-se: complicações obstétricas (problemas gestacionais ou de parto relevantes, como parto prolongado, fórceps, apresentação anômala ou anóxia perinatal) em 107 pacientes (17,5\%; IC 95\%: 14,5-20,7), história de convulsão febril relatada por 189 pacientes (30,5\%; IC 95\%: 26,9-34,3), crise prolongada não febril em 140 pacientes (22,6\%; IC 95\%: 19,4-26,1), status epilepticus como evento inicial em 47 pacientes (7,6\%; IC 95\%: 5,6-10,0) e status epilepticus em algum momento na evolução da história da epilepsia em 121 pacientes (19,5\%; IC 95\%: 16,5-22,9), história de TCE em 44 pacientes (7,1\%; IC 95\%: 5,2-9,4), infecção do sistema nervoso central (meningite e encefalite) em 41 pacientes (6,6\%; IC 95\%: 4,8-8,9), neurocisticercose em 67 pacientes (10,8\%; IC 95\%: 8,5-13,5), atraso no desenvolvimento neuropsicomotor em 29 pacientes (4,7\%; IC 95\%: 3,2-6,7), antecedente familiar de epilepsia em 305 pacientes (49,1\%; 95\% IC: 45,1-53,1\%) e antecedente familiar de convulsão febril em 32 pacientes (5,2 \%; 95\% IC: 3,6-7,2\%). 
Em relação ao exame neurológico, 15 pacientes apresentaram déficit neurológico focal prévio (2,4\%; IC 95\%: 1,4-4,0) e 358 (76,5\%; IC 95\%: 72,4-80,3) tinham QIG na faixa médio inferior, limítrofe e extremamente baixo, sendo que a média geral do QI foi de 83,46 (IC 95\%: 82,46 - 84,46, com desvio padrão de 10,99).

Durante a anamnese da avaliação pré-cirúrgica, 390 pacientes $(\mathbf{6 4 , 8} \%$; IC 95\%: 60,8-68,6) relataram frequência de crises semanais.

Tabela 3. Frequência de crises antes da cirurgia

\begin{tabular}{lllll}
\hline $\begin{array}{l}\text { Frequência de crises } \\
\text { antes da cirurgia }\end{array}$ & $\mathrm{N}$ & Percentual & $\begin{array}{l}\text { Percentual } \\
\text { válido }\end{array}$ & IC 95\% \\
\hline Diária & 77 & 12,4 & 12,8 & $10,2-15,7$ \\
Semanal & 390 & 62,8 & 64,8 & $60,8-68,6$ \\
Quinzenal & 66 & 10,6 & 11,0 & $8,6-13,7$ \\
Mensal & 69 & 11,1 & 11,5 & $9,0-14,3$ \\
Total válido & 602 & 96,9 & 100 & \\
Sem informação & 19 & 3,1 & & \\
\hline Total & 621 & 100 & & \\
\hline
\end{tabular}

Em relação à semiologia das crises, 536 (86,3\%; IC 95\%: 83,4-88,9) relataram a presença de aura, com destaque para as auras temporais mesiais, correspondendo à 394 pacientes (63,4\%; IC 95\%: 59,5-67,2) e aura epigástrica (isoladamente) referida por 252 pacientes (41,7\%; IC 95\%: 37,7-45,7). 
Tabela 4. Aura

\begin{tabular}{lllllll}
\hline Aura & $\mathrm{N}$ & Omissos & $\mathrm{N}$ total & Percentual & $\begin{array}{l}\text { Percentual } \\
\text { válido }\end{array}$ & IC 95\% \\
\hline Presença de aura & 536 & 0 & 621 & 86,3 & 86,3 & $83,4-88,9$ \\
Negou aura & 63 & 16 & 605 & 10,1 & 10,4 & $8,1-13,1$ \\
Inespecífica & 69 & 16 & 605 & 11,1 & 11,4 & $9,0-14,2$ \\
Epigástrica & 252 & 16 & 605 & 40,6 & 41,7 & $37,7-45,7$ \\
Afetiva & 106 & 16 & 605 & 17,1 & 17,5 & $14,6-20,8$ \\
Dismnésica & 17 & 16 & 605 & 2,7 & 2,8 & $1,6-4,5$ \\
Autonômica & 31 & 16 & 605 & 5,0 & 5,1 & $3,5-7,2$ \\
Sensitiva & 27 & 16 & 605 & 4,3 & 4,5 & $3,0-6,4$ \\
Visual & 9 & 16 & 605 & 1,4 & 1,5 & $0,7-2,8$ \\
Gustatória & 12 & 16 & 605 & 1,9 & 2,0 & $1,0-3,4$ \\
Olfatória & 8 & 16 & 605 & 1,3 & 1,3 & $0,6-2,6$ \\
Cefálica & 20 & 16 & 605 & 3,2 & 3,3 & $2,0-5,1$ \\
Vertiginosa & 22 & 16 & 605 & 3,5 & 3,6 & $2,3-5,5$ \\
Auditiva & 3 & 16 & 605 & 0,5 & 0,5 & $0,1-1,4$ \\
Afasia & 1 & 16 & 605 & 0,2 & 0,2 & $0-0,9$ \\
Temporal mesial & 394 & 16 & 605 & 63,4 & 65,1 & $59,5-67,2$ \\
Temporal lateral & 25 & 16 & 605 & 4,0 & 4,1 & $2,6-5,9$ \\
Extratemporal & 36 & 16 & 605 & 5,8 & 6,0 & $4,1-7,9$ \\
\hline
\end{tabular}

Oito pacientes (1,3\%; IC 95\%: 0,6-2,5) relataram história de crises TCG frequentes (mais do que duas por ano). O tipo mais frequente de crise epiléptica registrada durante VEEG foi a crise focal com alteração da consciência (crise disperceptiva) em 420 pacientes (70,8\%; IC 95\%: 67,0-74,5). Em 463 pacientes (79,6\%; IC 95\%: 76,0-82,8), os achados semiológicos foram concordantes com o lado da EMT.

Quatrocentos e dez pacientes (66,7\%; IC 95\%: 62,8-70,4) tinham de zero até duas farmacorresistências e 521 (85,0\%; IC 95\%: 81,9-87,7) estavam em uso de até dois fármacos anti-epilépticos imediatamente antes da cirurgia. 
Tabela 5. Número de farmacorresistências antes da cirurgia

\begin{tabular}{ccccc}
\hline $\begin{array}{c}\text { Número de } \\
\text { farmacorresistências antes } \\
\text { da cirurgia }\end{array}$ & $\mathrm{N}$ & Percentual & $\begin{array}{c}\text { Percentual } \\
\text { válido }\end{array}$ & IC 95\% \\
\hline 0 & 18 & 2,9 & 2,9 & $1,7-4,62$ \\
$\mathbf{1}$ & $\mathbf{2 0 1}$ & $\mathbf{3 2 , 4}$ & $\mathbf{3 2 , 7}$ & $\mathbf{2 9 , 0 - 3 6 , 5}$ \\
$\mathbf{2}$ & $\mathbf{1 9 1}$ & $\mathbf{3 0 , 8}$ & $\mathbf{3 1 , 1}$ & $\mathbf{2 7 , 4 - 3 4 , 9}$ \\
3 & 130 & 20,9 & 21,1 & $18,0-24,6$ \\
4 & 49 & 7,9 & 8,0 & $6,0-10,4$ \\
5 & 26 & 4,2 & 4,2 & $2,8-6,1$ \\
Total válido & 615 & 99,0 & 100 & \\
Sem informação & 6 & 1,0 & & \\
\hline Total & 621 & 100 & & \\
\hline
\end{tabular}

Tabela 6. Número de FAE antes da cirurgia

\begin{tabular}{lrrrr}
\hline Número de FAE antes da cirurgia & $\mathrm{N}$ & Percentual & $\begin{array}{c}\text { Percentual } \\
\text { válido }\end{array}$ & IC 95\% \\
\hline 1 & 126 & 20,3 & 20,6 & $17,4-24,0$ \\
$\mathbf{2}$ & $\mathbf{3 9 5}$ & $\mathbf{6 3 , 6}$ & $\mathbf{6 4 , 4}$ & $\mathbf{6 0 , 5 - 6 8 , 2}$ \\
3 & 92 & 14,8 & 15,0 & $12,3-18,1$ \\
Total válido & 613 & 98,7 & 100 & \\
Sem informação & 8 & 1,3 & & \\
\hline Total & 621 & 100 & & \\
\hline
\end{tabular}

Em relação à neurofisiologia, 420 pacientes (71,6\%; IC 95\%: 67,7-75,2) tinham atividade de base normal no EEG, 449 (75,3\%; IC 95\%: 71,7-78,7) apresentaram atividade epileptiforme interictal unilateral ipsilateral à esclerose hipocampal (> $90 \%$ das descargas epilépticas em apenas um lado), 505 (86,0\%; IC 95\%: 83,0-88,7) tiveram início do EEG ictal em região temporal ipsilateral à EMT, e 66 (10,6\%; IC 95\%: 8,3-13,3) realizaram avaliação invasiva. 
Tabela 7. Atividade de base

\begin{tabular}{lrrrr}
\hline \multicolumn{1}{c}{ Atividade de base } & N & Percentual & $\begin{array}{c}\text { Percentual } \\
\text { válido }\end{array}$ & IC 95\% \\
\hline Normal & 420 & 67,6 & 71,6 & $67,7-75,2$ \\
Alentecimento focal ipsilateral & 100 & 16,1 & 17,0 & $14,1-20,3$ \\
Alentecimento focal & 67 & 10,8 & 11,4 & $9,0-14,3$ \\
contralateral, bilateral e difuso & & & 100 & \\
Total válido & 587 & 94,5 & & \\
Sem informação & 34 & 5,5 & & \\
\hline Total & 621 & 100 & & \\
\hline
\end{tabular}

Tabela 8. EEG interictal

\begin{tabular}{lrrrr}
\hline \multicolumn{1}{c}{ EEG interictal } & $N$ & Percentual & $\begin{array}{c}\text { Percentual } \\
\text { válido }\end{array}$ & IC 95\% \\
\hline Normal & 27 & 4,3 & 4,5 & $3,0-6,5$ \\
Unilateral ipsilateral & 449 & 72,3 & 75,3 & $71,7-78,7$ \\
Bilateral & 106 & 4,0 & 4,0 & \\
Unilateral contralateral & 7 & 1,1 & 1,2 & $0,5-2,4$ \\
Extra temporal & 6 & 1,0 & 1,0 & $0,4-2,2$ \\
Multifocal & 1 & 0,2 & 0,2 & $0-0,9$ \\
Total válido & 596 & 96 & 100 & \\
Sem informação & 25 & 4,0 & & \\
\hline Total & 621 & 100 & & \\
\hline
\end{tabular}


Tabela 9. EEG ictal

\begin{tabular}{lrrrr}
\multicolumn{1}{c}{ EEG ictal } & N & Percentual & $\begin{array}{c}\text { Percentual } \\
\text { válido }\end{array}$ & IC 95\% \\
\hline Temporal ipsilateral & 505 & 81,3 & 86,0 & $83,0-88,7$ \\
$\begin{array}{l}\text { Temporal bilateral } \\
\text { independente }\end{array}$ & 33 & 5,3 & 5,6 & $3,9-7,8$ \\
$\begin{array}{l}\text { Temporal bilateral } \\
\text { simétrico }\end{array}$ & 25 & 4,0 & 4,3 & $2,8-6,2$ \\
Temporal contralateral & 11 & 1,8 & 1,9 & $0,9-3,3$ \\
Extra temporal & 2 & 0,3 & 0,3 & $0-1,2$ \\
Difuso & 11 & 1,8 & 1,9 & $0,9-3,3$ \\
Total válido & 587 & 94,5 & 100 & \\
Sem informação & 34 & 5,5 & & \\
\hline Total & 621 & 100 & & \\
\hline
\end{tabular}

Quanto aos exames de neuroimagem, 600 (96,6 \%; IC 95\%: 94,9-97,9) tinham EMT unilateral na RNM e 120 (49,0\%; IC 95\%: 42,6-55,4) tinham calcificações sugestivas de neurocisticercose na TC de crânio.

Sobre os dados operatórios, 293 pacientes (47,2 \%; IC 95\%: 43,2-51,2) realizaram a cirurgia em lobo temporal direito e 328 (52,8\%; IC 95\%: 48,8-56,8) em lobo temporal esquerdo, 355 (57,5 \%; IC 95\%: 53,5-61,5) realizaram lobectomia temporal anteromesial, que resseca o polo temporal e 262 (42,5\%; IC 95\%: 38,5-46,5) realizaram a cirurgia a que preserva o polo temporal.

Em relação às complicações no pós-operatório imediatas (POi), 540 (87\%; IC 95\%: 84,1-89,5) pacientes não tiveram nenhuma complicação. Em relação aos óbitos do peri-operatório ou pós-operatório imediato, não foi possível obter essa informação, pois foram excluídos da análise os pacientes com tempo de segmento menor do que 1 ano, e se o paciente faleceu no primeiro ano do segmento clínico, esse dado foi perdido. Como não era o objetivo principal do estudo, essa informação não foi profundamente revisada, poderá ser revisada futuramente. As complicações pósoperatórias imediatas serão descritas de forma detalhada na tabela 10, abaixo.

Observação: Não foram consideradas para a análise "cefaleia", pois essa queixa foi muito comum no pós-operatório imediato em praticamente todos os pacientes. Também não consideramos hemianopsia ipslateral, pois além de ser uma 
queixa comum, é subjetiva e não analisamos todas as campimetrias no pós-operatório para obter dados fidedignos, já que não era o objetivo principal do trabalho.

Tabela 10. Complicações POi

\begin{tabular}{|c|c|c|c|c|}
\hline Complicações POi & $\mathrm{N}$ & Percentual & $\begin{array}{c}\text { Percentual } \\
\text { válido }\end{array}$ & IC 95\% \\
\hline Nenhuma & 540 & 87,0 & 87,0 & $84,1-89,5$ \\
\hline Infecção trato-urinário & 1 & 0,2 & 0,2 & $0-0,9$ \\
\hline Erisipela & 2 & 0,32 & 0,3 & $0-1,2$ \\
\hline Disfunção ATM & 2 & 0,32 & 0,2 & $0-1,2$ \\
\hline Distúrbios psiquiátricos & 5 & 0,8 & 0,8 & $0,3-1,9$ \\
\hline Crise epiléptica & 17 & 2,7 & 2,7 & $1,6-4,3$ \\
\hline Diplopia & 7 & 1,1 & 1,1 & $0,5-2,3$ \\
\hline TVP & 3 & 0,5 & 0,5 & $0,1-1,4$ \\
\hline Otorragia & 1 & 0,2 & 0,2 & $0-0,9$ \\
\hline Hipoacusia ipsilateral & 1 & 0,2 & 0,2 & $0-0,9$ \\
\hline Necrose do retalho de pele & 1 & 0,2 & 0,2 & $0-0,9$ \\
\hline Meningite & 2 & 0,32 & 0,3 & $0,-1,2$ \\
\hline Infecção ferida operatória & 4 & 0,64 & 0,6 & $0,2-1,6$ \\
\hline Sangramento (HIP, HSD, HED) & 9 & 1,4 & 1,4 & $0,7-2,7$ \\
\hline Isquemia - AVC & 5 & 0,8 & 0,8 & $0,3-1,9$ \\
\hline Edema cerebral intra-operatório & 1 & 0,2 & 0,2 & $0-0,9$ \\
\hline Pneumonia nosocomial & 1 & 0,2 & 0,2 & $0-0,9$ \\
\hline Distúrbios de linguagem & 5 & 0,8 & 0,8 & $0,3-1,9$ \\
\hline Fístula liquórica & 3 & 0,5 & 0,5 & $0,1-1,4$ \\
\hline Sem informação & 11 & 1,8 & 1,8 & $0,9-3,1$ \\
\hline Total & 621 & 100 & 100 & \\
\hline
\end{tabular}

Em relação às complicações no pós-operatório tardio (POT), 537 pacientes $(\mathbf{8 6 , 5 \%}$; IC 95\%: 83,5-89,1) não tiveram nenhuma complicação e 33 (5,3\%; IC 95\%: 3,7-7,4) tiveram cefaleia crônica. 
Tabela 11. Complicações POT

\begin{tabular}{lrrrr}
\hline \multicolumn{1}{c}{ Complicações POT } & $N$ & Percentual & \multicolumn{2}{c}{$\begin{array}{c}\text { Percentual } \\
\text { válido }\end{array}$} \\
\hline Nenhuma & 537 & 86,5 & 86,5 & IC 95\% \\
Déficit motor & 1 & 0,2 & 0,2 & $0-0,99,1$ \\
Cefaleia crônica & 33 & 5,3 & 5,3 & $3,7-7,4$ \\
Distúrbios psiquiátricos & 30 & 4,8 & 4,8 & $3,3-6,8$ \\
AVE & 5 & 0,8 & 0,8 & $0,3-1,9$ \\
Disfunção ATM & 7 & 1,1 & 1,1 & $0,5-2,3$ \\
Abscesso cerebral & 1 & 0,2 & 0,2 & $0-0,9$ \\
Hidrocefalia & 1 & 0,2 & 0,2 & $0-0,9$ \\
Osteomielite de crânio & 1 & 0,2 & 0,2 & $0-0,9$ \\
Sem informação & 5 & 0,8 & 0,8 & $0,3-1,9$ \\
\hline Total & 621 & 100 & & \\
\hline
\end{tabular}

Em relação aos óbitos: foram registrados 27 óbitos de um total de 621 pacientes (4,3\%; IC 95\%: 2,9-6,3). Dos 27 óbitos, apenas 13 tinham relato da causa do óbito em prontuário médico, os outros 14 não tinham essa informação. Nenhum dos óbitos conhecidos, foi em decorrência de complicações da cirurgia ou SUDEP (Sudden unexpected death in epilepsy). As outras causas documentadas em prontuário foram: complicações por TCE após crise epiléptica $(n=2)$; câncer de pulmão $(n=1)$, câncer de mama $(n=2)$, câncer de intestino $(n=2)$, infarto agudo do miocárdio (IAM) $(n=3)$, complicações da esclerose lateral amiotrófica (ELA) $(n=1)$, complicações de pneumonia e insuficiência renal crônica $(I R C)(n=1)$. 
Tabela 12. Causa óbito

\begin{tabular}{lcccc}
\hline \multicolumn{1}{c}{ Causa óbito } & N & Porcentagem & $\begin{array}{c}\text { Porcentagem } \\
\text { válida }\end{array}$ & IC 95\% \\
\hline Câncer intestino & 2 & 0,3 & 0,3 & $0-1,2$ \\
Câncer de Mama & 2 & 0,3 & 0,3 & $0-1,2$ \\
Câncer de pulmão & 1 & 0,2 & 0,2 & $0-0,9$ \\
ELA & 1 & 0,2 & 0,2 & $0-0,9$ \\
IAM & 3 & 0,5 & 0,5 & $0,1-1,4$ \\
IRC & 1 & 0,2 & 0,2 & $0-0,9$ \\
Suicídio & 2 & 0,3 & 0,3 & $0-1,2$ \\
TCE & 2 & 0,3 & 0,3 & $0-1,2$ \\
Causa desconhecida & 14 & 2,3 & 2,3 & $1,2-3,8$ \\
\hline Total & 621 & 100 & 100 & \\
\hline
\end{tabular}

O tempo de segmento (acompanhamento clínico) variou de 1 ano até 23 anos,

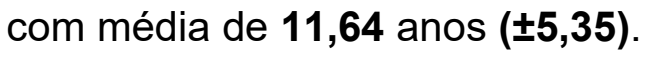

Em relação ao prognóstico cirúrgico, 457 (73,6 \%; IC 95\%: 69,9-77,0) ficaram livres de crises epilépticas (Engel I). Quando avaliamos um bom prognóstico cirúrgico, ou seja, Engel I + II, temos 526 pacientes que correspondem a 84,7\% (IC 95\%: 81,6$87,4)$.

Tabela 13. Engel

\begin{tabular}{ccccc}
\hline Engel & $\begin{array}{c}\text { Número } \\
\text { absoluto }\end{array}$ & Porcentagem & $\begin{array}{c}\text { Porcentagem } \\
\text { válida }\end{array}$ & $\begin{array}{c}\text { Porcentagem } \\
\text { cumulativa }\end{array}$ \\
\hline IA & $\mathbf{2 2 7}$ & $\mathbf{3 6 , 6}$ & 36,6 & 36,6 \\
IB & 81 & 13,0 & 13,0 & 49,6 \\
IC & 80 & 12,9 & 12,9 & 62,5 \\
Válido ID & 69 & 11,1 & 11,1 & $\mathbf{7 3 , 6}$ \\
II & 69 & 11,1 & 11,1 & $\mathbf{8 4 , 7}$ \\
III & 86 & 13,8 & 13,8 & 98,6 \\
IV & 9 & 1,4 & 1,4 & 100,0 \\
\cline { 2 - 5 } Total & 621 & 100,0 & 100,0 & \\
\hline
\end{tabular}


Tabela 14. Engel resumido

\begin{tabular}{clccc}
\hline Engel resumido & $\begin{array}{c}\text { Número } \\
\text { absoluto }\end{array}$ & Porcentagem & $\begin{array}{c}\text { Porcentagem } \\
\text { válida }\end{array}$ & IC 95\% \\
\hline I & $\mathbf{4 5 7}$ & $\mathbf{7 3 , 6}$ & $\mathbf{7 3 , 6}$ & $69,9-77,0$ \\
II & 69 & 11,1 & 11,1 & $8,7-13,9$ \\
Válido III & 86 & 13,8 & 13,8 & $11,2-16,8$ \\
& 9 & 1,4 & 1,4 & $0,7-2,7$ \\
\cline { 2 - 6 } & 921 & 100,0 & 100,0 & \\
\hline
\end{tabular}

Dos 621 pacientes, 23 foram reoperados (3,7\%; IC 95\%: 2,4-5,5). Desses pacientes reoperados, 12 (52,2\%; IC 95\% 30,6-73,2), ficaram livres de crises (Engel I).

Tabela 15. Engel pós-reoperação

\begin{tabular}{|c|c|c|c|}
\hline $\begin{array}{l}\text { Engel pós- } \\
\text { reoperação }\end{array}$ & $\mathrm{N}$ & Porcentagem válida & IC 95\% \\
\hline I & 12 & 52,2 & $30,6-73,2$ \\
\hline II & 3 & 13,0 & $2,3-33,6$ \\
\hline III & 6 & 26,1 & $10,2-48,4$ \\
\hline IV & 2 & 8,7 & $1,1-28,0$ \\
\hline Total & 23 & 100 & \\
\hline
\end{tabular}

Observação: pode haver um viés registro ou de coleta das informações, pois estas foram obtidas através da revisão de prontuários e dependeram das informações fornecidas pelo paciente ao médico assistente à época da internação.

\subsection{Resultados prognósticos significativos}

Analisamos os dados da avaliação pré-operatória que influenciaram no prognóstico cirúrgico, ou seja, comparamos os pacientes classificados como Engel I (livres de crises) com os pacientes que foram classificados como Engel II, III e IV, em relação às variáveis pré-operatórias. Destacarei aqui os achados significativos. 


\subsubsection{Crise Febril}

Os pacientes que relataram história de convulsão febril, apresentaram significativo melhor prognóstico (Engel I) em 79,4\% dos casos, em relação ao grupo que negou esse fator $(71,4 \%)\left(p=0,047^{*}\right)$.

Tabela 16. Convulsão Febril * Engel

\begin{tabular}{|c|c|c|c|c|c|}
\hline & & & \multicolumn{2}{|c|}{ Engel } & \multirow{2}{*}{ Total } \\
\hline & & & I & II,III,IV & \\
\hline \multirow{4}{*}{ CF } & NÃO & $\mathrm{N}$ & 307 & 123 & 430 \\
\hline & & $\%$ em CF & $71,4 \%$ & $28,6 \%$ & $100,0 \%$ \\
\hline & SIM & $\mathrm{N}$ & 150 & 39 & 189 \\
\hline & & $\%$ em CF & $79,4 \%$ * & $20,6 \%$ & $100,0 \%$ \\
\hline \multirow{2}{*}{\multicolumn{2}{|c|}{ Total }} & $\mathrm{N}$ & 457 & 162 & 619 \\
\hline & & $\%$ em CF & $73,8 \%$ & $26,2 \%$ & $100,0 \%$ \\
\hline
\end{tabular}

Qui-quadrado: 4,316; $\mathbf{p}=\mathbf{0 , 0 4 7 ^ { * }}$

\subsubsection{Aura Dismnésica}

Os pacientes que relataram aura dismnésica, tiveram pior prognóstico em relação aos que não relataram esse fator $\left(p=0,02^{*}\right)$.

Tabela 17. Aura dismnésica * Engel

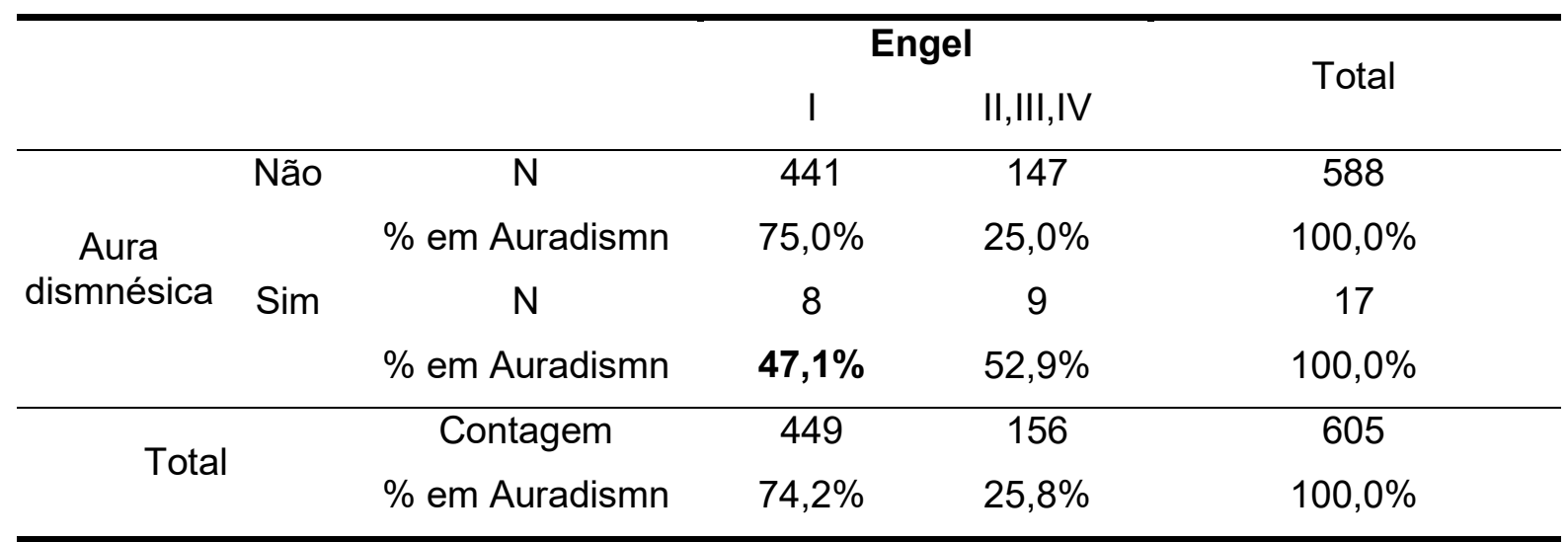

Qui-quadrado: 6,714; $\mathbf{p}=\mathbf{0 , 0 2 *}$ 


\subsubsection{Aura Olfatória}

Os pacientes que relataram aura olfatória, tiveram pior prognóstico do que aqueles que não relataram esse fator $\left(p=0,03^{*}\right)$.

Tabela 18. Aura olfativa * Engel

\begin{tabular}{|c|c|c|c|c|c|}
\hline & & & & & \\
\hline & & & I & II,III,IV & Tulal \\
\hline & Não & $\mathrm{N}$ & 446 & 151 & 597 \\
\hline Aura & & $\%$ em Auraolf & $74,7 \%$ & $25,3 \%$ & $100,0 \%$ \\
\hline olfatória & Sim & $\mathrm{N}$ & 3 & 5 & 8 \\
\hline & & $\%$ em Auraolf & $37,5 \%$ & $62,5 \%$ & $100,0 \%$ \\
\hline & & $\mathrm{N}$ & 449 & 156 & 605 \\
\hline 100 & & $\%$ em Auraolf & $74,2 \%$ & $25,8 \%$ & $100,0 \%$ \\
\hline
\end{tabular}

Qui-quadrado: 5,$711 ; \mathbf{p}=\mathbf{0 , 0 3}{ }^{*}$

\subsubsection{Tipo de Técnica Cirúrgica}

Em relação ao tipo de técnica cirúrgica, os pacientes que realizaram lobectomia temporal anteromesial (ressecção do polo temporal) apresentaram melhor prognóstico (78,6\% Engel I), em relação aos pacientes que realizaram cirurgia que preserva o polo temporal $\left(\mathbf{6 7 , 2} \%\right.$ Engel I), com valor de $\mathbf{p}=\mathbf{0 , 0 0 2 ^ { * }}$.

Tabela 19. Tipo Cirurgia * Engel

\begin{tabular}{clcccc}
\hline & & & \multicolumn{2}{c}{ Engel } & Total \\
& & I & II,III,IV & \\
\hline \multirow{3}{*}{ Tipo } & Ressecção & & 279 & 76 & 355 \\
cirurgia & polo temporal & $\%$ & $\mathbf{7 8 , 6 \%}$ & $21,4 \%$ & $100,0 \%$ \\
& Preservação & & 176 & 86 & 262 \\
& polo temporal & $\%$ & $\mathbf{6 7 , 2} \%$ & $32,8 \%$ & $100,0 \%$ \\
\hline \multirow{2}{*}{} & Total & $\%$ & $73,7 \%$ & $26,3 \%$ & 617 \\
& & & 455 & 162 & $100,0 \%$ \\
\hline
\end{tabular}

Qui-quadrado: 10,$146 ; \mathbf{p}=\mathbf{0 , 0 0 2 ^ { * }}$ 


\subsubsection{Idade de Início da Epilepsia}

Em relação à idade de início da epilepsia, os pacientes com melhor prognóstico (Engel I), tiveram média de idade de início da epilepsia significativamente menor $(11,6$ anos), em relação à média de idade (12,9 anos) dos pacientes com pior prognóstico (Engel II, III, IV), $p=0,005^{*}$.

Tabela 20. T-Test

\begin{tabular}{lllllll}
\hline T-Test & Engel & N & Média & $\begin{array}{c}\text { Desvio } \\
\text { Padrão }\end{array}$ & $\begin{array}{c}\text { Erro } \\
\text { Padrão da } \\
\text { Média }\end{array}$ & Sig. p \\
\hline Idepi & I & 453 & $\mathbf{1 1 , 6 6}$ & 8,160 &, 383 & $\mathbf{0 , 0 0 5}^{*}$ \\
& II,III,IV & 162 & $\mathbf{1 2 , 9 3}$ & 9,350 &, 735 & \\
\hline
\end{tabular}

\subsubsection{Número de FAEs antes da cirurgia}

O prognóstico dos pacientes que usavam menor número de FAEs antes da cirurgia (1 ou 2), foi melhor (em porcentagem) do que os pacientes que usavam maior número de FAEs antes da cirurgia (3 ou 4), $p=0,007^{*}$.

Tabela 21. FAE antes cirurgia * Engel

\begin{tabular}{cccccc}
\hline & & & \multicolumn{2}{c}{ Engel } & Total \\
& & & $\mathrm{I}$ & II,III,IV & \\
\hline & 1 & $\mathrm{~N}$ & 95 & 31 & 126 \\
& & $\%$ & $75,4 \%$ & $24,6 \%$ & $100,0 \%$ \\
FAE antes & 2 & $\mathrm{~N}$ & 301 & 94 & 395 \\
cirurgia & & $\%$ & $76,2 \%$ & $23,8 \%$ & $100,0 \%$ \\
& 3 & $\mathrm{~N}$ & 52 & 37 & 89 \\
& & $\%$ & $58,4 \%$ & $41,6 \%$ & $100,0 \%$ \\
& 4 & $\mathrm{~N}$ & 2 & 1 & 3 \\
\hline \multirow{2}{*}{ Total } & & $\mathrm{N}$ & $66,7 \%$ & $33,3 \%$ & $100,0 \%$ \\
\hline & & $\%$ & 450 & 163 & 613 \\
& & & $73,4 \%$ & $26,6 \%$ & $100,0 \%$ \\
\hline
\end{tabular}

Qui-quadrado: 12,$14 ; p=0,007^{*}$ 


\subsubsection{Retirada de FAEs}

Na última consulta em nosso serviço (após a cirurgia), 19,5 \% conseguiram retirar totalmente os FAEs e 35,9\% estavam em monoterapia, sendo que a proporção dos pacientes que estavam com menor número de FAEs (de 0 a 2), foi maior no grupo que estava livre de crises, ou seja, a proporção de pacientes com menor número FAEs, na última consulta, foi maior no grupo com melhor prognóstico; já os pacientes com pior prognóstico (Engel II,III e IV), apresentaram maior proporção de número de FAEs (3 ou 4) na última consulta, $p=0,000^{*}$.

Tabela 22. FAE última consulta * Engel

\begin{tabular}{|c|c|c|c|c|c|}
\hline & & & \multicolumn{2}{|c|}{ Engel } & \multirow[b]{2}{*}{ Total } \\
\hline & & & 1 & II,III,IV & \\
\hline \multirow{10}{*}{$\begin{array}{l}\text { FAE última } \\
\text { consulta }\end{array}$} & \multirow{2}{*}{0} & $\mathrm{~N}$ & 96 & 4 & 100 \\
\hline & & $\%$ & $96,0 \%$ & $4,0 \%$ & $100,0 \%$ \\
\hline & \multirow{2}{*}{1} & $\mathrm{~N}$ & 153 & 31 & 184 \\
\hline & & $\%$ & $83,2 \%$ & $16,8 \%$ & $100,0 \%$ \\
\hline & \multirow{2}{*}{2} & $\mathrm{~N}$ & 111 & 62 & 173 \\
\hline & & $\%$ & $64,2 \%$ & $35,8 \%$ & $100,0 \%$ \\
\hline & \multirow{2}{*}{3} & $\mathrm{~N}$ & 16 & 35 & 51 \\
\hline & & $\%$ & $31,4 \%$ & $68,6 \%$ & $100,0 \%$ \\
\hline & \multirow{2}{*}{4} & $\mathrm{~N}$ & 0 & 5 & 5 \\
\hline & & $\%$ & $0,0 \%$ & $100,0 \%$ & $100,0 \%$ \\
\hline \multirow{2}{*}{\multicolumn{2}{|c|}{ Total }} & $\mathrm{N}$ & 376 & 137 & 513 \\
\hline & & $\%$ & $73,3 \%$ & $26,7 \%$ & $100,0 \%$ \\
\hline
\end{tabular}

Qui-quadrado: 102,$358 ; p=0,000$

Em relação aos pacientes em que após a cirurgia conseguiram retirar o FAE, 22,2\% usavam $1 \mathrm{FAE}$ antes da cirurgia, 67,7\% usavam 2 FAEs, 10,1\% usavam 3 FAEs e nenhum que usava 4 FAEs. 
Tabela 23. FAE última consulta * FAE antes cirurgia

\begin{tabular}{|c|c|c|c|c|c|c|c|}
\hline & & & \multicolumn{4}{|c|}{ FAE antes cirurgia } & \multirow{2}{*}{ Total } \\
\hline & & & 1 & 2 & 3 & 4 & \\
\hline \multirow{10}{*}{$\begin{array}{l}\text { FAE última } \\
\text { consulta }\end{array}$} & \multirow{2}{*}{0} & $\mathrm{~N}$ & 22 & 67 & 10 & 0 & 99 \\
\hline & & $\%$ & $22,2 \%$ & $67,7 \%$ & $10,1 \%$ & $0,0 \%$ & $100,0 \%$ \\
\hline & \multirow{2}{*}{1} & $\mathrm{~N}$ & 49 & 109 & 22 & 2 & 182 \\
\hline & & $\%$ & $26,9 \%$ & $59,9 \%$ & $12,1 \%$ & $1,1 \%$ & $100,0 \%$ \\
\hline & \multirow{2}{*}{2} & $\mathrm{~N}$ & 22 & 127 & 22 & 1 & 172 \\
\hline & & $\%$ & $12,8 \%$ & $73,8 \%$ & $12,8 \%$ & $0,6 \%$ & $100,0 \%$ \\
\hline & \multirow{2}{*}{3} & $\mathrm{~N}$ & 6 & 26 & 19 & 0 & 51 \\
\hline & & $\%$ & $11,8 \%$ & $51,0 \%$ & $37,3 \%$ & $0,0 \%$ & $100,0 \%$ \\
\hline & \multirow{2}{*}{4} & $\mathrm{~N}$ & 0 & 1 & 4 & 0 & 5 \\
\hline & & $\%$ & $0,0 \%$ & $20,0 \%$ & $80,0 \%$ & $0,0 \%$ & $100,0 \%$ \\
\hline \multirow{2}{*}{\multicolumn{2}{|c|}{ Total }} & $\mathrm{N}$ & 99 & 330 & 77 & 3 & 509 \\
\hline & & $\%$ & $19,4 \%$ & $64,8 \%$ & $15,1 \%$ & $0,6 \%$ & $100,0 \%$ \\
\hline
\end{tabular}

Qui-quadrado: 53,597; $p=0,000$

\subsubsection{Experiência do serviço}

Analisamos a experiência do serviço e dividimos em três épocas:

1. - época 1: dos anos de 1994 a 2000;

2. - época 2: de 2001 a 2009;

3. - época 3: de 2007 a 2011.

Observamos que a porcentagem de pacientes que ficou livre de crises foi diminuindo com o passar das épocas $(79,2 \%$ - $77,0 \%$ - $62,8 \%$, respectivamente), com $p=0,000^{*}$. 
Tabela 24. Experiência* Engel

\begin{tabular}{|c|c|c|c|c|c|}
\hline & & & \multicolumn{2}{|c|}{ Engel } & \multirow{2}{*}{ Total } \\
\hline & & & I & II,III,IV & \\
\hline \multirow{6}{*}{ Experiência } & \multirow{2}{*}{$1994-2000$} & $\mathrm{~N}$ & 160 & 42 & 202 \\
\hline & & $\%$ & $79,2 \%$ & $20,8 \%$ & $100,0 \%$ \\
\hline & \multirow{2}{*}{$2001-2006$} & $\mathrm{~N}$ & 184 & 55 & 239 \\
\hline & & $\%$ & $77,0 \%$ & $23,0 \%$ & $100,0 \%$ \\
\hline & \multirow{2}{*}{$2007-2011$} & $\mathrm{~N}$ & 113 & 67 & 180 \\
\hline & & $\%$ & $62,8 \%$ & $37,2 \%$ & $100,0 \%$ \\
\hline \multirow{2}{*}{\multicolumn{2}{|c|}{ Total }} & $\mathrm{N}$ & 457 & 164 & 621 \\
\hline & & $\%$ & $73,6 \%$ & $26,4 \%$ & $100,0 \%$ \\
\hline
\end{tabular}

Qui-quadrado: 15,$527 ; p=0,000$

Quando comparamos a experiência com o tipo de cirurgia, encontramos que para os pacientes que realizaram cirurgia com ressecção do polo temporal, a porcentagem de pacientes classificados como Engel I permaneceu estável nas épocas 1 e 2 (80,3 - 80,8\%, respectivamente), e caiu na época 3 para 71,8\%, com valor de $p=0,252$, não significativo. Já para os pacientes que realizaram cirurgia com preservação do polo temporal, houve queda significativa da porcentagem de pacientes Engel I na época 3 (75,0 - 74,1 - 55,9\%, respectivamente), com valor de $p=\mathbf{0 , 0 0 8}$. 
Tabela 25. Experiência * Engel * Tipo de cirurgia

\begin{tabular}{|c|c|c|c|c|c|c|}
\hline \multirow{2}{*}{\multicolumn{4}{|c|}{ Tipo de cirurgia }} & \multicolumn{2}{|c|}{ Engel } & \multirow{3}{*}{$\begin{array}{c}\text { Total } \\
157\end{array}$} \\
\hline & & & & \multirow{2}{*}{$\frac{1}{126}$} & \multirow{2}{*}{$\frac{\mathrm{II}, \mathrm{III}, \mathrm{IV}}{31}$} & \\
\hline \multirow{8}{*}{$\begin{array}{c}\text { Resseca } \\
\text { polo }\end{array}$} & \multirow{8}{*}{ Exper } & \multirow{2}{*}{$1994-2000$} & $\mathrm{~N}$ & & & \\
\hline & & & $\%$ & $80,3 \%$ & $19,7 \%$ & $100,0 \%$ \\
\hline & & \multirow{2}{*}{ 2001-2006 } & $\mathrm{N}$ & 97 & 23 & 120 \\
\hline & & & $\%$ & $80,8 \%$ & $19,2 \%$ & $100,0 \%$ \\
\hline & & \multirow{2}{*}{ 2007-2011 } & $\mathrm{N}$ & 56 & 22 & 78 \\
\hline & & & $\%$ & $71,8 \%$ & $28,2 \%$ & $100,0 \%$ \\
\hline & & \multirow{2}{*}{ Total } & $\mathrm{N}$ & 279 & 76 & 355 \\
\hline & & & $\%$ & $78,6 \%$ & $21,4 \%$ & $100,0 \%$ \\
\hline \multirow{8}{*}{$\begin{array}{c}\text { Preserva } \\
\text { polo }\end{array}$} & \multirow{8}{*}{ Exper } & \multirow[t]{2}{*}{$1994-2000$} & $\mathrm{~N}$ & 33 & 11 & 44 \\
\hline & & & $\%$ & $75,0 \%$ & $25,0 \%$ & $100,0 \%$ \\
\hline & & \multirow[t]{2}{*}{ 2001-2006 } & $\mathrm{N}$ & 86 & 30 & 116 \\
\hline & & & $\%$ & $74,1 \%$ & $25,9 \%$ & $100,0 \%$ \\
\hline & & \multirow[t]{3}{*}{ 2007-2011 } & $\mathrm{N}$ & 57 & 45 & 102 \\
\hline & & & $\%$ & $55,9 \%$ & $44,1 \%$ & $100,0 \%$ \\
\hline & & & $\mathrm{N}$ & 176 & 86 & 262 \\
\hline & & Total & $\%$ & $67,2 \%$ & $32,8 \%$ & $100,0 \%$ \\
\hline \multirow{8}{*}{ Total } & \multirow{6}{*}{ Exper } & \multirow{2}{*}{$1994-2000$} & $\mathrm{~N}$ & 159 & 42 & 201 \\
\hline & & & $\%$ & $79,1 \%$ & $20,9 \%$ & $100,0 \%$ \\
\hline & & \multirow{2}{*}{ 2001-2006 } & $\mathrm{N}$ & 183 & 53 & 236 \\
\hline & & & $\%$ & $77,5 \%$ & $22,5 \%$ & $100,0 \%$ \\
\hline & & \multirow{2}{*}{ 2007-2011 } & $\mathrm{N}$ & 113 & 67 & 180 \\
\hline & & & $\%$ & $62,8 \%$ & $37,2 \%$ & $100,0 \%$ \\
\hline & & \multirow{2}{*}{ Total } & $\mathrm{N}$ & 455 & 162 & 617 \\
\hline & & & $\%$ & $73,7 \%$ & $26,3 \%$ & $100,0 \%$ \\
\hline
\end{tabular}

Tabela 26. Tipo de cirurgia

\begin{tabular}{lcc}
\hline Tipo de cirurgia & Qui-quadrado & Significância "p" \\
\hline Preservação do polo temporal & 2,758 & 0,252 \\
Ressecção do polo temporal & 9,671 & $0,008^{*}$ \\
\hline
\end{tabular}

Sobre experiência dos dados pré-operatórios (lateralização ictal, EEG interictal e EEG ictal) em relação ao prognóstico cirúrgico, não houve diferença significativa entre as épocas. 


\subsubsection{Reoperação}

Dos 621 pacientes, 23 foram reoperados (3,7\%; IC 95\%: 2,4-5,5). Desses, 12 (52,2\%; IC 95\% 30,6-73,2), ficaram livres de crises (Engel I). Houve uma diferença significativa em relação ao melhor prognóstico dos pacientes que não reoperaram $(74,4 \%)$ em relação aos pacientes que reoperaram $(52,2 \%)$, com valor de $p=0,027^{*}$.

Tabela 27. Reoperação * Engel

\begin{tabular}{|c|c|c|c|c|}
\hline & \multicolumn{2}{|c|}{ Engel } & \multirow{2}{*}{ Total } \\
\hline & & I & II,III,IV & \\
\hline \multirow{4}{*}{ Reop } & $\mathrm{N}$ & 445 & 153 & 598 \\
\hline & $\%$ & $74,4 \%$ & $25,6 \%$ & $100,0 \%$ \\
\hline & $\mathrm{N}$ & 12 & 11 & 23 \\
\hline & $\%$ & $52,2 \%$ & $47,8 \%$ & $100,0 \%$ \\
\hline \multirow{2}{*}{ Total } & $\mathrm{N}$ & 457 & 164 & 621 \\
\hline & $\%$ & $73,6 \%$ & $26,4 \%$ & $100,0 \%$ \\
\hline
\end{tabular}

Qui-quadrado: 5,637; $p=0,027^{*}$

\subsection{Resultados não significativos}

Destacarei algumas variáveis que classicamente são conhecidas por influenciarem no prognóstico, mas que em nosso trabalho não foram significativas, ou seja, não influenciaram no prognóstico, como por exemplo:

a) RNM com EMT unilateral versus EMT bilateral;

b) aura epigástrica;

c) presença de descargas interictais bilaterais ou contralaterais ou extratemporais;

d) atraso no desenvolvimento neuropsicomotor e quociente intelectual baixo;

e) história de crises tônico-clônico generalizadas frequentes;

f) idade na cirurgia;

g) tempo de epilepsia e idade na cirurgia; 
Destacarei aqui outras variáveis estudadas que também não foram significativas em relação ao prognóstico cirúrgico:

a) sexo;

b) presença de NCC;

c) crise prolongada não febril;

d) status epilepticus;

e) TCE;

f) complicações obstétricas;

g) história de crise febril na família;

h) história familiar de epilepsia;

i) déficit neurológico focal prévio;

j) diversas auras como: Afetiva, autonômica, sensitiva, visual, gustativa, cefálica, vertiginosa, auditiva, afásica, psíquica;

k) grupos de auras: aura temporal mesial, temporal lateral, extratemporal e inespecíficas;

I) frequência de crises epilépticas antes da cirurgia;

m) sinais de lateralização ictal;

n) atividade de base interictal;

o) EEG ictal

p) ter realizado avaliação invasiva com eletrodos profundos ou subdurais, ou semi-invasiva com eletrodos de forame oval.

q) lado da cirurgia; 
Tabela 28. RESUMO DA SIGNIFICÂNCIA "p"

\begin{tabular}{|c|c|c|}
\hline Variável & Qui-quadrado & $\begin{array}{l}\text { "p" Sig exata-Teste } \\
\text { exato de fisher }\end{array}$ \\
\hline Sexo & 0,002 & 1,000 \\
\hline RNM & 0,606 & 0,436 \\
\hline NCC & 0,526 & 0,556 \\
\hline CNF & 0,266 & 0,662 \\
\hline CF & 4,316 & $0,047^{*}$ \\
\hline SE & 0,344 & 0,605 \\
\hline Status na evolução & 0,194 & 0,818 \\
\hline TCE & 0,272 & 0,722 \\
\hline $\mathrm{CO}$ & 0,071 & 0,811 \\
\hline DNPM & 0,481 & 0,488 \\
\hline CFFam & 2,135 & $0,152^{*}$ \\
\hline HFE & 0,657 & 0,466 \\
\hline DNF & 1,461 & 0,240 \\
\hline HCTCGfreq & 0,807 & 0,464 \\
\hline Slict & 1,305 & 0,521 \\
\hline Aura epigástrica & 0,324 & 0,573 \\
\hline Aura Afetiva & 0,664 & 0,464 \\
\hline Aura dismnéstica & 6,741 & $0,02^{*}$ \\
\hline Aura autonômica & 0,706 & 0,528 \\
\hline Aura Sensitiva & 1,777 & 0,260 \\
\hline Aura visual & 0,272 & 0,701 \\
\hline Aura gustativa & 0,004 & 1,000 \\
\hline Aura olfativa & 5,711 & $0,03^{*}$ \\
\hline Aura cefálica & 0,007 & 1,000 \\
\hline Aura vertiginosa & 0,026 & 1,000 \\
\hline Aura auditiva & 0,090 & 1,000 \\
\hline Aura afásica & 2,883 & 0,258 \\
\hline Aura temporal mesial & 0,256 & 0,627 \\
\hline Aura temporal lateral & 0,670 & 0,816 \\
\hline Extratemporal & 0,540 & 0,980 \\
\hline Inespecífica / cefálica & 0,290 & 0,601 \\
\hline Freq crises & 3,836 & 0,280 \\
\hline$A B$ & 0,005 & 0,944 \\
\hline EEG interictal & 1,774 & 0,408 \\
\hline EEG ictal & 0,937 & 0,642 \\
\hline $\mathrm{TC}+\mathrm{NCC}$ & 0,103 & 0,748 \\
\hline Invasivo & 1,112 & 0,303 \\
\hline FO & 0,627 & 0,495 \\
\hline Invasivo não FO & 0,457 & 0,587 \\
\hline Tipo de cirurgia & 10,146 & $0,002^{*}$ \\
\hline Lado da cirurgia & 0,087 & 0,767 \\
\hline Idade de início epilepsia & Teste - T & $0,005^{*}$ \\
\hline QIG & Teste - T & 0,746 \\
\hline Tempo de epilepsia & Teste - T & 0,989 \\
\hline Idade na cirurgia & Teste - T & 0,648 \\
\hline Tempo de segmento & Teste - T & 0,14 \\
\hline
\end{tabular}




\subsection{Regressão Logística Binária}

Foram incluídas no modelo inicial as variáveis com valor de $p<0,2$ :

a) convulsão febril, $p=0,047$;

b) convulsão febril na família, $p=0,152$;

c) aura dismnéstica, $p=0,02$;

d) aura olfativa, $p=0,03$;

e) tipo de cirurgia, $p=0,002$;

f) idade de início epilepsia, $p=0,005$.

Não incluímos a experiência do serviço no modelo, apesar de o valor de "p" ser significativo, pois não teria relevância prática futura.

Após o cálculo do modelo inicial, foram excluídas as variáveis "convulsão febril na família" e "idade de início da epilepsia" em que o valor de "p" foi maior do que 0,05. No modelo final foram incluídas as seguintes variáveis: tipo de cirurgia, crise febril, aura olfatória e aura dismnésica.

Esse modelo foi criado com 520 pacientes do nosso banco de dados e os outros 101 pacientes do mesmo banco foram usados como testar e validar o modelo. Selecionamos os casos por ordem alfabética.

Tabela 29. Variáveis na equação

95\% C.I. para

B S.E. Wald df Sig. $\operatorname{Exp}(B) \quad \operatorname{EXP}(B)$ Inferior Superior

\begin{tabular}{|c|c|c|c|c|c|c|c|c|c|}
\hline \multirow{5}{*}{$\begin{array}{c}\text { Passc } \\
1^{a}\end{array}$} & Tipo cirurg(1) &,- 592 & ,211 & 7,872 & 1 & ,005 & ,553 & ,366 & ,836 \\
\hline & Auradism(1) & $-1,114$ & , 570 & 3,817 & 1 & ,051 & , 328 & , 107 & 1,004 \\
\hline & $\mathrm{CF}(1)$ & ,473 & ,233 & 4,116 & 1 & ,042 & 1,605 & 1,016 & 2,535 \\
\hline & Auraolf(1) & $-1,986$ & , 865 & 5,275 & 1 & ,022 & , 137 & ,025 & ,747 \\
\hline & Constante & 1,288 & 162 & 63,387 & 1 & , 000 & 3,627 & & \\
\hline
\end{tabular}


Através desse modelo, criamos a seguinte fórmula:

$$
P(y)=\frac{1}{\left\{1+e^{-\left[1,288+\left(-0,592^{\star} P P T\right)+\left(-1,114^{*} A D\right)+\left(0,473^{*} C F\right)+\left(-1,986^{*} A O\right)\right]}\right\}}
$$

Onde $\mathrm{P}(\mathrm{y})$ = probabilidade de $(\mathrm{y})$ ocorrer, ou seja, probabilidade do paciente ficar livre de crises (Engel I)

$\mathrm{e}=$ constante logaritmo natural $=2,718$;

PPT = cirurgia que preserva o polo temporal;

$A D$ = aura dismnésica;

$\mathrm{CF}=$ crise febril;

$\mathrm{AO}=$ aura olfatória;

Em que os coeficientes são: $\quad 0$ = ausência do fator

$1=$ presença do fator

Após, calculamos essa probabilidade para os 101 pacientes "teste" e verificamos que o modelo acertou em $67,3 \%$ das vezes, ou seja, esse modelo é válido e tem alta capacidade de predizer a probabilidade do paciente ficar livre de crises, quando a probabilidade encontrada é alta (maior que $70 \%$ ). No entanto, quando essa probabilidade é baixa (menor que 50\%), a chance de erro é maior. 
Gráfico 1. Proporção Observada X Probabilidade Predita

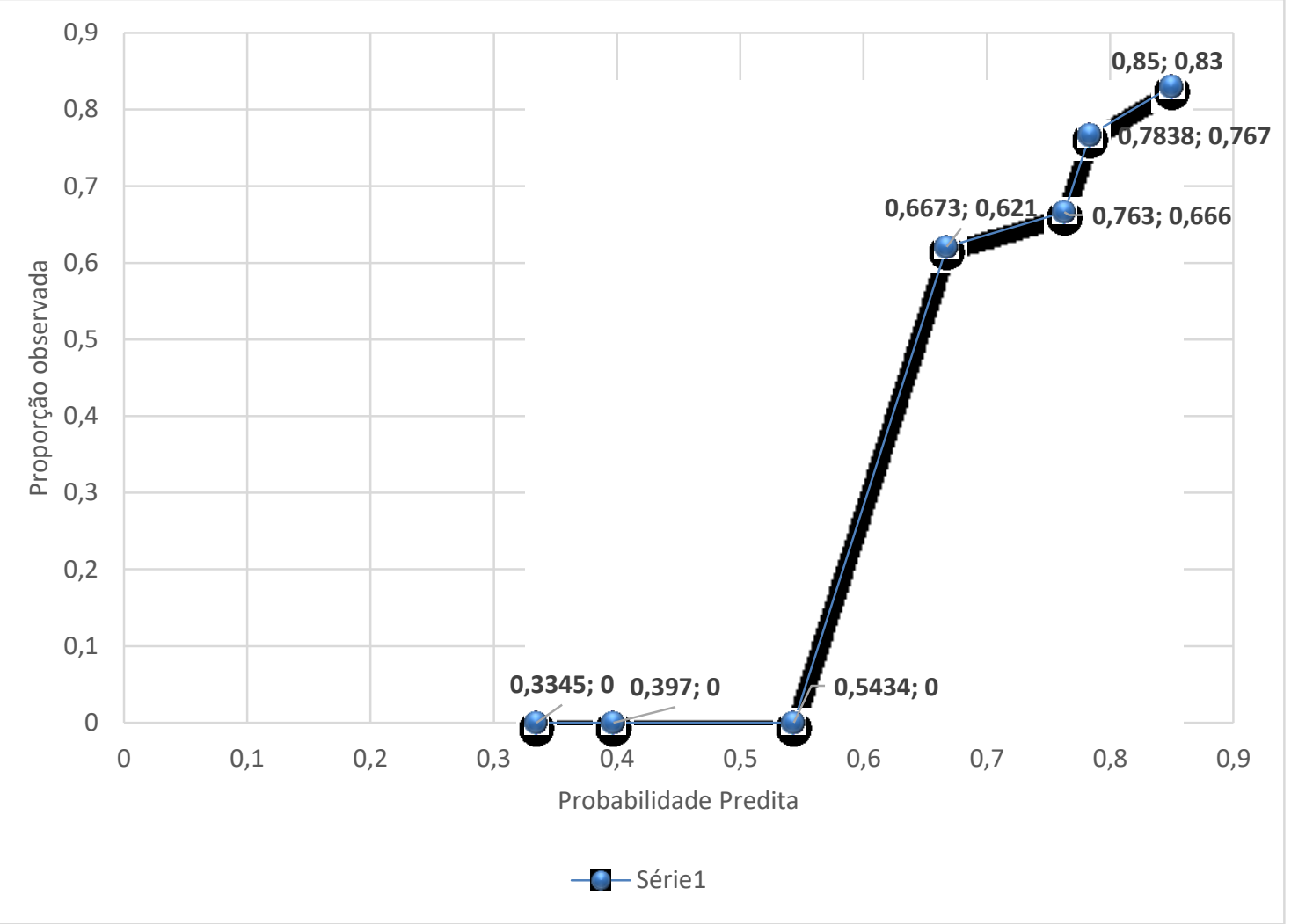

\subsection{Curva de prognóstico relacionada ao tempo}

Para a variável dependente tempo, observamos o tempo (em meses) que o paciente leva para recorrer de crises no pós-operatório.

A seguir apresentarei a curva de Kaplan-Meier, na qual a recidiva de crises epilépticas é o evento que representa a sobrevida.

No tempo de segmento clínico entre 250 e 300 meses (20 a 25 anos, aproximadamente), observa-se na curva uma sobrevida de aproximadamente $65 \%$, ou seja, após 20 a 25 anos de acompanhamento clínico, 65\% dos pacientes estavam livres de crises epilépticas.

\section{Kaplan-Meier}

\begin{tabular}{|l|l|l|l|}
\hline \multirow{2}{*}{$N$ total } & \multirow{2}{*}{$N$ de Eventos } & \multicolumn{2}{|l|}{ Censurado } \\
\cline { 3 - 4 } & $\mathrm{N}$ & Porcentagem \\
\hline 621 & 164 & 457 & $\mathbf{7 3 , 6 \%}$ \\
\hline
\end{tabular}


Gráfico 2. Curva de sobrevivência

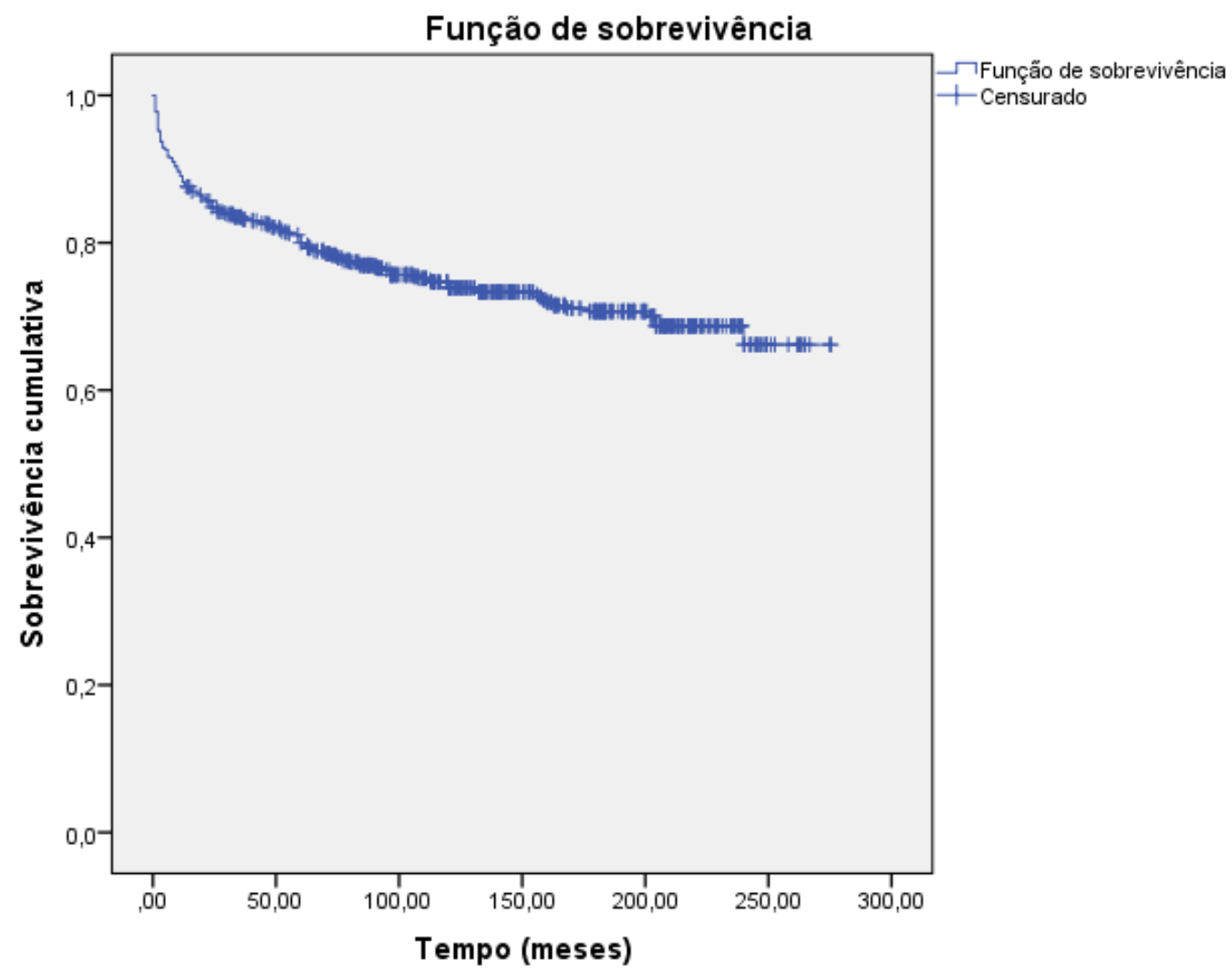

$\mathrm{Na}$ análise da curva Kaplan-Meier com o fator "tipo de cirurgia", observa-se que para os pacientes que realizaram cirurgia com ressecção do polo temporal, a sobrevida em 250 a 300 meses, foi maior que $70 \%$. Já para os pacientes que foram submetidos a cirurgia que preserva o polo temporal a sobrevida foi menor que $60 \%$, para o mesmo período de tempo.

O gráfico do risco, confirma esses achados, mostrando que os pacientes que realizaram cirurgia que preserva o polo temporal tiveram maior risco de recidiva, do que os pacientes que foram submetidos a cirurgia que resseca o polo temporal.

Como os valores foram significativos nas três análises (LogRank, Breslow e Tarone-Ware), podemos assumir que em todo o período de observação, houve diferença significativa entre os grupos dos tipos de cirurgia e os riscos são proporcionais.

As censuras ocorreram de forma homogênea durante todo o período de observação. 
Tabela 37. Tipo de Cirurgia em relação à recidiva (evento)

\begin{tabular}{ccccc}
\hline Tipo de Cirurgia & N total & N evento & N & Porcentagem \\
\hline Ressecção do polo temporal & 355 & 76 & 279 & $78,6 \%$ \\
$\begin{array}{c}\text { Preservação do polo } \\
\text { temporal } \\
\text { Geral }\end{array}$ & 262 & 86 & 176 & $67,2 \%$ \\
\hline
\end{tabular}

Tabela 38. Comparações globais

\begin{tabular}{cccc}
\hline & Qui-quadrado & gl & Sig. \\
\hline Log Rank (Mantel-Cox) & 11,898 & 1 &, 001 \\
Breslow (Generalized Wilcoxon) & 9,116 & 1 &, 003 \\
Tarone-Ware & 10,388 & 1 &, 001
\end{tabular}

Teste de igualdade de distribuições de sobrevivência para os diferentes níveis de tipo de cirurgia.

Gráfico 3. Funções de Sobrevivência Cumulativa em relação ao tipo de cirurgia

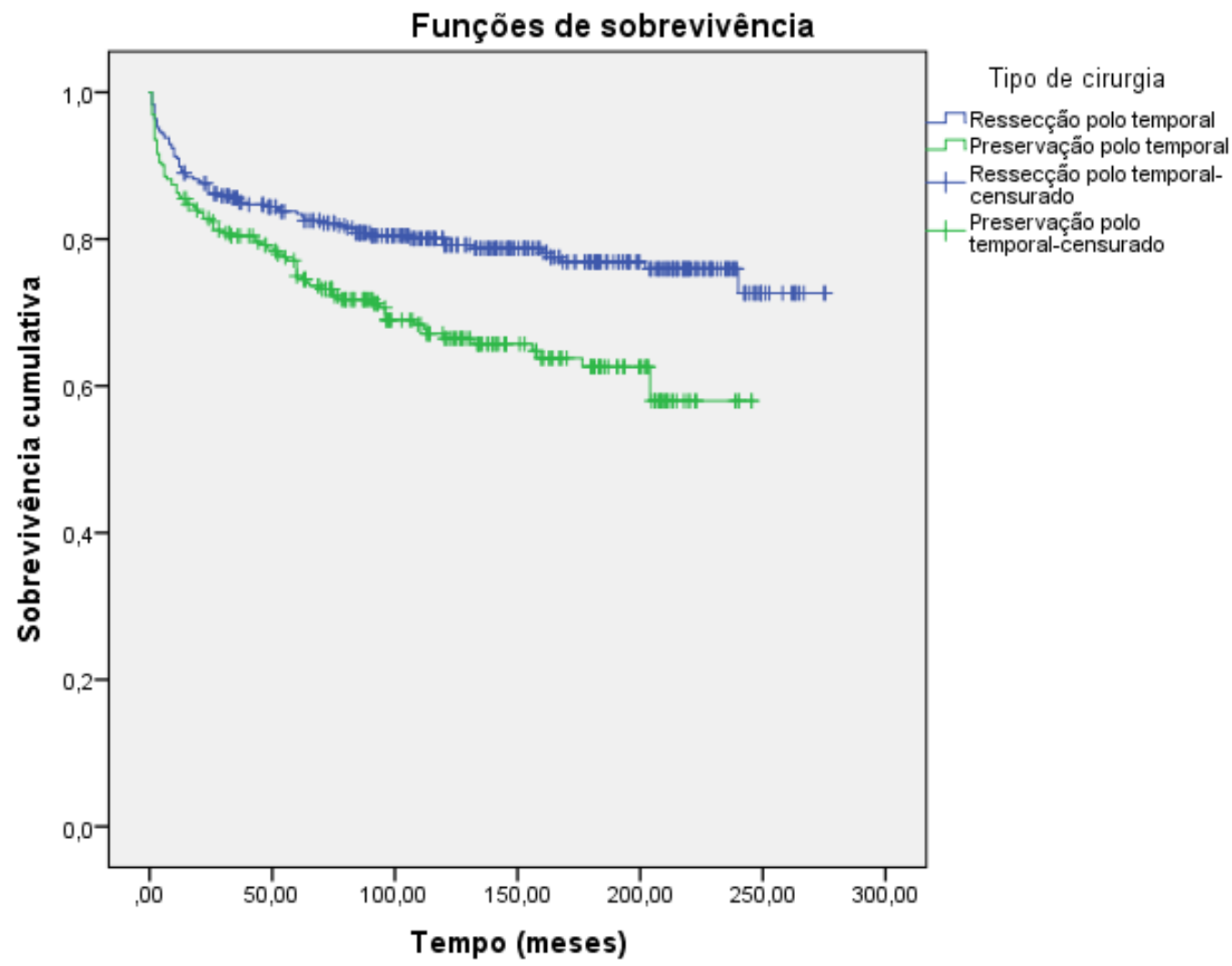


Gráfico 4. Risco Cumulativo em relação ao tipo de cirurgia

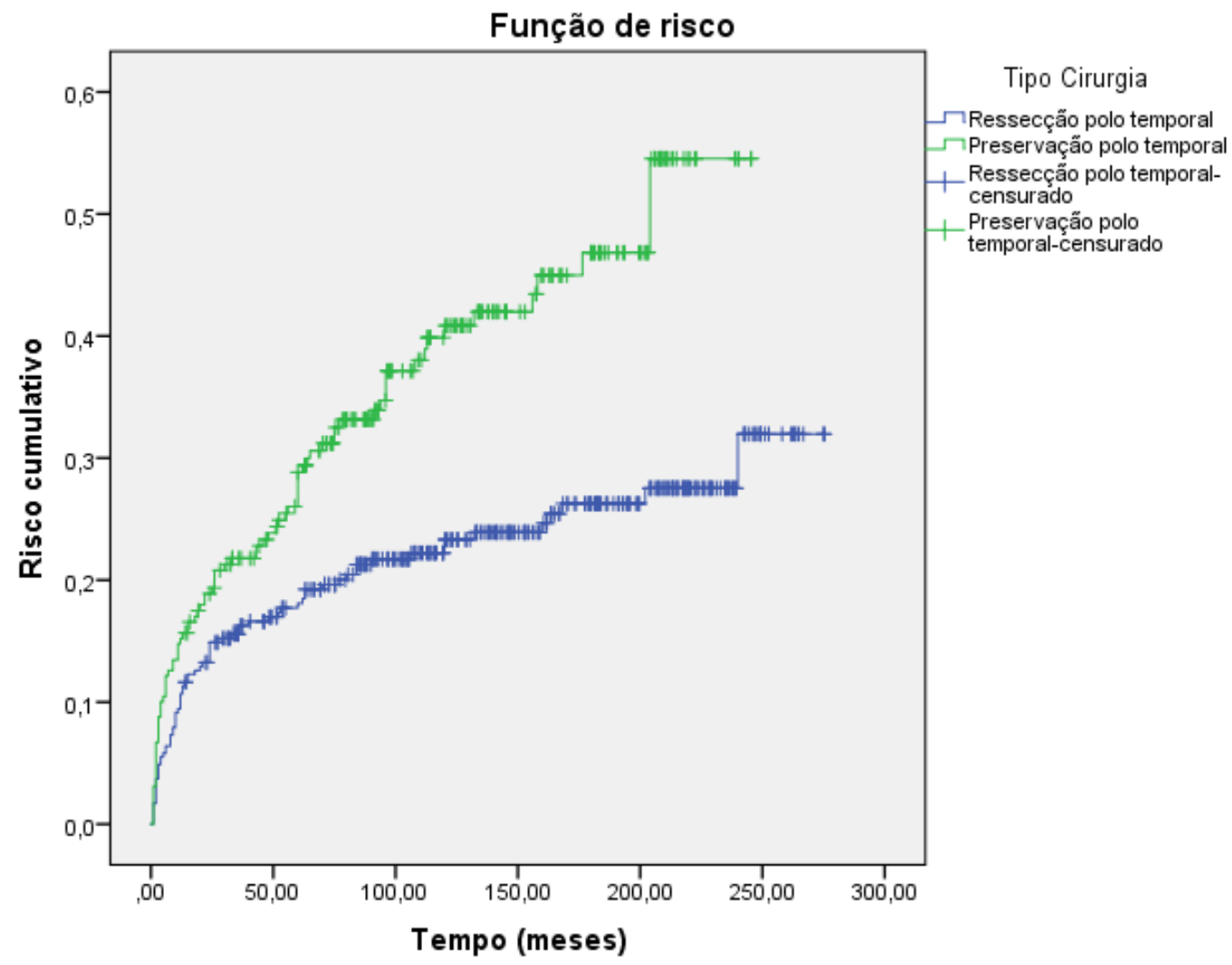




\section{Discussão}

\subsection{Homogeneidade do grupo}

Selecionamos para o nosso estudo um grupo homogêneo de 621 pacientes, desde o início da cirurgia de epilepsia no CIREP, de 1994 até 2011. Selecionamos os pacientes que tinham história clínica sugestiva de epilepsia do lobo temporal, neurofisiologia compatível, RNM com EMT unilateral ou bilateral e que no anatomopatológico foi confirmada esclerose hipocampal. Para esse primeiro estudo, optamos por analisar essa amostra homogênea e depois em um segundo estudo futuro comparar com outras etiologias, podendo assim avaliar a experiência do nosso serviço desde o início e comparar com os achados previamente descritos na literatura.

Todos os pacientes foram operados por apenas 2 cirurgiões e o grupo de neurofisiologistas sêniores é o mesmo desde o início até os dias de hoje.

\subsection{Prognóstico cirúrgico}

Já é classicamente conhecido na literatura mundial que a cirurgia de epilepsia é um tratamento eficaz para os pacientes com EMLT unilateral associada a $\mathrm{EH}$. Em um primeiro estudo controlado e randomizado (WIEBE et al., 2001), observaram que $58 \%$ dos pacientes do grupo que realizou a cirurgia, ficaram livres de crises com alteração da consciência (Engel I) por um ano de acompanhamento clínico, em comparação com apenas $8 \%$ dos pacientes do grupo farmacológico. Em segundo estudo randomizado (ENGEL, 2012b), 73,3\% dos pacientes do grupo que realizou a lobectomia temporal ficaram livres de crises com alteração da consciência (Engel I) por um período mínimo de acompanhamento de 2 anos, enquanto nenhum dos pacientes do grupo farmacológico, atingiu este objetivo.

Em um outro estudo de prognóstico a longo prazo para cirurgia de epilepsia do lobo temporal em pacientes com $\mathrm{EH}$, foi observado que a probabilidade do paciente manter-se livre de crises com alteração da consciência (Engel I) em 12 a 18 anos, foi de 77\% (HEMB et al., 2013). Baseado em uma revisão sistemática da literatura, recomenda-se que os benefícios da lobectomia temporal para $\mathrm{EH}$, são superiores aos do tratamento clínico e que os pacientes com EMLT-EH farmacorresistentes, devem 
ser encaminhados para um centro de cirurgia de epilepsia para avaliação (ENGEL et al., 2003).

No presente estudo, encontramos dados semelhantes aos da literatura. Avaliamos todas as lobectomias temporais associadas a $\mathrm{EH}$, realizadas em nosso serviço entre os anos de 1994 até 2011. Realizamos o acompanhamento clínico desses pacientes por até 23 anos, com média de 11,6 anos $( \pm 5,3)$ e encontramos que na última visita (consulta) ambulatorial, $\mathbf{7 3 , 6} \%$ dos pacientes estavam livres de crises com alteração da consciência (Engel I) e $\mathbf{8 4 , 7 \%}$ tiveram um bom prognóstico cirúrgico (Engel I + II).

Em nosso centro adotamos como critério geral para classificar o paciente como Engel II, a presença de até 2 crises com alteração da consciência por ano, pois o conceito de melhora de mais de $90 \%$ pode ser subjetivo. Fomos rigorosos ao classificar o paciente como Engel II, assim esse grupo de pacientes ficou mais restrito do que o grupo de Engel III. Engel II, é um grupo de transição entre Engel I e Engel III, pois de acordo com o momento do contato com o paciente ele poderá ter mudado de grupo.

Observamos que ao longo do tempo, através da curva de Kaplan-Meier, o bom prognóstico foi relativamente mantido. Entre 20 a 23 anos de acompanhamento clínico, $65 \%$ dos pacientes estavam livres de crises epilépticas.

\subsection{Fatores Preditores do Prognóstico Cirúrgico}

\subsubsection{Prognóstico Cirúrgico X Tipo De Técnica Cirúrgica}

Encontramos uma diferença significativa em relação ao prognóstico no que se refere ao controle de crises pós-operatório entre a cirurgia que realiza a ressecção do polo temporal, com significativo melhor prognóstico $(\mathbf{7 8 , 6 \%}$ dos pacientes livres de crises - Engel I), contra a cirurgia que preserva o polo temporal $(67,2 \%$ dos pacientes livres de crises - Engel I) $\left(\mathbf{p}=\mathbf{0 , 0 0 2 ^ { * }}\right)$.

Em uma meta-análise realizada em 2013, com 745 pacientes que realizaram amígdalo-hipocampectomia seletiva (AHS) e 766 que realizaram lobectomia temporal anterior (LTA), foi demonstrada uma redução significativa da chance de ficar livre de crises nos pacientes que realizaram AHS, comparados com os pacientes que realizaram LTA [OR $0.65(95 \% \mathrm{Cl}$ 0.51-0.82), $\mathrm{p}=0.0005]$ e não foi encontrada 
diferença significativa em relação ao quociente intelectual pós-operatório de ambos os tipos de cirurgia (HU et al., 2013).

Em uma outra meta-análise realizada por Dr. Josephson e colaboradores em 2013, com 583 pacientes que realizaram AHS e 620 que realizaram LTA, também foram encontrados resultados estatisticamente significativos em favor dos pacientes que realizaram LTA. Ou seja, os pacientes que realizaram LTA tiveram uma probabilidade maior de manterem-se livres de crises (Engel I) em relação aos pacientes que realizaram AHS (JOSEPHSON et al., 2013).

Arruda e colaboradores, avaliaram 74 pacientes com EMLT com EH unilateral, EH bilateral e sem atrofia hipocampal na RNM de encéfalo, e compararam o prognóstico cirúrgico de dois grupos: grupo 1: 37 pacientes que realizaram AHS; grupo 2: 37 pacientes que realizaram LTA. Concluiu-se que não houve diferença significativa em relação ao prognóstico cirúrgico de ambos os tipos de cirurgia $(p>0,8)$, com distribuição homogênea dos diferentes achados da RNM entre os grupos (ARRUDA et al., 1996).

Em outro estudo conduzido por um grupo do Canadá (BOUCHER et al., 2015), o prognóstico cirúrgico de 39 pacientes que realizaram AHS, foi avaliado durante 6 meses, em comparação com o dobro de pacientes que realizaram LTA. Foi observado que não houve diferença estatística entre os grupos, com resultados de 92,3\% e 96 $\%$ de Engel classe I, respectivamente ( $p=0.629)$.

Em um estudo de prognóstico a longo prazo, realizado em 2013 pelo grupo de Porto Alegre, não foi observado impacto no prognóstico em relação às mesmas técnicas cirúrgicas (HEMB et al., 2013).

Outro estudo de prognóstico cirúrgico a longo prazo em pacientes com EMLTEH conduzido por um grupo francês, também não foi encontrada diferença significativa entre os pacientes que realizaram LTA, AHS trans-silviana e AHS transcortical $(p=0,94)$, com pior desfecho cognitivo nos pacientes que realizaram LTA, do que nos que realizaram AHS (MATHON et al., 2017).

Alguns estudos mostram dados semelhantes aos nossos e outros mostram similaridade em relação ao prognóstico do controle de crises entre os procedimentos cirúrgicos mais ou menos amplos. Embora nenhum desses estudos tenha avaliado especificamente o tipo de cirurgia estudada aqui (preservação do polo temporal exclusivamente), tentamos correlacionar os nossos dados com os encontrados na literatura, mas ainda não há um consenso sobre esse assunto. 
Vários grupos têm estudado a importância do córtex têmporo-polar na gênese das crises do lobo temporal (ABEL et al., 2017). A falha do tratamento da AHS, sugere que as crises chamadas de "mesiais-temporais" nem sempre se iniciam no complexo amígdalo-hipocampo-parahipocampo. A zona epileptogênica pode se estender além das estruturas temporais mesiais. O polo temporal, é uma estrutura paralímbica que está fortemente conectada com a amígdala, hipocampo, giro parahipocampal, giro cingulado, córtex orbito-frontal e ínsula. Alguns estudos têm demonstrado que mesmo com a presença de esclerose hipocampal, a região têmporo-polar está frequentemente alterada, tanto histologicamente / anatomicamente, quanto funcionalmente (CHABARDĖS et al., 2005). Chassoux e colaboradores reportaram um subgrupo de pacientes com EMLT em que no PET, o hipometabolismo não estava apenas limitado ao hipocampo, mas também ao polo temporal e ínsula (CHASSOUX et al., 2004).

Em um estudo sobre o envolvimento do córtex têmporo-polar nas crises do lobo temporal, foram avaliados por stereo EEG (SEEG) 48 pacientes com ELT. Na neuroimagem desses 48 pacientes, 56\% tinham EMLT-EH, 25\% outras lesões (tumores, tumores de baixo grau e displasias) e 17\% RNM normal, sendo que de todos esses $37,5 \%$ tinham alterações no polo temporal. Na avaliação neurofisiológica com SEEG, concluiu-se que em $48 \%$ dos casos o polo temporal estava envolvido no início das crises e $52 \%$ tinham envolvimento tardio do polo temporal; em $35 \%$ dos pacientes com EMLT-EH as crises se iniciaram no polo temporal. Foram comparados os grupos I (no qual as crises se iniciavam no polo temporal) e o grupo II (no qual as crises tinham início no hipocampo), mesmo tendo sido realizada a mesma abordagem cirúrgica em ambos os grupos (LTA). Os melhores resultados de prognóstico foram alcançados no grupo I, 95\% dos pacientes - Engel I. Já no grupo 2, 72\% dos pacientes - Engel I. Foi levantada a hipótese de que as crises que têm início no polo temporal se propagavam para o giro temporal superior (que geralmente é ressecado na LTA) e córtex peri-silviano, enquanto as crises que se iniciam na região mesial se propagavam mais facilmente para o córtex orbito-frontal e córtex temporal lateral. Concluiu-se que o envolvimento do córtex têmporo-polar no início das crises pode ser a explicação para a falha da AHS em alguns casos (CHABARDĖS et al., 2005).

Esses dados em relação às conexões do córtex têmporo-polar com o hipocampo e o maior volume de tecido ressecado, tanto das estruturas mesiais quanto do neocórtex, poderiam explicar o melhor prognóstico encontrado nos nossos casos 
em que foi realizada uma cirurgia mais ampla, como a lobectomia temporal anteromesial que resseca o polo temporal.

Em um estudo recente realizado no CIREP/HCFMRP-USP em 2018, comparou-se o prognóstico cognitivo de 146 pacientes entre os anos de 2006 a 2012 com diagnóstico EMLT-EH do lado esquerdo que realizaram cirurgia que resseca o polo temporal em relação aos pacientes que realizaram cirurgia com preservação do polo temporal. Encontraram que tanto a lobectomia temporal com ressecção quanto com preservação do polo temporal acarretou em declínio de memória episódica verbal. Nesses pacientes, a cirurgia com ressecção do polo acarretou em um pior prognóstico cognitivo com relevância clínica no teste de nomeação por confronto visual, quando comparado ao grupo com preservação do polo. Também encontrou que a lobectomia temporal esquerda com ressecção do polo obteve um melhor prognóstico de controle de crises do que o com preservação do polo temporal. Esses dados são importantes no momento da avaliação pré-cirúrgica, quando o paciente tem o perfil cognitivo preservado, especialmente no que se refere a nomeação, para a decisão sobre o tipo de cirurgia a ser realizada, para orientar o paciente em relação ao possível prognóstico pós-operatório tanto cognitivo quanto do controle de crises, também para orientar sobre uma possível reoperação nos casos selecionados para a cirurgia mais econômica (GARGARO-SILVA, 2019)

\subsubsection{Reoperação}

Em nosso estudo, dos 621 pacientes, 23 (3,7\%) foram reoperados para ampliação da lobectomia temporal. Desses, 12 (52,2\%), ficaram livres de crises (Engel I). Quando analisamos um bom prognóstico cirúrgico, 65,3 \% foram classificados como Engel I + II.

Dos 23 pacientes que reoperaram, 18 (78\%) tinham realizado inicialmente a cirurgia que preserva o polo temporal e desses 50 \% ficaram livres de crises após a segunda cirurgia.

Em 2011, um grupo de Viena analisou 10 pacientes em que houve falha no controle de crises após AHS e comparou com 10 pacientes que realizaram a mesma cirurgia e ficaram livres de crises. Foi encontrado na RNM pós-operatória tecido residual do córtex entorrinal em 9 de 10 pacientes do grupo estudado e em nenhum paciente do grupo controle. Após a reoperação, com remoção das estruturas mesiais 
residuais e do neocórtex temporal, 8 em 10 pacientes ficaram completamente livres de crises, o que sugere que as estruturas mesiais residuais e a incompleta ressecção do córtex entorrinal pode estar relacionada à falha da AHS. Esse estudo confirma que a reoperação é um tratamento efetivo para os pacientes com recorrência de crises após AHS (ZACHENHOFER et al., 2011).

Em outro estudo realizado na Alemanha em 2016, foi avaliada a performance neuropsicológica após a realização subsequente de LTAM em pacientes nos quais a AHS inicial falhou em controlar as crises. Observou-se que os dados neuropsicológicos dos pacientes que reoperaram, quando comparados com o grupo controle (aqueles que realizaram somente a AHS), não foram significativamente diferentes, ou seja, a performance neuropsicológica geral após a segunda cirurgia não foi afetada, exceto a memória verbal que teve um significativo declínio nos pacientes que realizaram a ampliação cirúrgica no hemisfério dominante. Também foi constatado uma melhora significativa do prognóstico cirúrgico após a segunda cirurgia, onde $69,2 \%$ dos pacientes ficaram livres de crises debilitantes (Engel I). Concluiu-se que o risco de declínio neuropsicológico após a segunda cirurgia foi baixo e que a melhora no controle de crises após a segunda cirurgia teve influência positiva na performance cognitiva. Este pode ser um critério valioso para aconselhar os pacientes elegíveis para uma segunda cirurgia em relação aos riscos de déficits cognitivos (SAUVIGNY et al., 2016). Isso pode ter ocorrido, pelo fato de o paciente já ter algum grau de déficit cognitivo prévio antes da primeira cirurgia e as estruturas ressecadas na ampliação da segunda cirurgia já apresentarem alteração funcional.

\subsubsection{Esclerose Mesial Temporal Unilateral versus Bilateral}

Sabe-se que aproximadamente $20 \%$ dos pacientes com EMLT terão EH bilateral (QUIGG et al., 1997), ou algum grau de alteração volumétrica do hipocampo contralateral (ARAÚJO et al., 2006). Em um estudo já citado acima de Arruda e colaboradores (1966), foi observado que os pacientes com EMT unilateral tiveram significativo melhor prognóstico cirúrgico (Engel I: $85.1 \%$ ) em relação aos pacientes com EMT bilateral (Engel | 47.1\%), com valor de $p<0,001$, mesmo tendo sido realizada avaliação invasiva e independentemente do tipo da técnica cirúrgica adotada (ARRUDA et al., 1996). 
Em nosso estudo o número de pacientes no grupo com EMT unilateral, foi significativamente maior, 96,6\% ( $n=600)$, enquanto que o grupo com EMT bilateral foi bem menor, 3,3\% ( $n=21)$. Não observamos diferença significativa em relação ao prognóstico cirúrgico entre os grupos de pacientes com EMT unilateral versus bilateral, independentemente do tipo cirúrgico. Acreditamos que os pacientes com EMT bilateral os quais durante a avaliação neurofisiológica de superfície o EEG ictal foi bilateral ou duvidoso foram para avaliação invasiva (SEEG ou eletrodos subdurais) ou semi-invasiva (eletrodos de forame oval). Nesses casos, a avaliação invasiva foi lateralizatória e localizatória e os pacientes foram para a cirurgia. Nos casos que a avaliação invasiva foi bilateral ou duvidosa, a cirurgia foi contra-indicada. Sendo assim, nosso " $n$ " de pacientes com EMT bilateral que operaram foi baixo, pois provavelmente contraindicamos muitas cirurgias em que o EEG ictal da avaliação invasiva foi bilateral. Portanto, nosso prognóstico cirúrgico em relação a esses dois grupos, foi semelhante, pois na avaliação neurofisiológica pré-operatória conseguimos lateralizar e localizar a zona de início ictal.

\subsubsection{Experiência do Grupo X Prognóstico}

Analisamos a experiência do nosso serviço e dividimos em três épocas:

1) Época 1: dos anos de 1994 a 2000;

2) Época 2: de 2001 a 2009;

3) Época 3: de 2007 a 2011.

Observamos que a porcentagem de pacientes que ficou livre de crises (Engel I) foi diminuindo significativamente com o passar das épocas $(79,2 \%-77,0 \%-62,8 \%$, respectivamente), com $p=0,000^{*}$. Para aqueles que realizaram cirurgia com preservação do polo temporal (AHS), houve queda significativa da porcentagem de pacientes Engel I na época $3\left(75,0 \%-74,1 \%-55,9 \%\right.$, respectivamente, $\left.p=0,008^{*}\right)$, já para os que realizaram a LTAM essa diferença não foi significativa.

Ao longo dos anos, observamos que o número de pacientes com EMT que chegavam em nosso serviço era muito grande. Com o passar dos anos, essa fila foi diminuindo e o número de casos de EMTs que passaram a chegar foi ficando cada vez menor, sendo substituídos por casos cada vez mais complexos, como por exemplo epileptogênese bilateral ou "temporal plus" (achados extratemporais). Nos 
anos em que tínhamos muitos casos de EMTs, o critério para indicação de lobectomia temporal pode ter sido mais rigoroso e com o passar dos anos, nossa permissividade pode ter sido maior, devido a maior complexidade dos casos.

Um estudo com pacientes com EMLT demonstrou que mesmo naqueles em que foram registradas crises temporais bilaterais e independentes na avaliação com eletrodos intracranianos, foi oferecida cirurgia se pelo menos $50 \%$ das crises se iniciassem em um dos lobos temporais. Dois terços desses pacientes ficaram livres de crises após 4 anos (SIRVEN et al., 1997), o que sugere que mesmo nos casos bilaterais, pode ser tentada a cirurgia.

Já em relação aos achados clínicos de lateralização ictal e neurofisiológicos, esse percentual foi estável ao longo dos anos, mostrando que a equipe de neurofisiologistas manteve-se tecnicamente estável.

\subsubsection{Fatores Preditores do Prognóstico Cirúrgico}

\subsubsection{Crise Febril}

Os pacientes que relataram história de convulsão febril, apresentaram significativo melhor prognóstico, em relação ao grupo que negou esse fator. Esse dado já é classicamente conhecido na literatura, descrito por vários autores (TONINI et al., 2004; VICENTA SALANOVA, 1994). Porém outros estudos mostraram essa relação quando comparados casos de ELT-EH com ELT e RNM normal, considerando que nos casos de ELT-EH a história de crise febril é mais comum do que nos casos com RNM normal (ELSHARKAWY et al., 2009; TEZER et al., 2008).

A história familiar de epilepsia também foi relacionada a um bom prognóstico cirúrgico (ELSHARKAWY et al., 2009), porém em nosso estudo esse dado não foi relevante.

\subsubsection{Auras}

A aura epigástrica é classicamente conhecida na literatura por ser um fator de bom prognóstico cirúrgico nos casos de EMLT-EH, como ficou demonstrado em um estudo que avaliou a relação entre os diversos tipos de auras e o prognóstico cirúrgico 
de pacientes com ELT e encontrou que aqueles com aura epigástrica tiveram melhor prognóstico do que os que negaram aura (ASADI-POOYA et al., 2015).

Em nossa série de casos a aura epigástrica isoladamente não teve relevância significativa em relação ao prognóstico cirúrgico, muito provavelmente por que os nossos casos selecionados foram típicos para EMLT- EH uni ou bilateral e não foram incluídos casos com outras etiologias, o que poderia diferenciar os casos da síndrome clássica EMLT-EH.

Em nosso estudo a ausência de aura (negou aura), não apresentou diferença significativa em relação ao prognóstico cirúrgico, quando comparado com os casos com presença de aura epigástrica, por exemplo. A ausência de aura não sugere um pior prognóstico, pois a zona epileptogênica pode estar em uma área silente do córtex e quando atinge uma zona sintomatogênica, o paciente já está com alteração do nível de consciência ou com rápida generalização secundária.

Agrupamos os diversos tipos de aura de acordo com sua localização e de acordo com a Classificação das Crises epilépticas da ILAE (PENRY, 1981) em 4 grupos:

a) temporal mesial: afetiva, dismnésica, autonômica, epigástrica, olfatória e gustatória;

b) temporal lateral: aura vertiginosa e auditiva;

c) extratemporal: sômato-sensitiva, visual e disfásicas;

d) inespecíficas: sensações vagas e cefálicas.

Realizamos o teste do Qui-quadrado e avaliamos a relação entre os grupos de auras com o prognóstico cirúrgico. Observamos que não houve relação significativa entre os quatro grupos com o prognóstico cirúrgico. Fizemos essa análise com a intenção de aumentar o "n", agrupando os diversos tipos de auras, mas mesmo assim não houve significância estatística. Essa análise foi inspirada em um estudo, no qual foi avaliada a relação entre as auras na EMLT-EH com o prognóstico cirúrgico. Neste, verificou-se que apenas as auras extratemporais tiveram relação significativa com o pior prognóstico cirúrgico $\left(p=0,014^{*}\right)$ (FERRARI-MARINHO et al., 2012). Assim, sugere-se epileptogenicidade extratemporal e que os casos com esse tipo de aura devem ser avaliados com mais cautela para evitar ressecção incompleta da zona epileptogênica.

Como não encontramos diferença significativa entre os grupos de auras e o prognóstico cirúrgico, aventamos a hipótese de que a neurofisiologia foi superior para 
a localização da zona epileptogênica em relação a semiologia das crises epilépticas, pois somente operamos os casos os quais a neurofisiologia foi localizatória. Nos casos de aura extratemporal, a neurofisiologia foi soberana.

Isoladamente as auras que tiveram resultados significativos em relação a um pior prognóstico cirúrgico, foram as auras olfatória e dismnésica.

\subsection{Aura Olfatória}

Aura olfatória é um tipo relativamente incomum de aura e tem sido associada à epilepsia do lobo temporal ou do lobo frontal. É um sintoma caracterizado por alucinação ou ilusão olfativa, geralmente descrito por uma percepção de odor, que pode ser desagradável ou não, muitas vezes não relacionados ao ambiente. Esse tipo de aura pode estar presente em 0,6-16\% das epilepsias do lobo temporal (VAUGHAN; JACKSON, 2014).

O córtex olfatório primário é composto pelo córtex piriforme, pelo núcleo olfatório anterior, tubérculo olfatório, córtex periamigdalóide e pela parte anterior do córtex entorrinal, com suas relações (conexões) com o córtex orbitofrontal, tálamo e ínsula. O córtex piriforme, que está localizado entre o giro temporal superior e o frontal basal, recebe informações do bulbo olfatório e se comunica com o tálamo, (VAUGHAN; JACKSON, 2014).

Figura 17. Localização do córtex piriforme.
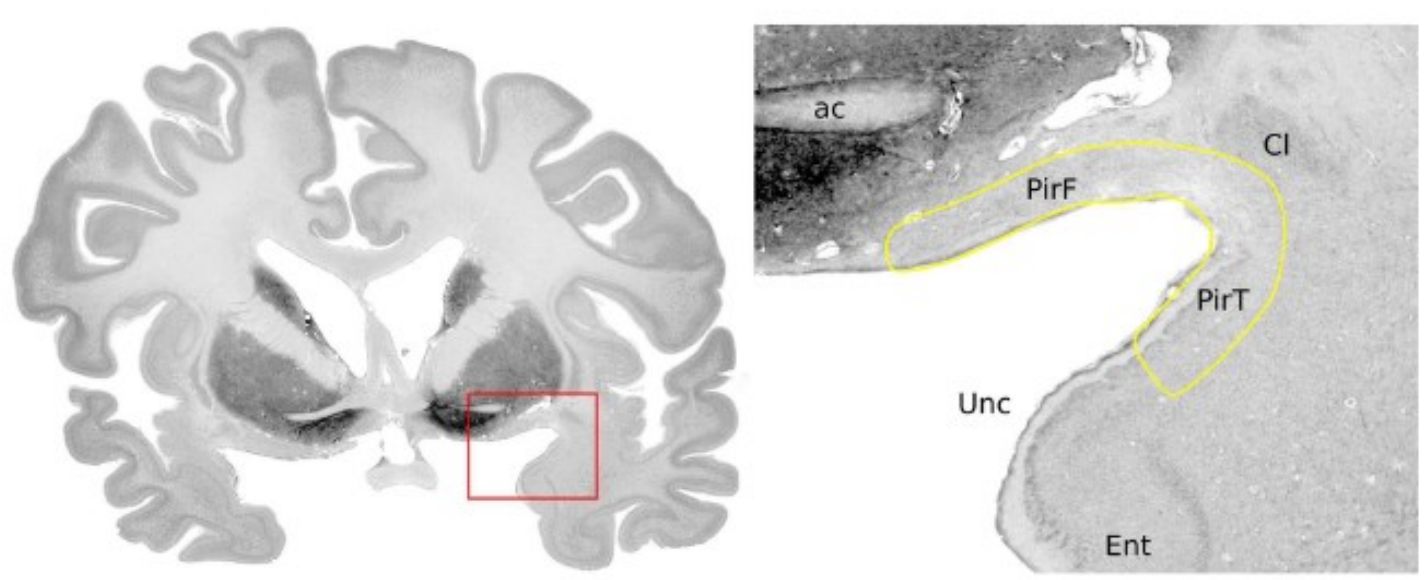

Fonte: (VAUGHAN; JACKSON, 2014). 
A aura olfatória pode estar associada com outros tipos de auras, por coestimulação de áreas adjacentes, como por exemplo estruturas límbicas. A ordem da progressão vai indicar a possível propagação da crise e sua zona sintomatogênica.

As etiologias de ELT mais comumente relacionadas com a aura olfatória são esclerose hipocampal e tumores (ASADI-POOYA et al., 2017). Nos pacientes com EMLT-EH, estudos de neuroimagem mostraram que pacientes com aura olfatória têm maior probabilidade de ter anormalidades na amígdala, o que sugere que a amígdala pode ser uma porta de entrada para a propagação das conexões olfatórias (VAN PAESSCHEN et al., 2001).

Áreas que estão relacionadas à produção de sensações olfatórias quando estimuladas são: amígdala, bulbo olfatório, córtex insular, córtex orbitofrontal e uncus (FOLDVARY-SCHAEFER; UNNWONGSE, 2011).

Em um estudo de prognóstico cirúrgico em pacientes com ELT, foram comparados dois grupos: no primeiro grupo, pacientes que relataram aura olfatória (32 casos $-3,8 \%$ ); no segundo grupo, pacientes que não relataram este sintoma, com 800 casos (grupo controle). Após 2 anos de acompanhamento clínico, observou-se que não houve diferença significativa entre o prognóstico cirúrgico de ambos os grupos, com $67 \%$ a $74 \%$ dos pacientes livres de crises epilépticas $(p=0,4)$ (ASADIPOOYA et al., 2017). Um outro estudo com 12 pacientes com aura olfatória, $8(66,7 \%)$ ficaram livres de crises (Engel I) e $3(25 \%)$ tiveram raras crises (Engel II). As principais etiologias foram lesões nas estruturas mesiais do lobo temporal, envolvendo a amígdala, alterações atróficas ou tumores (CHEN et al., 2003).

Em nosso estudo, 1,3 \% dos pacientes relataram aura olfatória, sendo que, dos 8 pacientes que relataram aura olfatória, 2 também relataram aura epigástrica, 1 aura dismnéstica e 4 aura gustatória. De acordo com a literatura, esses pacientes podem ter mais de um tipo de aura, especialmente as auras do lobo temporal. Observamos um significativo pior prognóstico nesses pacientes. Engel I em 37,5\% dos pacientes com aura olfatória e Engel I em $74,7 \%$ nos pacientes sem esse fator, $p=0,03^{*}$. Esse achado poderia ser explicado pelas complexas conexões envolvidas pelo trato olfatório e pela localização do córtex olfatório primário, incluindo o córtex orbitofrontal, localizado no lobo frontal basal e córtex pirifome. Assim, sugere-se que a aura olfatória não só está relacionada com a zona sintomatogênica, mas também pode estar envolvida com a zona de início ictal em áreas adjacentes ao lobo temporal. 


\subsection{Aura Dismnésica}

Auras psíquicas são fenômenos experienciais, dismnésicos (déjà vu e jamais vu), ilusões, alucinações e cognitivos (como despersonalização), por estimulação de estruturas límbicas e neocorticais do lobo temporal. Aura emocional ou afetiva, como por exemplo, a sensação de medo, sugere envolvimento amigdaliano. Essas auras apresentam valor localizatório para zona epileptogênica (FRANZON, 2002).

Quando analisamos juntamente as auras afetiva e dismnésica (como auras psíquicas), com "n" total de 121 pacientes (20\%; IC 95\%: 16,9-23,4) e avaliamos o prognóstico desses pacientes, não encontramos diferença significativa entre o prognóstico dos pacientes que relataram aura psíquica, com o daqueles que negaram esse fator $(p=0,9)$.

Quando analisamos a aura dismnésica isoladamente, observamos significativo pior prognóstico $\left(p=0,02^{*}\right)$. Não encontramos dados na literatura que corroboram os nossos achados. Na análise desse dado, é importante considerar que o " $\mathrm{n}$ " foi pequeno (apenas 17 casos), e que os pacientes relataram mais de um tipo de aura. Assim podemos aventar a hipótese de que a circuitaria das redes neuronais envolvidas, podem ser mais extensas, e que a aura dismnésica pode fazer parte da zona sintomatogênica e não necessariamente, da zona de início ictal. Estudos futuros poderão explicar esses dados.

\subsubsection{Fatores que classicamente influenciam no prognóstico cirúrgico}

$\mathrm{Na}$ literatura científica são classicamente conhecidos como fatores de mau prognóstico cirúrgico, a presença de história de crises tônico-clônico generalizadas (CTCG) frequentes, história de traumatismo crânio-encefálico, história de infecção do sistema nervoso central (BARBA et al., 2016), o tempo de epilepsia e idade na cirurgia (ELSHARKAWY et al., 2009).

O quociente intelectual baixo e o atraso cognitivo prévios, foram considerados por décadas como uma variável que contraindicava a cirurgia de epilepsia, pois considerava-se que essa condição era um dano cerebral difuso, o que diminuía a chance do paciente ficar livre de crises (FALCONER, 1973). Em um estudo realizado mais recentemente pela Universidade Federal de São Paulo, foi avaliado o prognóstico cirúrgico em pacientes com QI baixo e foi constatado que não houve 
relação entre o QI e o prognóstico cirúrgico. Assim, esse grupo de pacientes pode se beneficiar da cirurgia (GAÇA et al., 2018).

Em nosso estudo, esses fatores citados acima não influenciaram no prognóstico cirúrgico. Cabe aqui uma autocrítica em relação à informação sobre história de CTCG: encontramos um " $n$ " muito baixo para esse fator ( $n=8 ; 1,3 \%)$, o que pode sugerir um problema de registro dessa informação no prontuário dos pacientes ou de coleta dos dados, por dificuldade de encontrar essa informação.

Apesar das variáveis, idade de início da epilepsia, tempo de epilepsia e idade na cirurgia, estarem relacionadas, em nosso estudo encontramos que uma menor idade média de início da epilepsia teve relação significativa com melhor prognóstico cirúrgico $\left(p=0,0058^{*}\right)$, porém o tempo de epilepsia não foi relevante, tanto na análise numérica por variável contínua (Test-T), como quando realizamos a análise categorizada em épocas (teste do Qui-quadrado). Assim aventamos a hipótese de que os pacientes com maior tempo de epilepsia podem ter maior epileptogênese bilateral e crises bilaterais. Se estes foram avaliados por métodos invasivos, a cirurgia pode ter sido contra-indicada e ficamos com uma população mais homogênea, por isso não influenciou no nosso prognóstico. Ou seja, o tempo de epilepsia não influiu no nosso prognóstico cirúrgico, pois a neurofisiologia foi soberana.

Em um estudo de prognóstico cirúrgico em longo prazo em pacientes com EMLT-EH realizado por um grupo francês, também não foi identificada influência da idade de início da epilepsia, do tempo de epilepsia, da idade na cirurgia e da frequência de crises no pré-operatório, em relação ao prognóstico cirúrgico, corroborando os nossos achados. Esse mesmo estudo encontrou como fatores de mau prognóstico a necessidade de avaliação com eletrodos invasivos $\left(p=0.002^{*}\right)$ e história de status epilepticus pré-operatória $\left(p=0.003^{*}\right)$. Outro dado interessante, é que para os pacientes Engel la, os seguintes fatores foram discriminativos: anormalidades bilaterais e extratemporais ao EEG interictal (MATHON et al., 2017).

Em nosso estudo não encontramos influência da frequência de crises epilépticas e da história de status epilepticus pré-operatório no prognóstico cirúrgico.

Em relação à neurofisiologia, a literatura científica também relaciona atividade interictal bilateral e de início ictal temporal bilateral simétrico, independente ou difusa, como fatores de mau prognóstico (ELSHARKAWY et al., 2009).

Em nossa série não encontramos diferença significativa entre os pacientes com EEG de superfície interictal normal, unilateral e ictal ipsilateral à EMT, em relação aos 
pacientes que tiveram descargas epilépticas interictais bilaterais. Também não encontramos diferença significativa em relação aos pacientes os quais o início ictal, ao EEG de superfície, foi bilateral, contralateral ou difuso. Esses pacientes em que o EEG ictal era duvidoso, foram enviados para avaliação invasiva ou semi-invasiva, e somente foram operados aqueles em que o EEG ictal foi localizatório e lateralizatório, proporcionando o mesmo prognóstico cirúrgico dos que na avaliação de superfície foram unilaterais.

Não encontramos diferença significativa entre os pacientes que realizaram avaliação invasiva pelo mesmo motivo citado acima. Dos 66 que foram para avaliação invasiva, 48 casos foram avaliados com eletrodos de forame oval. Desses, apenas 2 necessitaram de uma terceira avaliação invasiva (eletrodos profundos ou subdurais), pois o EEG do FO foi bilateral independente. Dos 48 pacientes que realizaram avaliação com FO, 68,8\% ficaram livres de crises (Engel I), comparados com $74 \%$ dos que foram para cirurgia direto, sem avaliação com FO ( $p=0,495$, não significativo). Dos outros 18 pacientes que realizaram avaliação invasiva (eletrodos profundos ou subdurais), 66,7\% ficaram livres de crises (Engel I), comparados com 73,8\% dos que não realizaram ( $p=0,587$, não significativo). Ou seja, os pacientes que realizaram tanto avaliação semi-invasiva, quanto invasiva tiveram um bom prognóstico cirúrgico, sem diferença significativa em relação aos que foram para cirurgia direto, confirmando a nossa hipótese.

\subsection{Retirada de Fármacos anti-epilépticos (FAEs)}

O prognóstico dos pacientes que usavam menor número de FAEs antes da cirurgia (1 ou 2), foi melhor (em porcentagem) do que aqueles que usavam maior número (3 ou 4$)\left(p=0,007^{*}\right)$.

Na última consulta em nosso serviço, após a cirurgia, 19,5\% dos pacientes conseguiram retirar totalmente os FAEs e 35,9\% estavam em monoterapia. A proporção dos que estavam com menor número de FAEs (de 0 a 2), foi maior no grupo que estava livre de crises, ou seja, a proporção de pacientes com menor número FAEs, na última consulta, foi maior no grupo com melhor prognóstico; já os pacientes com pior prognóstico (Engel II, III e IV), apresentaram maior proporção de número de FAEs (3 ou 4) na última consulta, $p=0,000^{*}$. 
Em relação aos pacientes que após a cirurgia conseguiram retirar o $\mathrm{FAE}, 22,2 \%$ usavam 1 FAE antes da cirurgia, 67,7\% usavam 2 FAEs, 10,1\% usavam 3 FAEs e nenhum que usava 4 FAEs $(p=0,000)$.

Em um estudo de prognóstico em longo prazo após lobectomia temporal com 434 pacientes, $28,4 \%$ dos casos conseguiram suspender o FAE e 41,7\% estavam em monoterapia após 2 anos de acompanhamento pós-operatório. A descontinuação do FAE não foi relacionada ao risco de recorrência (ELSHARKAWY et al., 2009).

Em nosso estudo observamos que os pacientes que usavam menor número de FAEs antes da cirurgia, tiveram melhor prognóstico cirúrgico.

A conduta de retirada de FAEs após a cirurgia, foi uma conduta guiada pelo desejo do paciente em retirar o fármaco, por efeitos adversos ou interação medicamentosa e não foi uma conduta estritamente protocolar.

\subsection{Regressão Logística Binária - Aplicação Prática e Relevância Clínica}

Através da análise univariada encontramos alguns fatores preditores significativos de bom e mau prognóstico cirúrgico. Criamos um modelo de regressão logística binária, com o objetivo de criar um "index" que pudesse predizer qual a probabilidade do paciente ficar livre de crises no pós-operatório. Foram incluídas nesse modelo as seguintes variáveis significativas: tipo de cirurgia, convulsão febril, aura dismnésica e aura olfatória. Através desse modelo, criamos a seguinte fórmula:

$$
P(y)=\frac{1}{\left\{1+e^{-\left[1,288+\left(-0,592^{*} P P T\right)+\left(-1,114^{*} A D\right)+\left(0,473^{*} C F\right)+\left(-1,986^{*} A O\right)\right]}\right\}}
$$

Onde $\mathrm{P}(\mathrm{y})$ = probabilidade de $(\mathrm{y})$ ocorrer, ou seja, probabilidade do paciente ficar livre de crises (Engel I);

e = constante logaritmo natural = 2,718;

PPT = cirurgia que preserva o polo temporal;

$A D$ = aura dismnésica;

CF = crise febril;

$A O=$ aura olfatória;

Em que os coeficientes são: $\quad 0$ = ausência do fator; 1 = presença do fator 
Após a aplicação do modelo nos 101 pacientes "teste", concluímos que o modelo acertou em $67,3 \%$ das vezes, ou seja, esse modelo é válido e tem alta capacidade de predizer a probabilidade do paciente ficar livre de crises, quando a probabilidade encontrada é alta (maior que $70 \%$ ), porém quando essa probabilidade é baixa (menor que 50\%), a chance de erro é maior.

Em nossa prática clínica pretendemos aplicar esse modelo para os novos pacientes candidatos a cirurgia de epilepsia com os mesmos pré-requisitos da presente tese. Assim poderemos explicar ao paciente e seus familiares sobre os riscos e benefícios da cirurgia, bem como dizer com mais clareza qual a probabilidade de ficar livre de crises no pós-operatório. Esses dados também irão ajudar a equipe na tomada de decisões em relação ao tratamento e no acompanhamento clínico pósoperatório.

Exemplo para o melhor cenário: se o paciente tiver história de crise febril, não tiver história de aura dismnésica ou olfatória e for realizar a lobectomia temporal anteromesial (que resseca o polo temporal), a probabilidade de ficar livre de crises é: $P=0,8533$, ou seja, terá $85,3 \%$ de chance de ficar livre de crises no pós-operatório e o modelo tem $83,33 \%$ de chance de acertar.

Exemplo de outro cenário: o paciente não tem história de crise febril, tem história de aura dismnésica e olfatória e irá realizar a cirurgia que preserva o polo temporal. A probabilidade de ficar livre de crises no pós-operatório é de: 0,08265 $(8,2 \%)$, menor do que $30 \%$, mas nesse caso o modelo tem mais chances de errar. Sendo assim, quando a probabilidade de ficar livre de crises é baixa, o modelo tem mais chance de errar do que quando ela é alta. Então, podemos interpretar da seguinte forma: esse paciente tem maior chance de não ficar livre de crises, mas como nesse caso o modelo também tem maior chance de errar, não poderemos afirmar isso ao paciente. Portanto, poderemos apenas alertá-lo sobre esse possível risco e no pósoperatório os médicos assistentes deverão ficar mais atentos ao risco de recidiva. 


\subsection{Considerações Finais}

A maioria dos dados referentes a essa tese não são inéditos, muitos autores já descreveram dados semelhantes na literatura, porém a importância desse trabalho foi avaliar o desempenho do Centro de Cirurgia de Epilepsia de Ribeirão Preto - CIREP, em relação à cirurgia de epilepsia desde o início do programa de cirurgia de epilepsia, iniciado em 1994. Assim tivemos a oportunidade de avaliar os dados de sucesso que se comparam à literatura científica, mas também as nossas falhas e assim melhorar a nossa curva de aprendizado para o futuro dos nossos pacientes.

Assim como outros estudos longitudinais e retrospectivos, os dados da revisão de prontuários médicos podem ter sido perdidos ao longo do tempo, também pode ter havido viés de registro e da coleta das informações, por mais rigorosos que fomos na nossa metodologia. 


\section{CONCLUSÕES}

1. A cirurgia de epilepsia do lobo temporal associada à esclerose hipocampal no CIREP, foi eficaz em deixar o paciente livre de crises epilépticas em $\mathbf{7 3 , 6 \%}$ dos casos e $\mathbf{8 4 , 7 \%}$ tiveram um bom prognóstico cirúrgico (Engel I + II). Esse prognóstico foi relativamente mantido ao longo do tempo, com aproximadamente $65 \%$ dos pacientes livres de crises epilépticas após 20 a 23 anos da cirurgia. Portanto, é um procedimento com resultados positivos em longo prazo.

2. Os índices de complicações pós-operatórias graves foram baixos. Assim, foi possível estabelecer uma relação de eficácia e segurança do procedimento em longo prazo, podendo auxiliar na tomada de decisão cirúrgica com segurança.

3. Quando comparamos os tipos de cirurgia em relação ao prognóstico cirúrgico da EMLT-EH, observamos que a lobectomia temporal anteriomesial, que resseca o polo temporal, obteve melhor prognóstico (78,6\% Engel I) no controle de crises em relação à cirurgia que preserva o polo temporal (67,2\% Engel I), com valor de $p=0,002^{*}$, sugerindo que as conexões neurais envolvidas na zona epileptogênica podem estar além das estruturas mesiais. Muitos centros de epilepsia no mundo defendem a cirurgia mais seletiva, porém sugerimos uma indicação mais cautelosa e em casos selecionados.

4. Encontramos que a história de crise febril foi um fator de bom prognóstico, enquanto que aura dismnésica e/ou olfatória foram fatores de mau prognóstico cirúrgico.

5. A avaliação neurofisiológica foi soberana para indicar a cirurgia, com prognósticos semelhantes nos casos de EMT uni ou bilateral e nos casos em que foram realizadas avaliações invasivas ou semi-invasivas.

6. Através da regressão logística binária, criamos um "index" capaz de predizer o prognóstico cirúrgico, com o potencial de ajudar a equipe na tomada de decisões no pré e no pós-operatório, além da oportunidade de esclarecer ao paciente com maior acurácia sua probabilidade de ficar livre de crises após a cirurgia.

7. Encontramos que apenas $19,5 \%$ dos nossos pacientes conseguiram retirar o FAE após a cirurgia e que a maioria dos que ficaram livres de crises 
mantiveram-se em uso das medicações. Assim concluímos que o nosso prognóstico cirúrgico não está relacionado à retirada do FAE após a cirurgia.

8. Finalmente, para os epileptologistas e neurologistas gerais: na suspeita de epilepsia mesial do lobo temporal associada à esclerose hipocampal farmacorresistente, a cirurgia tem maior eficácia em deixar o paciente livre de crises do que uma nova terapia farmacológica. Assim está recomendado o encaminhamento para um centro de referência em cirurgia de epilepsia para avaliação pré-cirúrgica. 


\section{Referências}

ABEL, T. J. et al. Role of the temporal pole in temporal lobe epilepsy seizure networks: an intracranial electrode investigation. Journal of Neurosurgery, v. 129, n. July, p. 1-9, 2017.

\section{ABUD, L. G. Análise quantitativa por Ressonância Magnética da Epilepsia Parcial Sintomática de difícil controle com imagem qualitativa negativa para lesão epileptogênica. [s.I.] Univertsity of São Paulo, 2017.}

ARAÚJO, D. et al. Volumetric evidence of bilateral damage in unilateral mesial temporal lobe epilepsy. Epilepsia, v. 47, n. 8, p. 1354-1359, 2006.

ARRUDA, F. et al. Mesial atrophy and outcome after amygdalohippocampectomy or temporal lobe removal. Annals of Neurology, v. 40, n. 3, p. 446-450, 1996.

ASADI-POOYA, A. A. et al. Type of preoperative aura may predict postsurgical outcome in patients with temporal lobe epilepsy and mesial temporal sclerosis. Epilepsy \& Behavior, v. 50, p. 98-100, set. 2015.

ASADI-POOYA, A. A. et al. Postsurgical outcome in patients with olfactory auras and drug-resistant epilepsy. Epilepsy and Behavior, v. 68, p. 8-10, 2017.

BABB T, B. W. Pathological Findings in Epilepsy. In: In Engel J Jr. (ed) Surgical Treatment of Epilepsies. First ed. New York: Raven Press, 1993. p. 511-540.

BARBA, C. et al. Temporal plus epilepsy is a major determinant of temporal lobe surgery failures. Brain, v. 139, n. 2, p. 444-451, fev. 2016.

BAULAC, S. et al. Fever, genes, and epilepsy. Lancet Neurology, v. 3, n. 7, p. 421430, 2004.

BAXENDALE, S. The Wada test. Current Opinion in Neurology, v. 22, n. 2, p. 185189, 2009.

BERGER, H. Über das Elektroenkephalogramm des Menschen. Archiv für Psychiatrie und Nervenkrankheiten, v. 87, p. 527-570, 1929.

BIANCHIN, M. M. et al. Neurocysticercosis, mesial temporal lobe epilepsy, and hippocampal sclerosis: an association largely ignored. The Lancet Neurology, v. 5, n. 1, p. 20-21, jan. 2006.

BIANCHIN, M. M. et al. Neuroimaging observations linking neurocysticercosis and mesial temporal lobe epilepsy with hippocampal sclerosis. Epilepsy Research, v. 116, p. 34-39, 2015.

BINDER, D.; SCHRAMM, J. Resective surgical techniques: mesial temporal lobe epilepsy. In: LÜDERS, H. O. (Ed.). . Textbook of epilepsy surgery. First ed. London, UK: Informa healthcare, 2008. p. 1083-1092.

BLÜMCKE, I. et al. A new clinico-pathological classification system for mesial 
temporal sclerosis. Acta Neuropathologica, v. 113, n. 3, p. 235-244, 2007.

BLÜMCKE, I. et al. Defining clinico-neuropathological subtypes of mesial temporal lobe epilepsy with hippocampal sclerosis. Brain Pathology, v. 22, n. 3, p. 402-411, 2012.

BLÜMCKE, I. et al. International consensus classification of hippocampal sclerosis in temporal lobe epilepsy: A Task Force report from the ILAE Commission on Diagnostic Methods. Epilepsia, v. 54, n. 7, p. 1315-1329, 2013.

BONILHA, L. et al. Medial temporal lobe atrophy in patients with refractory temporal lobe epilepsy. Journal of neurology, neurosurgery, and psychiatry, v. 74, n. 12, p. 1627-30, dez. 2003.

BONILHA, L. et al. Subtypes of medial temporal lobe epilepsy: Influence on temporal lobectomy outcomes? Epilepsia, v. 53, n. 1, p. 1-6, 1 jan. 2012.

BORGES, M. A. et al. Urban prevalence of epilepsy: Populational study in São José do Rio Preto, a medium-sized city in Brazil. Arquivos de Neuro-Psiquiatria, v. 62, n. 2 A, p. 199-205, 2004.

BOUCHER, O. et al. Different effects of anterior temporal lobectomy and selective amygdalohippocampectomy on verbal memory performance of patients with epilepsy. Epilepsy and Behavior, v. 52, p. 230-235, 2015.

BRATZ, E. Ammonshornbefunde bei epileptikern. Arch Psychiatr Nervenkr, v. 32, p. 820-835, 1899.

BRODIE, M.; DICHTER, M. Drug therapy. THE NEW ENGLAND JOURNAL OF MEDICINE, v. 334, n. 3, p. 168-175, 1996.

CARRENO M, L. H. Textbook of epilepsy surgery. London/Boca Raton: Informa Healthcare, Taylor \& Francis distributor, 2008.

CENDES F, KAHANE P, BRODIE MJ, A. F. The mesio-temporal lobe epilepsy syndrome. In: JOSEPH ROGER, MICHELLE BUREAU, CHARLOTTE DRAVET, PIERRE GENTON, C. A. T. AND P. W. (Ed.). . Epileptic syndromes in infancy, childhood and adolescence. 4th. ed. Eastleigh UK: John Libbey Eurotext Ltd, 2012. p. $555-575$.

CENDES, F. et al. Early childhood prolonged febrile convulsions, atrophy and sclerosis of mesial structures, and temporal lobe epilepsy: an MRI volumetric study. Neurology, v. 43, n. 6, p. 1083-7, jun. 1993.

CENDES, F. Progressive hippocampal and extrahippocampal atrophy in drug resistant epilepsy. Current Opinion in Neurology, v. 18, n. 2, p. 173-177, 2005.

CENDES, F. Neuroimaging in investigation of patients with epilepsy. CONTINUUM Lifelong Learning in Neurology, v. 19, n. 3, p. 623-642, 2013.

CENDES, F. et al. Epilepsies associated with hippocampal sclerosis. Acta Neuropathologica, v. 128, n. 1, p. 21-37, 2014. 
CENDES, F.; ANDERMANN, F. Do Febrile Seizures Promote Temporal Lobe Epilepsy? Retrospective Studies. In: Febrile Seizures. [s.I.] Academic Press, 2002. p. $77-86$.

CHABARDĖS, S. et al. The temporopolar cortex plays a pivotal role in temporal lobe seizures. Brain, v. 128, n. 8, p. 1818-1831, 2005.

CHASSOUX, F. et al. Metabolic changes and electro-clinical patterns in mesiotemporal lobe epilepsy: a correlative study. Brain : a journal of neurology, v. 127, n. Pt 1, p. 164-74, 1 jan. 2004.

CHEN, C. et al. Olfactory auras in patients with temporal lobe epilepsy. Epilepsia, v. 44, n. 2, p. 257-260, 2003.

COAN, A. C.; CENDES, F. Epilepsy as progressive disorders: What is the evidence that can guide our clinical decisions and how can neuroimaging help?Epilepsy and BehaviorElsevier, , 1 mar. 2013. Disponível em:

<http://www.ncbi.nlm.nih.gov/pubmed/23127969>. Acesso em: 1 nov. 2018

CRANDALL, P.; WALTER, R.; RAND, R. Clinical applications of studies on stereotactically implanted electrodes in temporal-lobe epilepsy. J Neurosurg, v. 20, p. 827-840, 1963.

DUCHOWNY M.S. Indications and criteria for Surgical intervention. In: In J. Engel, T.A. Pedley Epilepsy: A comprehensive Textbook. First ed. [s.I.] Lippincott-Raven, 1997. p. Cap 160.

DUPONT, S. et al. Accurate Prediction of Postoperative Outcome in Mesial Temporal Lobe Epilepsy. Archives of Neurology, v. 57, p. 1331-1336, 1 set. 2000.

EBERSOLE, J. S.; PACIA, S. V. Localization of temporal lobe foci by ictal EEG patterns. Epilepsia, v. 37, n. 4, p. 386-399, 1996.

ELSHARKAWY, A. E. et al. Long-term outcome after temporal lobe epilepsy surgery in 434 consecutive adult patients. Journal of Neurosurgery, v. 110, n. 6, p. 11351146, 2009.

ENGEL, J. et al. Outcome With Respect To Epileptic Seizures. In: JEROME ENGEL JR. (Ed.). . In Engel J Jr, Editor. Surgical Treatment of The Epilepsies. 2nd Ed ed. New York: Raven Press, 1993. p. 609-621.

ENGEL, J. SURGERY FOR SEIZURES J. The New England journal of medicine, v. 334 , n. 10 , p. $647,1996$.

ENGEL, J. Etiology as a risk factor for medically refractory epilepsy A case for early surgical intervention. Editorial Neurology, v. 51, n. 5, p. 1243-1244, nov. 1998.

ENGEL, J. Mesial Temporal Lobe Epilepsy: What Have We Learned? The Neuroscientist, v. 7, n. 4, p. 340-352, 2001a.

ENGEL, J. A proposed diagnostic scheme for people with epileptic seizures and with epilepsy: Report of the ILAE task force on classification and terminology. Epilepsia, 
v. 42 , n. 6 , p. $796-803,20$ dez. 2001 b.

ENGEL, J. et al. Practice parameter: temporal lobe and localized neocortical resections for epilepsy: report of the Quality Standards Subcommittee of the American Academy of Neurology, in association with the American Epilepsy Society and the American Association of Neuro. Neurology, v. 60, n. 4, p. 538-47, 2003.

ENGEL, J. Early Surgical Therapy for Drug-Resistant Temporal Lobe Epilepsy. Jama, v. 307, n. 9, p. 922, 2012a.

ENGEL, J. Early Surgical Therapy for Drug-Resistant Temporal Lobe Epilepsy. Jama, v. 307, n. 9, p. 922, 2012b.

ENGEL, J.; WILSON, C.; BRAGIN, A. Advances in understanding the process of epileptogenesis based on patient material: what can the patient tell us? Epilepsia, v. 44 Suppl 12, p. 60-71, 2003.

EPILEPSY, C. ON C. AND T. OF THE I. L. A. Proposal for Revised Classification of Epilepsies and Epileptic Syndromes. v. 30, n. 389-399, 1989.

FALCONER, M. A. Genetic and Related Aetiological Factors in Temporal Lobe Epilepsy: A Review. Epilepsia, v. 12, n. 1, p. 13-31, 1971.

FALCONER, M. A. REVERSIBILITY BY TEMPORAL-LOBE RESECTION OF THE BEHAVIORAL ABNORMALITIES OF TEMPROAL LOBE EPILEPSY. The New England journal of medicine, v. 289, n. 10, p. 451-455, mar. 1973.

FERNANDES JG, SCHMIDT MI, MONTE TL, TOZZI S, J. S. Prevalence of epilepsy. The Porto Alegre Study. Epilepsia, 1992.

FERRARI-MARINHO, T. et al. Auras in temporal lobe epilepsy with hippocampal sclerosis: Relation to seizure focus laterality and post surgical outcome. Epilepsy and Behavior, v. 24, n. 1, p. 120-125, 2012.

FISHER, R. S. et al. Epileptic seizures and epilepsy: definitions proposed by the $\{\mid\} n t e r n a t i o n a l ~\{L\}$ eague $\{A\}$ gainst $\{E\}$ pilepsy ( $\{I L A E\})$ and the $\{l\}$ nternational $\{B\}$ ureau for $\{$ E\}pilepsy (\{IBE\}). Epilepsia, v. 46, n. 4, p. 470-472, 2005.

FISHER, R. S. et al. ILAE Official Report: A practical clinical definition of epilepsy. Epilepsia, v. 55, n. 4, p. 475-482, 2014.

FISHER, R. S. et al. Operational classification of seizure types by the International League Against Epilepsy: Position Paper of the ILAE Commission for Classification and Terminology. Epilepsia, v. 58, n. 4, p. 522-530, 2017 a.

FISHER, R. S. et al. Instruction manual for the ILAE 2017 operational classification of seizure types. Epilepsia, v. 58, n. 4, p. 531-542, $2017 \mathrm{~b}$.

FOLDVARY-SCHAEFER, N.; UNNWONGSE, K. Localizing and lateralizing features of auras and seizures. Epilepsy \& Behavior, v. 20, n. 2, p. 160-166, fev. 2011.

FRANZON, R. C. Valor lateralizatório do EEG interictal na avaliação pré- 
cirúrgica de crianças com epilepsia do lobo temporal. [s.I.] Universidade Estadual de Campinas. Faculdade de Ciências Médicas., 2002.

GAÇA, L. B. et al. Morphometric MRI features and surgical outcome in patients with epilepsy related to hippocampal sclerosis and low intellectual quotient. Epilepsy and Behavior, v. 82, p. 144-149, 2018.

GAMBARDELLA, A. et al. Focal Intermittent Delta Activity in Patients with Mesiotemporal Atrophy: A Reliable Marker of the Epileptogenic Focus. Epilepsia, v. 36, n. 2, p. 122-129, 1995.

GARGARO-SILVA, A. C. Cirurgia de epilepsia em pacientes com epilepsia do lobo temporal associada à esclerose hipocampal esquerda: uma comparação do prognóstico cognitivo com e sem ressecção do polo temporal. [s.l.] Universidade de São Paulo, 2019.

GIBBS, E.; GIBBS, F.; FUSTER, B. Psychomotor epilepsy. Arch Neurol Psychiatry, v. 60 , n. 4 , p. 331-339, 1948.

GLAUSER, T. et al. Updated ILAE evidence review of antiepileptic drug efficacy and effectiveness as initial monotherapy for epileptic seizures and syndromes. Epilepsia, v. 54, n. 3, p. 551-563, 2013.

GLOOR, P. Mesial temporal sclerosis: Historical background and na overview from a modern perspective. In: In Lüders H (ed) Epilepsy surgery. New York: Raven Press, 1991. p. 689-703.

GOWERS, W. Epilepsy and other convulsive diseases: their causes, symptoms, and treatment. In: In: Brinklow M, ed. Pathology. Philadelphia USA: PA: P. Blakiston's Son \& Co;, 1901. p. 213-228.

HAMER HM, M. I. H. Indications for invasive video-electroencephalographic monitoring. In: LUDERS, H. O. (Ed.). . In Lüders HO, Comair YG (eds) Epilepsy Surgery. Second ed. Philadelphia USA: Lippincott Williams \& Wilkins, 2001. p. 559566.

HAUSER, W. A.; ANNEGERS, J. F.; ROCCA, W. A. Descriptive epidemiology of epilepsy: contributions of population-based studies from Rochester, Minnesota. Mayo Clinic proceedings, v. 71, n. 6, p. 576-86, jun. 1996.

HEMB, M. et al. An 18-year follow-up of seizure outcome after surgery for temporal lobe epilepsy and hippocampal sclerosis. Journal of Neurology, Neurosurgery and Psychiatry, v. 84, n. 7, p. 800-805, 2013.

HILL, D. et al. Discussion on the surgery of temporal lobe epilepsy. Proceedings of the Royal Society of Medicine, v. 46, n. 11, p. 965-76, nov. 1953.

HIRTZ, D. et al. How common are the "common" neurologic disorders? Neurology, v. 68 , n. 5, p. 326-337, 2007.

HORSLEY, V. Brain surgery. Br Med J., p. 670-676, 1886. 
HOYT, A. T.; SMITH, K. A. Selective Amygdalohippocampectomy. Neurosurgery Clinics of North America, v. 27, n. 1, p. 1-17, 2016.

HU, W.-H. et al. Selective amygdalohippocampectomy versus anterior temporal lobectomy in the management of mesial temporal lobe epilepsy: a meta-analysis of comparative studies. Journal of Neurosurgery, v. 119, n. 5, p. 1089-1097, 2013.

JEROME ENGEL JR., GREGORY D. CASSINO, W. D. S. Surgically Remediable Syndromes. In: ENGEL, J. J.; PEDLEY, T. A. (Eds.). . Epilepsy A Comprehensive Textbook. First ed. Philadelphia US: Lippincott-Raven, 1997. p. 1687-1696.

JONES-GOTMAN, M. et al. Etomidate speech and memory test (eSAM): A new drug and improved intracarotid procedure. Neurology, v. 65, n. 11, p. 1723-1729, 2005.

JOSEPHSON, C. B. et al. Systematic review and meta-analysis of standard vs selective temporal lobe epilepsy surgery. Neurology, v. 80, n. 18, p. 1669-1676, abr. 2013.

JUNI, J. E. Taking brain SPECT seriously: Reflections on recent clinical reports in The Journal of Nuclear Medicine. Journal of Nuclear Medicine, v. 35, n. 12, p. 1891-1895, 1994.

JUNI, J. E. et al. Procedure guideline for brain perfusion SPECT using (99m)Tc radiopharmaceuticals 3.0. Journal of nuclear medicine technology, v. 35, n. 5, p. 923-926, 1 set. 1998.

KAADA, B. Somato-motor, autonomic and electrocorticographic responses to electrical stimulation of rhinencephalic and other structures in primates, cat, and dog; a study of responses from the limbic, subcallosal, orbito-insular, piriform and temporal cortex, hippoc. Acta Physiol Scand Suppl, v. 24, n. 83, p. 1-262, 1951.

KAHANE, P.; BARTOLOMEI, F. Temporal lobe epilepsy and hippocampal sclerosis: Lessons from depth EEG recordings. Epilepsia, v. 51, n. SUPPL. 1, p. 59-62, 2010.

KANNER, A. M. et al. Depression and epilepsy: Epidemiologic and neurobiologic perspectives that may explain their high comorbid occurrence. Epilepsy and Behavior, v. 24, n. 2, p. 156-168, 2012.

KOBAYASHI, E. et al. Seizure outcome and hippocampal atrophy in familial mesial temporal lobe epilepsy. Neurology, v. 56, n. 2, p. 166-72, 23 jan. 2001.

KUZNIECKY, R. et al. Temporal lobe developmental malformations and hippocampal sclerosis: epilepsy surgical outcome. Neurology, v. 52, n. 3, p. 479-84, fev. 1999.

KWAN, P. et al. Definition of drug resistant epilepsy: Consensus proposal by the ad hoc Task Force of the ILAE Commission on Therapeutic Strategies. Epilepsia, v. 51, n. 6 , p. 1069-1077, 2010.

LEITE, J. P.; GARCIA-CAIRASCO, N.; CAVALHEIRO, E. A. New insights from the use of pilocarpine and kainate models. Epilepsy Research, v. 50, n. 1-2, p. 93-103, 2002. 
LOWE, A. J. 1 et al. EPILEPSY SURGERY FOR PATHOLOGICALLY PROVEN HIPPOCAMPAL SCLEROSIS PROVIDES LONG-TERM SEIZURE CONTROL AND IMPROVED QUALITY OF LIFE. [Abstract]. v. 45, n. 3, p. 237-242, 2004.

MARINO JÚNIOR, R.; CUKIERT, A.; PINHO, E. [Epidemiological aspects of epilepsy in São Paulo: a prevalence study]. Arquivos de neuro-psiquiatria, v. 44, n. 3, p. 243-54, set. 1986.

MATHERN, G. W. et al. The clinical-pathogenic mechanisms of hippocampal neuron loss and surgical outcomes in temporal lobe epilepsy. Brain : a journal of neurology, v. 118 ( Pt 1), p. 105-18, fev. 1995.

MATHON, B. et al. Predictive factors of long-term outcomes of surgery for mesial temporal lobe epilepsy associated with hippocampal sclerosis. Epilepsia, v. 58, n. 8, p. 1473-1485, 2017.

MCINTOSH, A. M. et al. Temporal lobectomy: Long-term seizure outcome, late recurrence and risks for seizure recurrence. Brain, v. 127, n. 9, p. 2018-2030, 2004.

MINTZER, S. et al. Unilateral hippocampal sclerosis with contralateral temporal scalp ictal onsetEpilepsiaFlower Mound, TX, USAWiley/Blackwell (10.1111), , 1 jul. 2004. Disponível em: <http://doi.wiley.com/10.1111/j.0013-9580.2004.35703.x>. Acesso em: 1 nov. 2018

NGUGI, A. K. et al. Estimation of the burden of active and life-time epilepsy: A metaanalytic approach. Epilepsia, v. 51, n. 5, p. 883-890, 2010.

NIEMEYER, P. The transventricular amygdalo-hipocampectomy in temporal lobe epilepsy. In: In: MBP B, ed. Temporal Lobe Epilepsy. Springfield, IL: Charles C. Thomas. [s.l: s.n.]. p. 461-482.

PANAYIOTOPOULOS, C. Temporal lobe epilepsies in: A Clinical Guide to Epileptic Syndromes and their Treatment. [s.l.] Springer Healthcare, 2010.

PENFIELD, W. Observations on the anatomy of memory. Folia Psychiatr Neurol Neurochir Neerl, v. 53, n. 2, p. 349-351, 1950.

PENFIELD, W.; FLANIGIN, H. The surgical therapy of temporal lobe seizures. Trans Am Neurol Assoc, v. 51, p. 146-149, 1950.

PENRY, K. Proposal for Revised Clinical and Electroencephalographic Classification of Epileptic Seizures. Epilepsia, v. 22, n. 4, p. 489-501, 1981.

QUIGG, M. et al. Volumetric Magnetic Resonance Imaging Evidence of Bilateral Hippocampal Atrophy in Mesial Temporal Lobe Epilepsy. v. 38, n. 5, p. 588-594, 1997.

RANGEL, R. et al. Cysticercotic encephalitis: a severe form in young females. The American journal of tropical medicine and hygiene, v. 36, n. 2, p. 387-92, mar. 1987.

ROSENOW, F.; LÜDERS, H. Presurgical evaluation of epilepsy. Brain : a journal of 
neurology, v. 124, n. Pt 9, p. 1683-700, set. 2001.

RYVLIN, P.; CROSS, H.; RHEIMS, S. Review Epilepsy surgery in children and adults. The Lancet Neurology, v. 13, n. 11, p. 1114-1126, 2014.

SALANOVA, V.; MARKAND, O.; WORTH, R. Temporal lobe epilepsy surgery: Outcome, complications, and late mortality rate in 215 patients. Epilepsia, v. 43, n. 2, p. 170-174, 2002.

SAUVIGNY, T. et al. Neuropsychological performance and seizure control after subsequent anteromesial temporal lobe resection following selective amygdalohippocampectomy. Epilepsia, v. 57, n. 11, p. 1789-1797, 2016.

SCHEFFER, I. E. et al. ILAE classification of the epilepsies: Position paper of the ILAE Commission for Classification and Terminology. Epilepsia, v. 58, n. 4, p. 512521, 2017.

SEPKUTY, J. P. et al. An automated injection system (with patient selection) for SPECT imaging in seizure localization. Epilepsia, v. 39, n. 12, p. 1350-1356, 1998.

SIRVEN, J. I. et al. Outcome after temporal lobectomy in bilateral temporal lobe epilepsy. Annals of Neurology, v. 42, n. 6, p. 873-878, 1997.

SPENCER, D.; BURCHIEL, K. Selective amygdalohippocampectomy. Epilepsy research and treatment, v. 2012, n. 1, p. 382095, jan. 2012.

SPENCER, D. D. et al. Access to the posterior medial temporal lobe structures in the surgical treatment of temporal lobe epilepsy. Neurosurgery, v. 15, n. 5, p. 667-671, nov. 1984.

SPENCER, S. S. et al. Morphological Patterns of Seizures Recorded Intracranially. Epilepsia, v. 33, n. 3, p. 537-545, 1992.

TEZER, F. I. et al. Predictive factors for postoperative outcome in temporal lobe epilepsy according to two different classifications. Seizure, v. 17, n. 6, p. 549-560, 2008.

THURMAN, D. J. et al. Standards for epidemiologic studies and surveillance of epilepsy. Epilepsia, v. 52, n. SUPPL. 7, p. 2-26, 2011.

TONINI, C. et al. Predictors of epilepsy surgery outcome: A meta-analysis. Epilepsy Research, v. 62, n. 1, p. 75-87, 2004.

USTUN, M. L. AND T. B. The Global Burden of Epilepsy. Epilepsia, v. 43, n. 6 Suppl, p. 21-25, jul. 2002.

VAN PAESSCHEN, W. et al. The Amygdala and Temporal Lobe Simple Partial Seizures: A Prospective and Quantitative MRI Study. Epilepsia, v. 42, n. 7, p. 857862, 20 dez. 2001.

VAUGHAN, D. N.; JACKSON, G. D. The piriform cortex and human focal epilepsy. Frontiers in Neurology, v. 5, n. DEC, p. 1-18, 2014. 
VELASCO, T. R. Estudo randomizado sobre a utilidade clínica do SPECT ictal em pacientes com epilepsia mesial temporal refratária. [s.I.] Universidade de São Paulo, 2007.

VELASCO, T. R. et al. Utility of ictal single photon emission computed tomography in mesial temporal lobe epilepsy with hippocampal atrophy: A randomized trial.

Neurosurgery, v. 68, n. 2, p. 431-436, 2011.

VELASCO, T. R.; MATHERN, G. W. SURGICAL TREATMENT OF REFRACTORY TEMPORAL LOBE EPILEPSY. In: WYLLIE, E. et al. (Eds.). . WYLLIE'S

TREATMENT OF EPILEPSY. Fith ed. Philadelphia USA: Lippincott Williams \& Wilkins, 2011. p. 922-936.

VICENTA SALANOVA, M. ET AL. Clinical Characteristics and Predictive Factors in 98 Patients With Complex Partial Seizures Treated With Temporal Resection. Arch Neurol, v. 51, p. 1008-1013, 1994.

VIVES, K. Anterior Temporal Resection. In: In J. Engel, T.A. Pedley Epilepsy: A comprehensive Textbook. 2nd Ed ed. [s.I.] Lippincott-Raven, 2008.

WA HAUSER, D. H. Epilepsy: frequency, causes, and consequences. New York: [s.n.].

WALTHER, C. Hippocampal terminology: concepts, misconceptions, origins.

Endeavour, v. 26, n. 2, p. 41-4, jun. 2002.

WICHERT-ANA, L. et al. Typical and atypical perfusion patterns in periictal SPECT of patients with unilateral temporal lobe epilepsy. Epilepsia, v. 42, n. 5, p. 660-666, 2001.

WICHERT-ANA, L. et al. Ictal chronology and interictal spikes predict perfusion patterns in temporal lobe epilepsy: a multivariate study. Seizure, v. 13, n. 5, p. 34657, jul. 2004.

WIEBE, S. et al. A Randomized, Controlled Trial of Surgery for Temporal-Lobe Epilepsy. New England Journal of Medicine, v. 345, n. 5, p. 311-318, 2001.

WIESER, H. G. Mesial temporal lobe epilepsy with hippocampal sclerosis. Epilepsia, v. 45, n. 6, p. 695-714, 2004.

WIESER, H. G.; YAŞARGIL, M. G. Selective amygdalohippocampectomy as a surgical treatment of mesiobasal limbic epilepsy. Surgical neurology, v. 17, n. 6, p. 445-57, jun. 1982.

WILLIAMSON, P. D. et al. Characteristics of Medial Temporal Lobe: Interictal and Ictal Scalp Electroencephalography, Neuropsychological Testing, Neuroimaging, Surgical Results, and Pathology. Annals of neurology, v. 34, p. 781-787, 1993.

YAŞARGIL, M. G. et al. The selective amygdalohippocampectomy for intractable temporal limbic seizures. Journal of Neurosurgery, v. 112, n. 1, p. 168-185, 2010.

YOSHOR, D.; HAMILTON, W. J.; GROSSMAN, R. G. TEMPORAL LOBE 
OPERATIONS FOR DRUG RESISTENT EPILEPSY. In: SCHMIDEK, H. H.; ROBERTS, D. W. (Eds.). . OPERATIVE NEUROSURGICAL TECHNIQUES:

INDICATIONS, METHODS AND RESULTS. Fifth ed. [s.I.] SAUNDERS - ELSEVIER, 2006. p. Vol 2, 1383-1393.

ZACHENHOFER, I. et al. Reoperation after selective amygdalohippocampectomy: An MRI analysis of the extent of temporomesial resection in ten cases. Acta Neurochirurgica, v. 153, n. 2, p. 239-248, 2011. 


\section{Apêndice}

\section{Instrumento de coleta de dados via telefônica}

Bom dia / boa tarde. Meu nome é ----. Sou o (a) Neurologista (a) do CIREP (Centro de cirurgia de epilepsia de Ribeirão Preto), do Hospital das Clínicas de Ribeirão Preto. Posso falar com o(a) Sr. (a) (nome) ou com o cuidador mais próximo?

\begin{tabular}{|l|l|}
\hline \multicolumn{1}{|c|}{ NÃO } & \multicolumn{1}{c|}{ SIM } \\
\hline $\begin{array}{l}\text { Entrevistador: Qual é o melhor horário para } \\
\text { conversar com o (a) Sr. (a) nome? Se } \\
\text { possível, agendar a próxima ligação e anotar } \\
\text { na planilha. }\end{array}$ & $\begin{array}{l}\text { Quero convidá-lo a participar de uma } \\
\text { pesquisa sobre pacientes operados por } \\
\text { epilepsia do lobo temporal. Para isso, é } \\
\text { necessário que o (a) Sr. (a) responda } \\
\text { algumas perguntas simples, que levarão } \\
\text { aproximadamente 10 minutos. Caso o (a) Sr. } \\
\text { Obrigado (a) bom dia / boa tarde. }\end{array}$ \\
$\begin{array}{l}\text { (a) concorde, as informações serão } \\
\text { registradas no prontuário do (a) paciente. } 0 \\
\text { (a) Sr. (a) concorda em participar? }\end{array}$ \\
\hline
\end{tabular}

\begin{tabular}{|c|c|}
\hline NÃO & SIM \\
\hline $\begin{array}{l}\text { Entrevistador: Participando da pesquisa, o (a) } \\
\text { Sr. (a) irá contribuir para o conhecimento } \\
\text { sobre a evolução dos pacientes que } \\
\text { realizaram cirurgia de epilepsia desde 1996, } \\
\text { assim ajudar novos pacientes na tomada de } \\
\text { decisão cirúrgica. } \\
\text { Ao final, perguntar novamente se aceita } \\
\text { participar, se a resposta for SIM, seguir o } \\
\text { script ao lado, caso permaneça negando a } \\
\text { participação, encerre a ligação e deixe um } \\
\text { contato, em caso de futuro aceite. }\end{array}$ & $\begin{array}{l}\text { Muito obrigado (a) por aceitar nosso convite. } \\
\text { Realizar as perguntas do questionário } 1 . \\
\text { Ao final, agradecer novamente a participação } \\
\text { do paciente. }\end{array}$ \\
\hline
\end{tabular}

\section{Em caso de óbito, perguntar se a causa da morte.}
a. Morte súbita
b. Acidente
c. Comorbidade conhecida
d. Infecção
e. Outra causa
f. Causa não conhecida 


\section{QUESTIONÁRIO / ALGORÍTMO DE AVALIAÇÃO DO DESFECHO EM LONGO PRAZO NA CIRURGIA DE EPILEPSIA DO LOBO TEMPORAL}

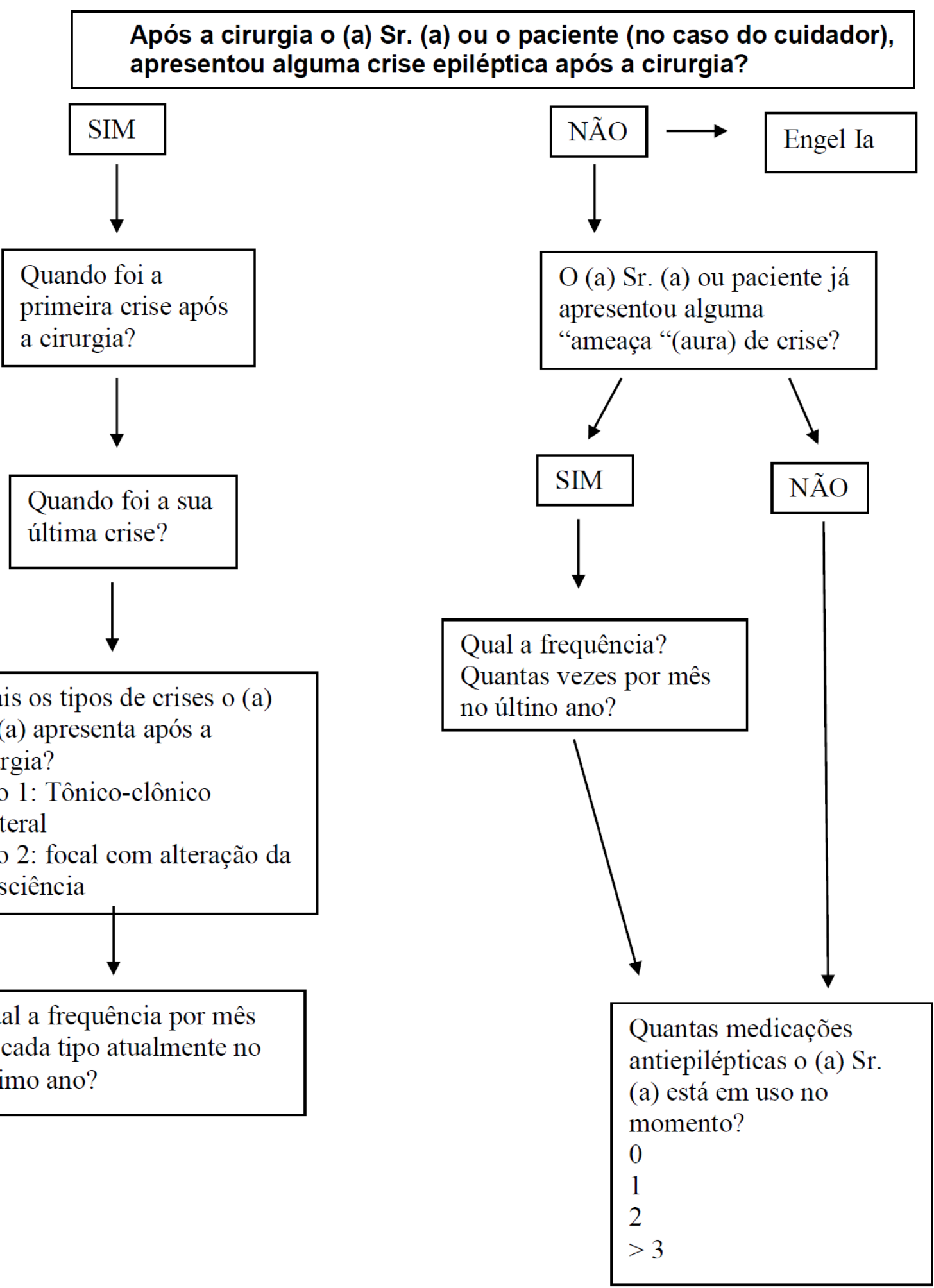

Quais os tipos de crises o (a)

Sr. (a) apresenta após a cirurgia?

Tipo 1: Tônico-clônico bilateral

Tipo 2: focal com alteração da consciência

Qual a free de cada tipo atualmente no último ano?

Qual a frequência?

Quantas vezes por mês no últino ano?
Quantas medicações antiepilépticas o (a) Sr. (a) está em uso no momento?

0

$>3$ 
ALGORITMO PARA A REALIZAÇÃO DAS LIGAÇÕES TELEFÔNICAS

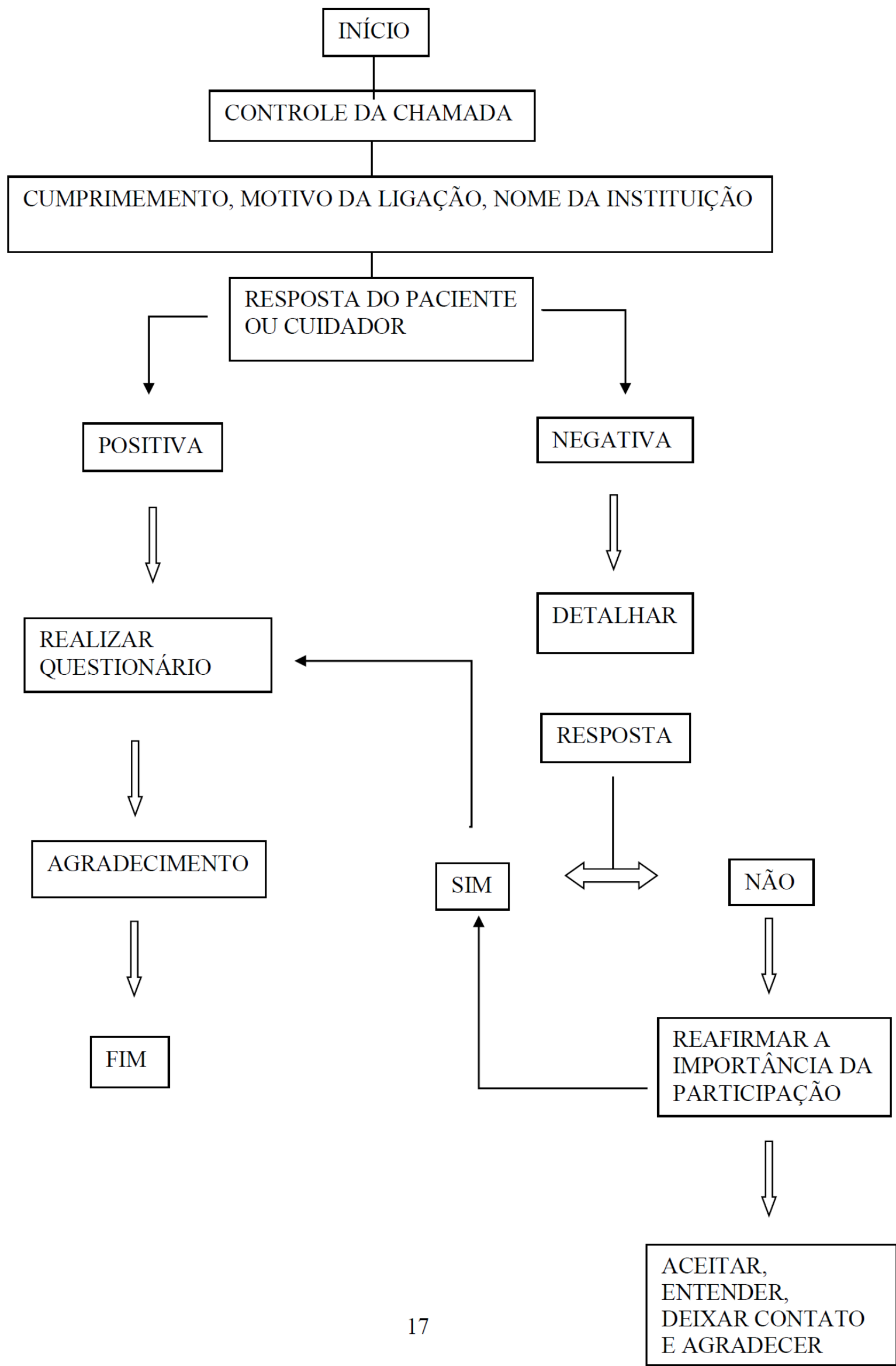

